University of South Florida

DIGITAL COMMONS @ UNIVERSITY OF SOUTH FLORIDA
Digital Commons @ University of South Florida

$5-1-2007$

\title{
Impact of Employer-Based Programs on Transit System Ridership and Transportation System Performance
}

CUTR

Follow this and additional works at: https://digitalcommons.usf.edu/cutr_nctr

\author{
Recommended Citation \\ "Impact of Employer-Based Programs on Transit System Ridership and Transportation System \\ Performance," National Center for Transit Research (NCTR) Report No. CUTR-NCTR-RR-2007-11, Center \\ for Urban Transportation Research, University of South Florida, 2007. \\ DOI: https://doi.org/10.5038/CUTR-NCTR-RR-2007-11 \\ Available at: https://scholarcommons.usf.edu/cutr_nctr/171
}

This Technical Report is brought to you for free and open access by the National Center for Transit Research (NCTR) Archive (2000-2020) at Digital Commons @ University of South Florida. It has been accepted for inclusion in Research Reports by an authorized administrator of Digital Commons @ University of South Florida. For more information, please contact digitalcommons@usf.edu. 


\section{Jmpact of Employer-Gased Programs on \\ Transit System Ridership and \\ Transportation System Performance}

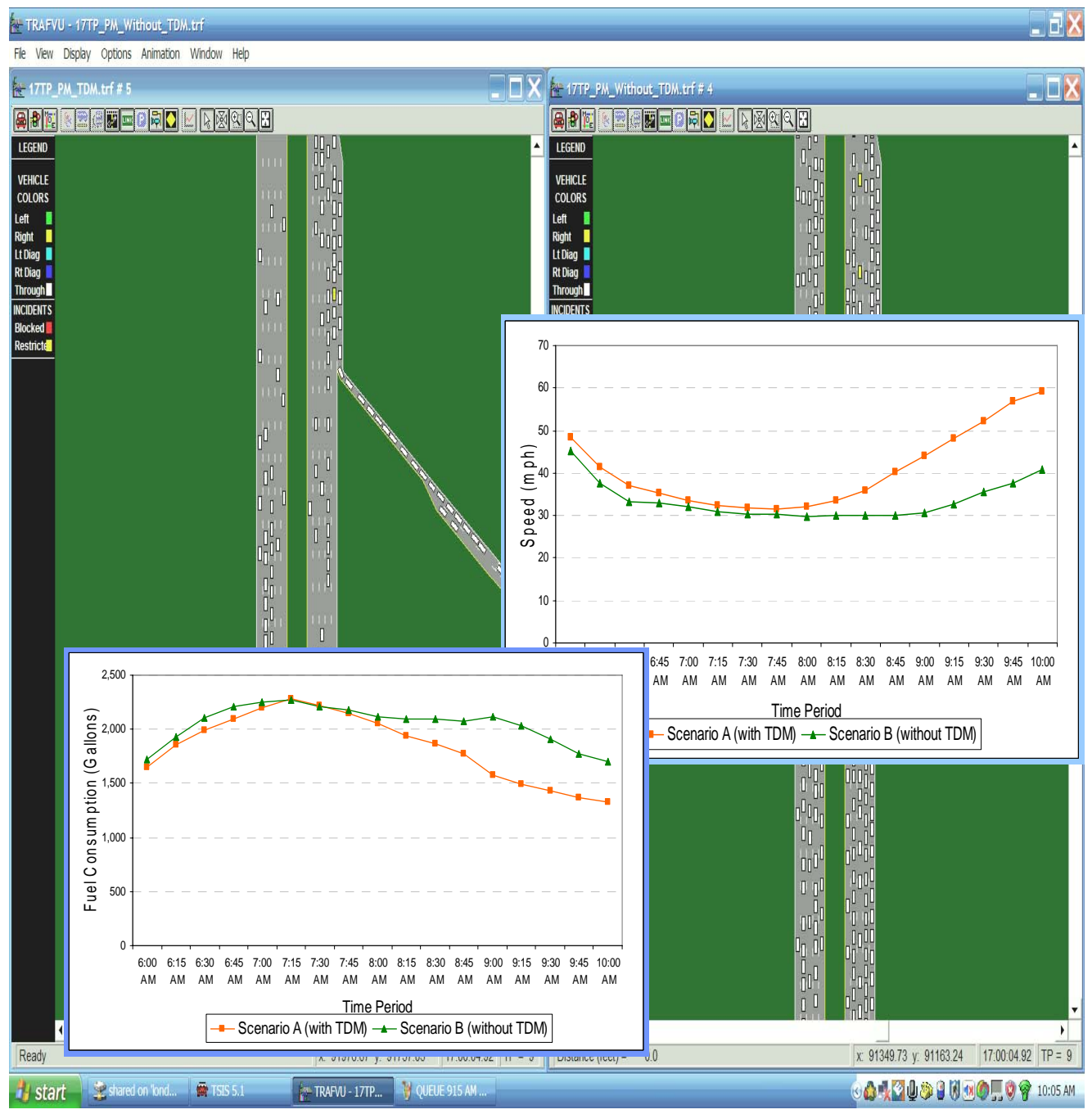

BD.549.25

Final Report

May 2007 


\title{
Impact of Employer-based Programs on \\ Transit System Ridership and Transportation System Performance
}

\author{
Final Report \\ FDOT BD 549 WO 25
}

\begin{abstract}
Prepared for

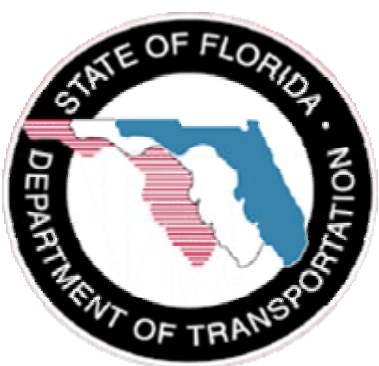

FDOT Project Manager

Michael Wright, Commuter Assistance Program Manager
\end{abstract}

Prepared by

National Center for Transit Research at

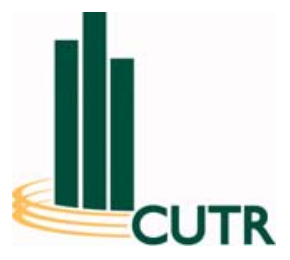

Research Team

Phil Winters, TDM Program Director

Nevine Labib Georggi, Research Associate

Sachin Rai, Research Associate

Liren Zhou, Graduate Research Assistant

May 2007 
TECHNICAL REPORT STANDARD TITLE PAGE

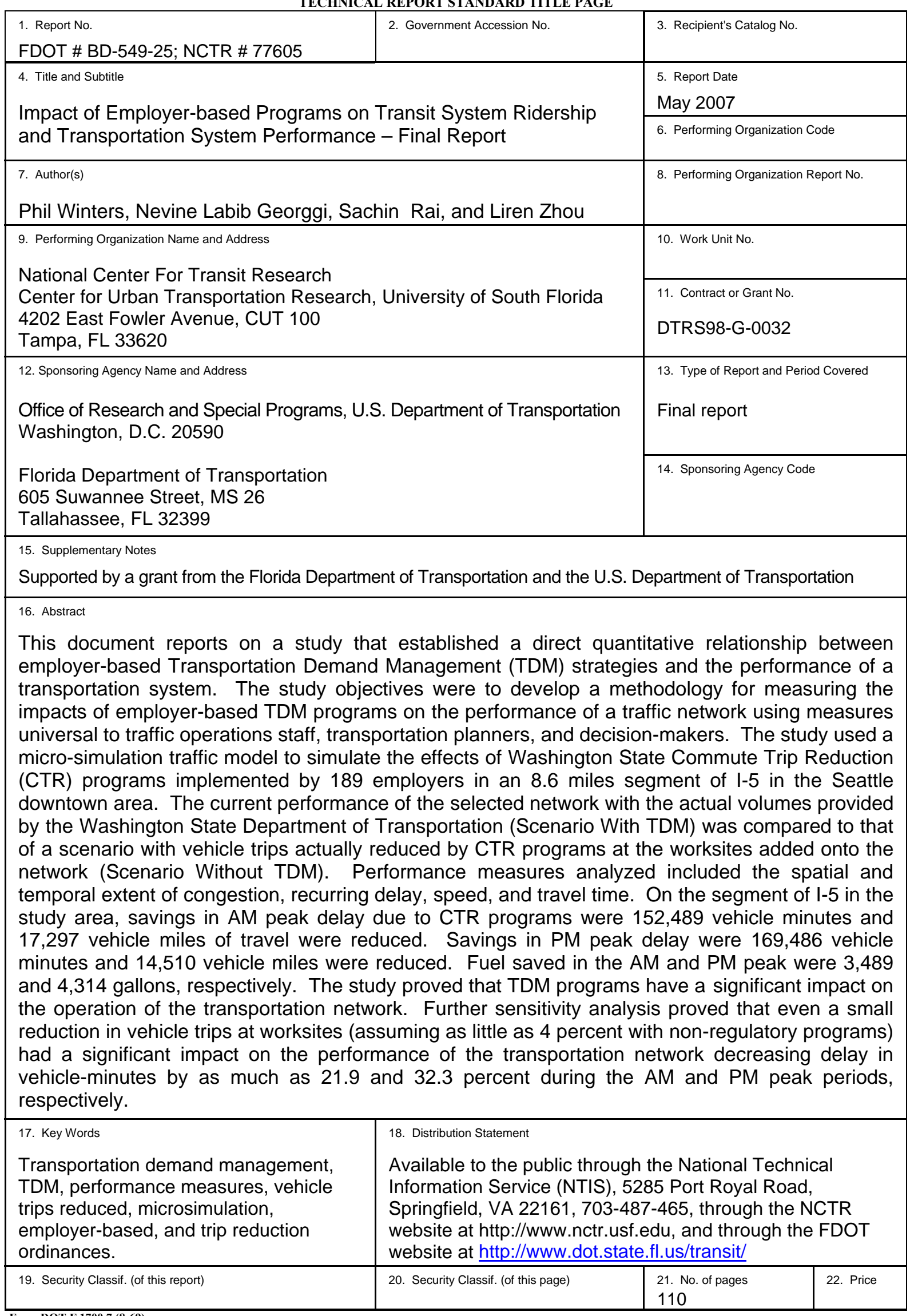

Form DOT F 1700.7 (8-69) 


\section{Acknowledgments}

The authors offer special thanks to Edward L. Hillsman, Ph.D. and Brian Lagerberg of the Washington State Department of Transportation for providing data and ideas throughout the research process. The research team would also like to acknowledge the support of the following individuals who provided valuable input to enhance this research:

Robert Ancar, Office of Policy and Performance, New York State DOT

Stuart Anderson, Urbantrans Consultants

Wayne Berman, FHWA Office of Transportation Management

Kay Carson, Executive Office of Transportation, Massachusetts Highway Department Lori Diggins, LDA Consulting, Washington DC Allen Greenberg, FHWA Office of Transportation Management Jennifer Gregory, Center for Transportation and the Environment Matt Hansen, Supervisor of Market Development, King County Metro, WA Nicholas Ramfos, Metropolitan Washington Council of Governments Bill Roach, Market Development for King County Metro - retired Eric Schreffler, Transportation Consultant ESTC, San Diego, CA. Kevin Shannon, Association for Commuter Transportation Jim Udvardy, South Florida Commuter Services David Ungemah, Texas Transportation Institute Peter Valk, Transportation Management Services, Pasadena, CA Grant Zammit, Traffic Management and System Operations, FHWA - Atlanta, GA

The authors thank Carol Hunter of WSDOT, John Perlic and Peter Chen of Parametrix, Inc. for providing I-5 CORSIM files and Mark Bandy of WSDOT and Mark Yand of DKS Associates for providing I-90 VISSIM files.

The research team recognizes Dr. Huaguo Zhou of the Intelligent Transportation System Program at the Center for Urban Transportation Research (CUTR) for imparting his expertise and Ms. Patricia Ball of CUTR for editing the report. 


\section{Disclaimer}

The opinions, findings, and conclusions expressed in this publication are those of the authors and not necessarily those of the State of Florida Department of Transportation 


\section{Table of Contents}

EXECUTIVE SUMMARY

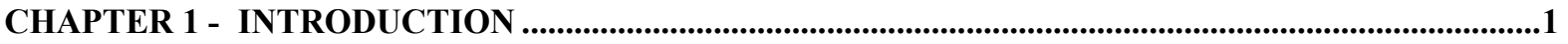

1.1 Study Background And PROBLEM StATEMENT ….................................... 1

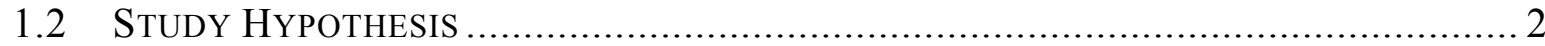

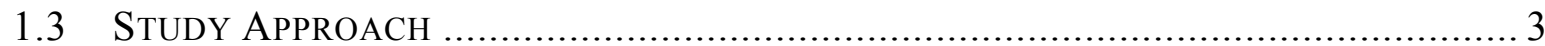

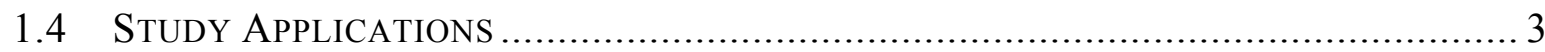

1.5 OutLINE OF RESEARCH METHOdOLOGY ....................................................... 3

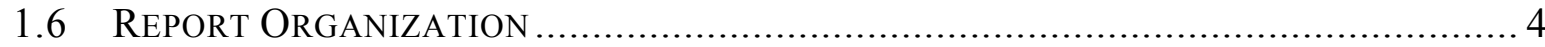

CHAPTER 2 - LITERATURE REVIEW …….............................................................................................6

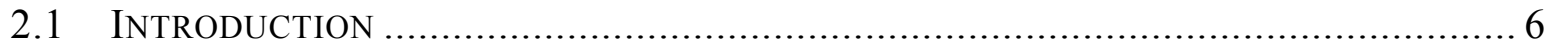

2.2 TransPortation PERFORMANCE MEASUREMENT ....................................... 7

2.2.1 State Efforts on Performance Measurement ......................................................... 7

2.2.2 National Efforts on Performance Measures ……................................................. 12

2.2.3 TRB and International Performance Measures ................................................... 15

2.3 Notes on Literature ReView on Performance Measurement ................... 20

2.4 REVIEW OF MODELS FOR TDM EFFECTIVENESS EVALUATION ....................... 20

2.4.1 Air Resources Board (California) Cost-Effective Model...........................................20

2.4.2 Washington State TDM Effectiveness Estimation Methodology (TEEM) Model............ 21

2.4.3 Environmental Protection Agency (EPA) COMMUTER Model ................................. 22

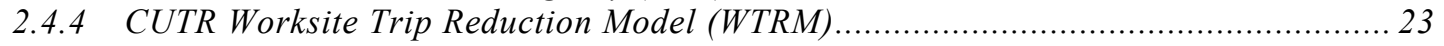

2.5 REVIEW OF ANALYSIS TOOLS .......................................................... 25

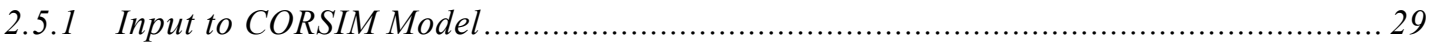

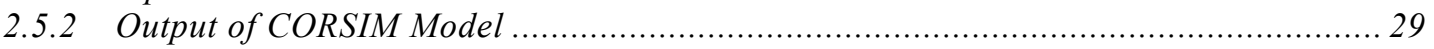

CHAPTER 3 - GROUNDWORK FOR MICROSIMULATION ANALYSIS.............................................31

3.1 Selection of IMPACt Area................................................................. 31

3.2 DATA COLLECTION .......................................................................... 32

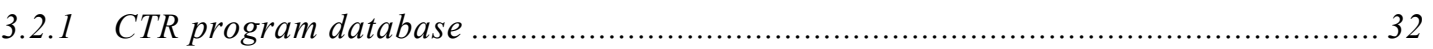

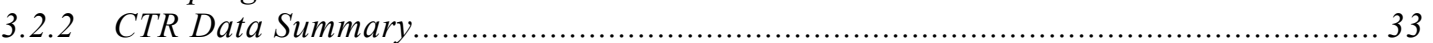

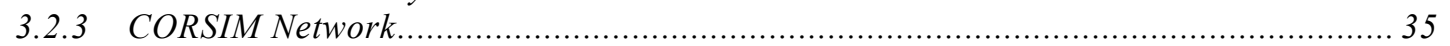

3.3 Estimation of Vehicle Trips ReducED due to CTR ProgRAmS ................. 36

3.3.1 VTR Estimation, Distribution, and Assignment - An Overview ................................. 36

3.3.2 Introduction to Worksite Trip Reduction Estimation .............................................. 36

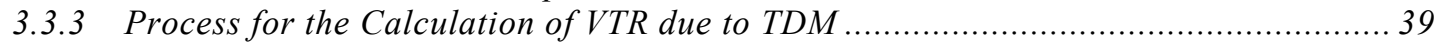

3.4 Distribution OF VEHICLE TRIPS REDUCED .............................................. 49

3.5 ASSIGNMENT OF VEHICLE TRIPS REDUCED ............................................ 49

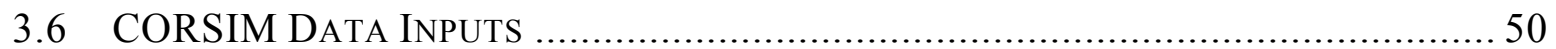

3.6.1 Statistics of CTR Employer Support Strategies.................................................. 51

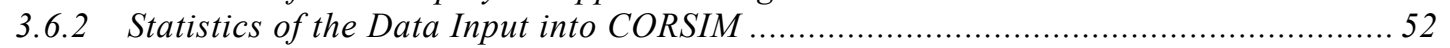

CHAPTER 4 - MICROSIMULATION ANALYSIS.........................................................................................58

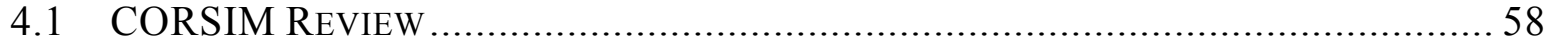

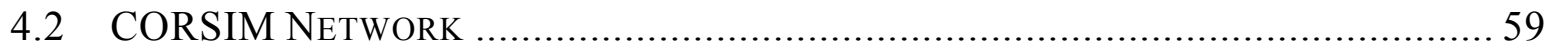

4.3 ANALYSIS OF THE WITH TDM AND WITHOUT TDM SCENARIOS ........................ 62

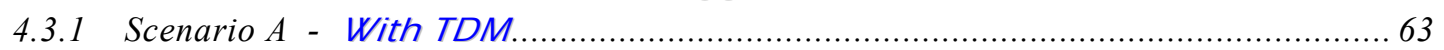

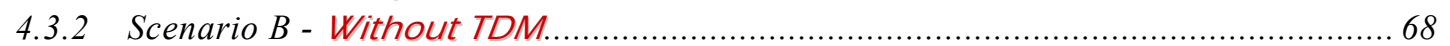


CHAPTER 5 - PERFORMANCE MEASURES WITH TDM AND WITHOUT TDM.................................. 72

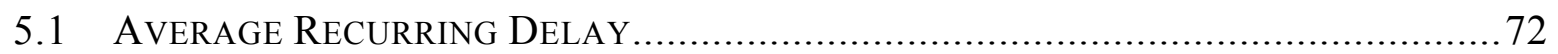

5.2 RECURRING DELAY ....................................................................... 75

5.3 SPATIAL EXTENT Of CONGESTION..................................................... 78

5.4 TEMPORAL EXTENT OF CONGESTION ....................................................... 81

5.5 AVERAGE SPEED ...................................................................... 88

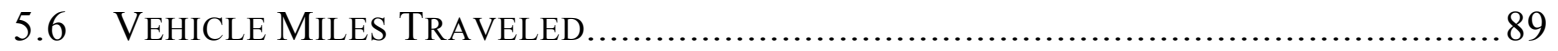

5.7 FUEL CONSUMPTION AND EMISSIONS ................................................. 91

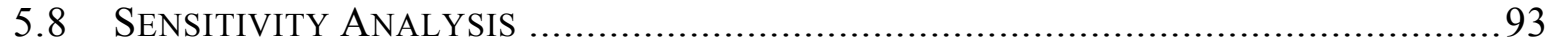

5.8.1 Groundwork for CORSIM Input for Sensitivity Analysis ....................................... 93

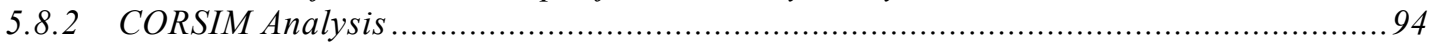

5.9 FACTORS AFFECTING THE RESULTS................................................. 96

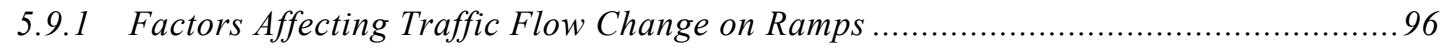

CHAPTER 6 - FINDINGS, CONCLUSIONS, AND RECOMMENDATIONS......................................... 101

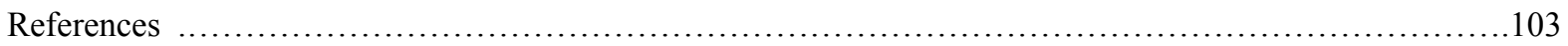

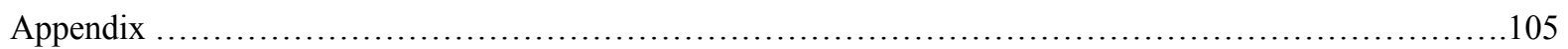




\section{List of Tables}

Table 1: Florida Statewide ITS Performance Measures........................................................................ 11

Table 2: Summary of Performance Measures from NTOC ……............................................................. 14

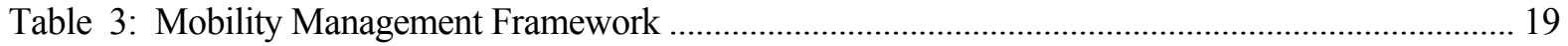

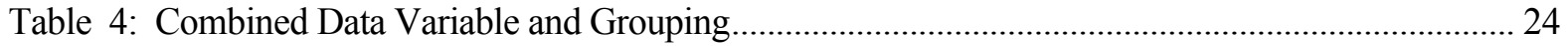

Table 5: Weighted Totals of Scores from the Decision Toolbox ............................................................ 28

Table 6: Combined Groups of TDM Strategies for Scenarios A and B ….............................................. 39

Table 7: Composition of Modal Support Strategy Program ...................................................................... 42

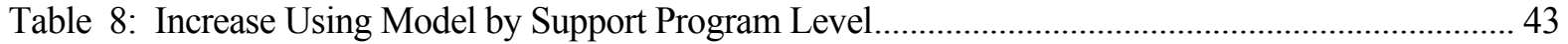

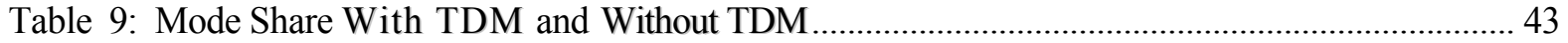

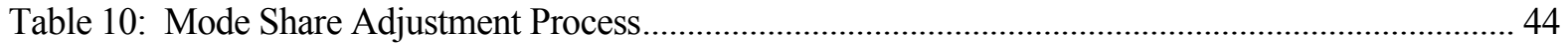

Table 11: Logit Mode-Choice Coefficients for Individual Urban Areas..................................................... 46

Table 12: Percent of Trips Shifted by Length of Peak Period ................................................................... 47

Table 13: Illustration of the TDM Reduced Trip Distribution Procedure ................................................... 49

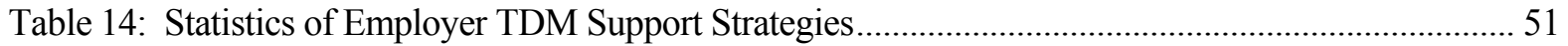

Table 15: Statistics of Employer Parking and Financial Subsidies........................................................... 52

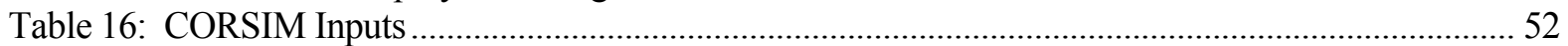

Table 17: I-5 Ramp Traffic Flow Change for AM Peak Period (Home-Worksite) .................................... 53

Table 18: I-5 Ramp Traffic Flow Change for PM Peak Period (Worksite-Home) ........................................ 54

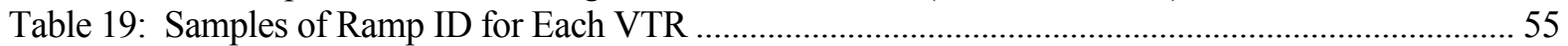

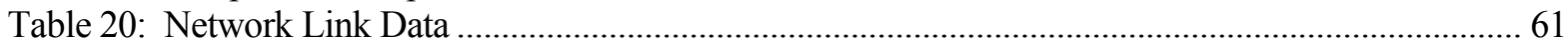

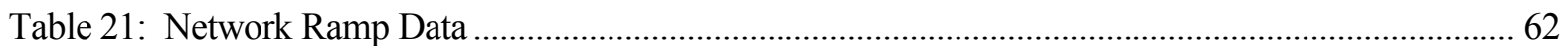

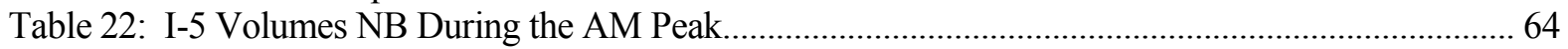

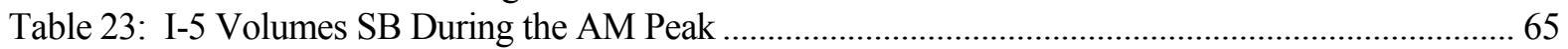

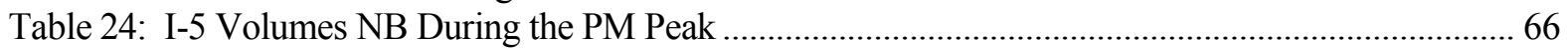

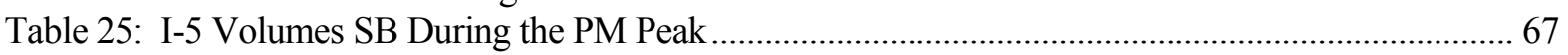

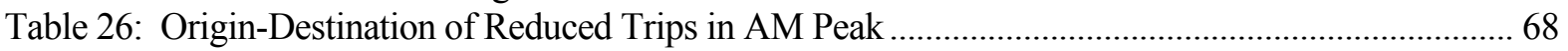

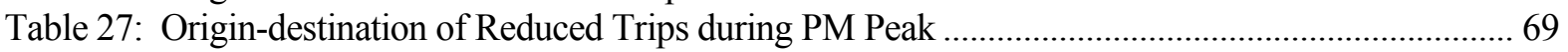

Table 28: Additional Volumes on Links in the Without TDM Scenario ..................................................... 70

Table 29: Summary of Performance Measures ……................................................................................. 72

Table 30: Difference in AM Peak Average Delay With TDM and Without TDM................................ 73

Table 31: Difference in PM Peak Average Delay With TDM and Without TDM ................................. 74

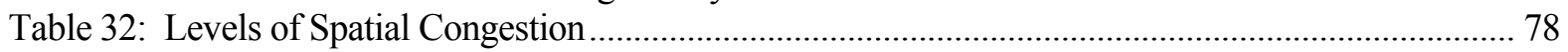

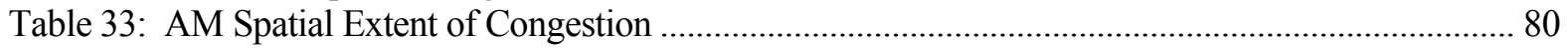

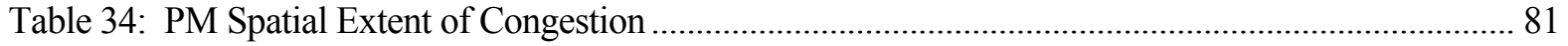

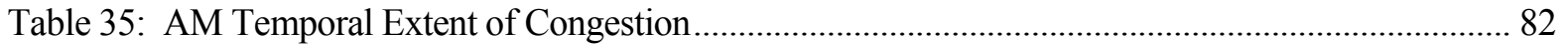

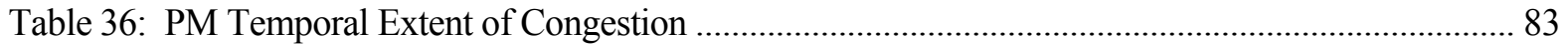

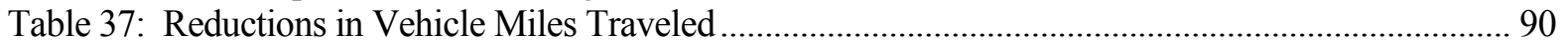

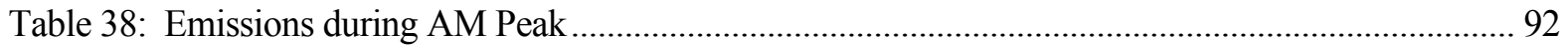

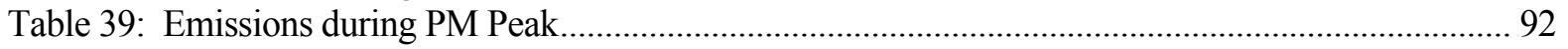

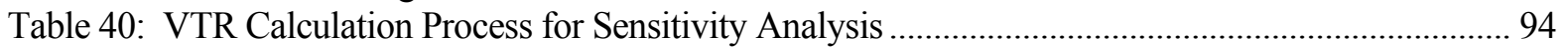

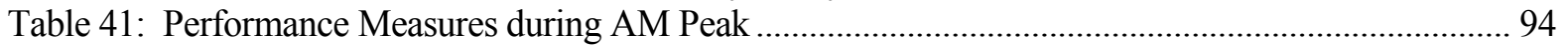

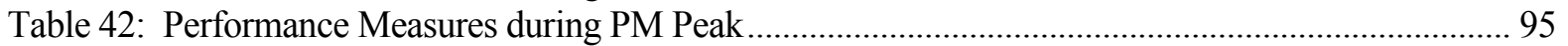

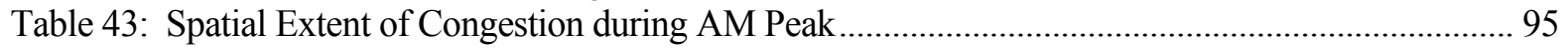

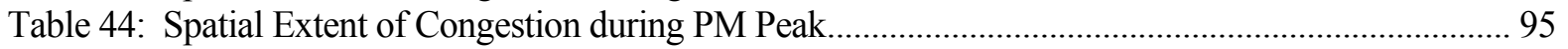

Table 45: On-ramp Traffic Flow at AM Peak (Home to Work)................................................................... 97

Table 46: Off-ramp Traffic Flow at AM Peak (Home to Work) ................................................................... 98

Table 47: On-ramp Traffic Flow at PM Peak (Work to Home) ………….................................................... 99

Table 48: Off-ramp Traffic Flow at PM Peak (Work to Home)............................................................. 100 


\section{List of Figures}

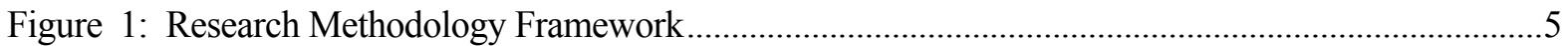

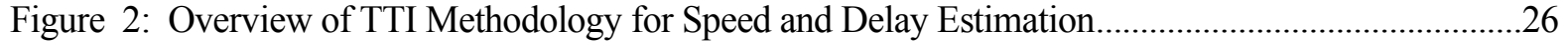

Figure 3: A Sample of Graphical Interface Provided by CORSIM ............................................................30

Figure 4: Pavement Reconstruction and Bottleneck Improvement Project for the I-5 Corridor .................31

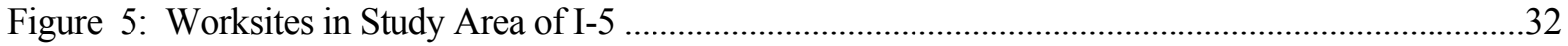

Figure 6: Study Area and Distribution of the Worksites...........................................................................34

Figure 7: Transportation Network of Five Counties and the Distribution of the Employees'

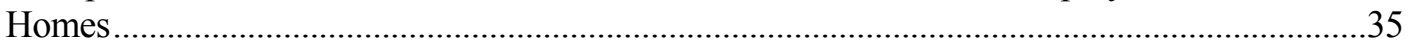

Figure 8: CORSIM Traffic Flow Input and Modification Interface ……..............................................50

Figure 9: CORSIM Traffic O-D Percentage Input and Modification Interface ..........................................51

Figure 10: Locations of On-ramps and Off-ramps with Significant Flow Change at AM Peak ................56

Figure 11: Locations of On-ramps and Off-ramps with Significant Flow Change at PM Peak ..................57

Figure 12: Schematic Sketch of the Study Area Segment of I-5 …....................................................60

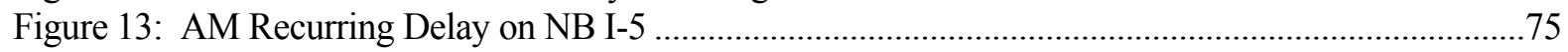

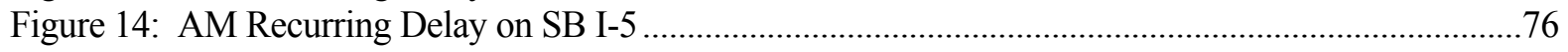

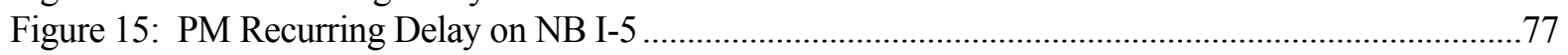

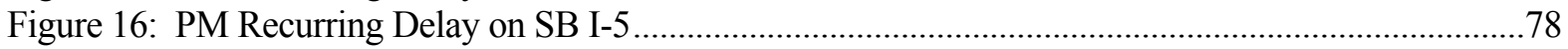

Figure 17: AM Spatial and Temporal Extents of Congestion on NB I-5 ..............................................84

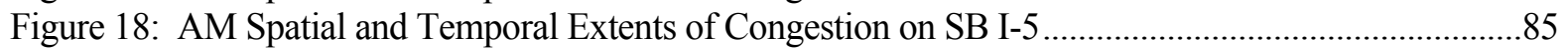

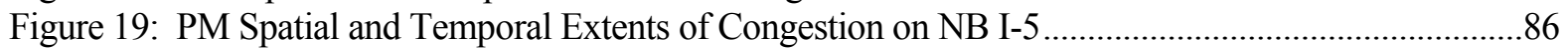

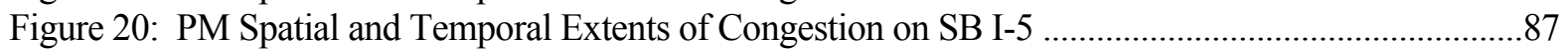

Figure 21: Average Corridor Speed During AM Peak..............................................................................8

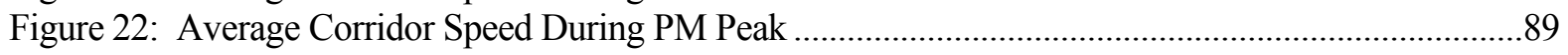

Figure 23: Fuel Consumption During AM Peak …….............................................................................91

Figure 24: Fuel Consumption During PM Peak .....................................................................................92 


\section{Executive Summary}

Performance measurements of operational effectiveness of highway systems include level of service, vehicle miles traveled (VMT), speed, and duration of congestion. Performance evaluation should also take account of such factors as mobility, accessibility, reliability, costeffectiveness, economic well-being, sustainability, environmental quality, safety, equity, and customer satisfaction. At the local level, for example, universal transit passes, given to employees in the form of a free or discounted flash pass, have significantly reduced the need to build additional parking and have shifted more travelers to modes other than driving alone. At the University of California's Los Angeles campus, transit ridership for commuting to campus increased by 56 percent during the first year of promotion of an unlimited access pass program, and solo driving fell by 20 percent. These impressive numbers directly correlate to improvements in transportation system efficiency and performance. If these thousands of workers were to join in daily peak hour traffic, then levels of transportation system congestion, air quality, lost time, VMT, and fuel consumption will dramatically worsen. Although this observation may seem evident, there is no recognized process for performance measurement that captures the actual impacts of employer-based Transportation Demand Management (TDM) programs on a transportation system at local, corridor, and regional levels. The scale of the employer-based programs is another issue. Though the programs may, in total, substantially reduce VMT, the reductions are likely to be spread geographically and temporally so the "observed" impact may be difficult to discern. The State of Washington invested \$2.7 million in the Commute Trip Reduction (CTR) program in 2005. This investment, combined with those of local jurisdiction partners and participating employers, provided significant benefits for the state's citizens.

The study goal was to develop a methodology that 1) measures the impacts of TDM programs on the overall transportation system, and 2) clearly communicates these impacts to policy makers and transportation decision makers. The hypothesis of the study was that a wide-scale adoption of employer-based TDM strategies is likely to have a noticeable effect on the transportation system performance of a corridor. The project's main objective was to establish the relationship between these strategies and corridor traffic performance expressed in terms of commonly used measures of effectiveness (MOEs). This research also tackled challenges facing TDM and traffic operations professionals alike including:

1. Are there better ways to communicate TDM successes to elected officials?

2. Can other measures/indicators convey the effectiveness of TDM by relating employer-based TDM programs directly to traffic congestion?

3. Can TDM strategies prove their effectiveness in ways that make them eligible for consideration by traffic operations staff?

4. Can a methodology be developed where TDM benefits are calculated in terms of widely used measures of transportation system efficiency?

5. If such a methodology exists, would different users with varied backgrounds and expertise be able to utilize it for assessing TDM impacts on their perspective areas of interest? 
6. How helpful would a graphical representation of a transportation system be with employer-based TDM program(s) impacts clearly visualized in terms of speed and time?

The Washington State Department of Transportation (WSDOT) maintains comprehensive databases of worksite-based TDM plans and employee travel characteristics. These databases were used to calculate vehicle trips reduced (VTR) due to TDM programs implemented at employer worksites in and around the Seattle downtown area. Two scenarios were compared: Scenario A "With TDM" represented existing traffic conditions on the network (where CTR is currently affecting the traffic) and Scenario B "Without TDM" represented traffic conditions after trips reduced because of CTR programs were added onto the network, i.e., as though CTR did not exist in the study area. The comparison was conducted using a microscopic simulation model, CORSIM, as the assessment tool to evaluate the impacts of CTR programs on the traffic network. This research measured the impacts of TDM programs on traffic performance in that area by combining CORSIM with mode split and origin/destination data for 63,000 commuters working at 189 worksites along an 8.6-mile stretch of Interstate-5 in the Seattle area. The analysis was conducted for the duration of the peak periods defined for this study as from 5:30 AM to 10:15 AM for AM peak and from 3:00 PM to 7:45 for PM peak.

In the corridor analyzed, the cumulative savings in delay due to TDM programs were estimated to be 152,489 and 169,486 vehicle-minutes for the AM and PM periods, respectively, attributable to the extensive worksite TDM programs. The TDM programs resulted in a total reduction of 102 lane-miles of spatial congestion in the AM peak period and 143 lane-miles in the PM peak period. A significant total reduction in travel time of 60 and 45 minutes for the AM and PM peak periods was observed, respectively. The average speed increased up to $19 \mathrm{mph}$ for the $\mathrm{AM}$ and up to $11 \mathrm{mph}$ for the PM peak period. The cumulative VMT reductions ranged from 17,297 vehicle-miles in the AM to 14,511 vehiclemiles in the PM peak period. Fuel savings for all travelers, not just those using non-single occupant vehicles, were estimated to be 3,489 gallons during the AM peak period and 4,314 gallons during the PM periods. The total estimated peak hour emission reductions due to improved traffic flow were 16.4 and 21.7 kilograms of hydrocarbon (HC) emissions and 1,109 and 1,545 kilograms of carbon monoxide (CO) emissions for the AM and PM peak periods, respectively. These results indicate that TDM had significant impacts on the performance of the transportation corridor.

The selected performance measures used the language of traffic operations professionals to communicate the impacts of TDM strategies. This research study also graphically presented the results of the CORSIM analysis showing the isolated impacts of CTR programs on the I-5 corridor study area to more effectively capture the spatial and temporal nature of traffic congestion.

The findings included significant reduction in recurring delay, reduction in spatial and temporal extent of congestion, and lesser emissions due to TDM programs. In addition, TDM programs resulted in fuel savings, VMT reduction, and an increase in the average speed of the corridor. 
Sensitivity analyses were conducted by assuming a conservative estimate of 4 percent decrease in average VTR due to less intensive trip reduction efforts (versus the observed 14 percent due to current CTR programs). There was a 29 percent reduction in delay as compared to 31.5 percent from the With TDM scenario. However, other system performance measures such as decrease in delay in vehicle-minutes, emissions, energy consumption, and spatial extent of congestion (i.e., decrease in lane-miles that takes 30 percent or longer than uncongested travel time) was 70 percent of the more intensive commute trip reduction program on larger employers. This reinforces the "tipping point" impact TDM can have on congestion.

The transferability of this analysis approach to estimate the impacts of employer-based TDM programs on a traffic network, is achieved through a web-based course. The course provides guidance to transportation and traffic professionals on the methodology developed by this research study.

The aforementioned results do not encompass all the impacts. The analysis was limited to an 8.6-mile corridor. Also, this study takes into account the impact of only 189 CTR employers in the region. However, there might be more worksites where TDM programs might have reduced vehicle trips, which might have affected the corridor analyzed in this study. Further, the CTR database does not account for all of the TDM programs in the Seattle region. Therefore, TDM programs might have an even greater impact on the performance of the transportation network. In many areas of the study corridor and/or times of day, TDM made a significant impact on congestion but not in all areas or times of day. This recognizes that TDM, like every other transportation solution, will not eliminate delay for every congested segment or time period. While some TDM advocates may need to manage expectations of the impacts of TDM programs, other transportation professionals and community leaders should better appreciate the benefits of TDM as an effective tool in the congestion reduction toolbox.

In the future, data collected by intelligent transportation systems (ITS) should help improve the methodology of assessing the impacts on TDM on the total system, not just a corridor, particularly before and after evaluations. Another area for future research is the synergistic effects of TDM and ITS strategies. For example, on a given corridor, are the effects of implementing a 511 system with HOV lanes equal to the sum of the individual effects of each application or does combining these strategies have a multiplicative effect that could result in larger or smaller impacts?

With respect to future research, this study sets a foundation for future work on:

- The development of national standards for measuring the performance of TDM that integrate with other transportation systems measures

- Development of cost/benefit analysis of TDM programs to communities and businesses

- Measuring the impact of TDM programs on freeways, arterials, and surface streets

- Analyzing the additive or multiplicative effects of combining different TDM strategies with appropriate ITS applications locally and regionally 



\section{Chapter 1 - Introduction}

\subsection{Study Background and Problem Statement}

Performance measurement of operational effectiveness of highway systems include level of service (LOS), traffic volume, vehicle miles traveled (VMT), speed, and duration of congestion. Performance evaluation should include such factors as mobility, accessibility, reliability, cost-effectiveness, economic well-being, sustainability, environmental quality, safety, equity, and customer satisfaction. At the local level, for example, universal transit passes, given to employees in the form of a free or discounted flash pass, have significantly reduced the need to build additional parking and have shifted more travelers to modes other than driving alone. At the University of California's Los Angeles campus, transit ridership for commuting to campus increased by 56 percent during the first year of promotion of an un-limited access pass program, and solo driving fell by 20 percent. Since the pass reduced the demand for parking by at least 1,020 spaces, the reduction in parking demand was worth $\$ 32.1$ million (1,020 spaces $\times \$ 31,500$ per space) (1). Widespread adoption of alternative work schedules programs is another type of employer work/life policy that is likely to influence travel behavior, at a corridor or regional level. The United States General Services Administration (GSA) estimates that $80 \%$ of federal agencies adopt alternate work schedules such as telework or compressed work week (2). From 2003 to 2004, there was a 37 percent increase in the number of teleworkers $(102,921$ to 140,694$)$. The number of employees teleworking as a percentage of those eligible to telework increased from 14 percent in 2003 to 19 percent in 2004. Approximately 41 percent of federal employees were eligible to telework during 2004. Thirty-eight agencies, 46 percent, reported that more than 25 percent of their workforce participated in telework during 2004. These hard numbers are a result of only one strategy, teleworking, which totally eliminates vehicle trips from the road, and did not take other commute alternatives such as compressed workweek into account.

These impressive numbers directly correlate to improvements in transportation system efficiency and performance. If these thousands of workers were to join in daily peak hour traffic then levels of transportation system congestion, air quality, lost time, VMT, and fuel consumption will dramatically worsen. Although this observation may seem to be evident, there is not a recognized process for performance measurement that captures the actual impacts of employer-based Transportation Demand Management (TDM) programs on a transportation system at local, corridor, and regional levels.

The scale of the employer-based programs is another issue. Though the programs may, in total, substantially reduce VMT, the reductions are likely to be spread geographically and temporally so the "observed" impact may be difficult to discern. The State of Washington invested \$2.7 million in the Commute Trip Reduction (CTR) program in 2005 (3). This investment, combined with those of local jurisdiction partners and participating employers, provided significant benefits for the state's citizens. Quantifying some of the performance indicators, the program provided the following benefits: 
- At least $\$ 24$ million in reduced cost of delay in the Puget Sound region (calculated using 2003 data).

- Savings of $\$ 13.7$ million in fuel costs for employees commuting to CTR worksites based on driving fewer miles.

- Reduction of 3,700 tons of criteria pollutants.

- Reduction of the equivalent of 74,200 tons of carbon dioxide.

The above measures/indicators are definitely marks of success for CTR. However, unanswered questions remain about making these measures clearer in terms that are universally communicated. Some of the challenges facing TDM and traffic operations professionals alike are:

1. Are there better ways to communicate CTR successes to the Legislature?

2. Can other measures/indicators convey the effectiveness of CTR by relating employer-based TDM programs directly to traffic congestion?

3. Can TDM strategies prove their effectiveness in ways that make them eligible for consideration by traffic operations staff?

4. Can a methodology be developed where TDM benefits are calculated in terms of widely used measures of transportation system efficiency?

5. If such a methodology exists, would different users with varied backgrounds and expertise be able to utilize it for assessing TDM impacts on their perspective areas of interest?

6. How helpful would a graphical representation of a transportation system be with employer-based TDM program(s) impacts clearly visualized in terms of speed and time?

This research report answers these questions and provides insights into future opportunities of tackling congestion by adding vehicle capacity, but not necessarily road capacity. This research study combines a common goal of transportation agencies and that is relieving congestion while utilizing the efficiency of the transportation system. By monitoring, evaluating, and communicating TDM strategies and their combined impacts on the roadway system in a visual way, planners, traffic operations staff, TDM professionals, decisionmakers, and elected officials can be "on the same page" choosing to combine and compare all the available cost-effective measures to reduce congestion.

\subsection{Study Hypothesis}

The hypothesis of the study is that a wide-scale adoption of employer-based TDM strategies is likely to have a noticeable effect on the transportation system performance at the local, corridor, and regional levels.

The research documented as much as 152,489 vehicle-minutes of savings in delay for the AM peak period of the study area due to TDM programs, while 17,297 vehicle-miles of travel were reduced for the same period. The savings in PM peak delay were 169,486 vehicle-minutes, and 14,510 vehicle-miles were reduced. Fuels saving, because of TDM 
programs implemented at worksites in the study area, were 3,489 and 4,314 gallons in the AM and PM peak periods, respectively.

\subsection{Study Approach}

The study goal was to develop a methodology that 1) measures the impacts of TDM programs on the overall transportation system, and 2) clearly communicates these impacts to policy makers and transportation decision makers.

The CTR program in the state of Washington maintains comprehensive databases of employer-based TDM programs and employees survey data. These databases were used to calculate vehicle trips reduced (VTR) due to TDM programs implemented at employer worksites in and around the Seattle downtown area. Two scenarios were compared: Scenario A represented existing traffic conditions on the network where CTR programs, since their inception, have been affecting the traffic. Scenario B represented traffic conditions where trips reduced because of CTR programs were added onto the network, i.e., as though the study area was not impacted by CTR. The comparison was conducted using a microscopic simulation model, CORSIM, as the assessment tool to evaluate the impacts of CTR programs on the traffic network.

The performance measures used for this research study include the following:

- $\quad$ Recurring delay in vehicle-minutes

- Average recurring delay in seconds/vehicle

- Average speed in mph

- Vehicle miles traveled

- Spatial extent of congestion

- Temporal extent of congestion

- Fuel consumption in gallons

- $\quad$ Emissions - Hydrocarbon (HC), Carbon monoxide (CO) and Nitrogen Oxides (NOx)

\subsection{Study Applications}

The project's products should facilitate multimodal, performance-based planning for use by transportation planners and decision makers. The linkage to public transportation system performance is likely to come through the impact of these employer-based programs on ridership and mobility. The measurement of the impacts of the TDM programs on a transportation network can be calibrated for use by models such as CORSIM for other corridors.

\subsection{Outline of Research Methodology}

Figure 1 is a sketch of the framework of the research methodology, the basis of which is to simulate the impacts of employer-based programs affecting a segment of a corridor. To study the impacts of TDM programs on a transportation system, the steps summarized below and outlined in Figure 1 were followed: 
1. A traffic network that is likely affected by employer-based TDM programs in its surroundings was selected.

2. Worksites utilizing TDM programs within the impact area were inventoried

3. Time period for the analysis was defined.

4. Data including worksite information, types of employer-based TDM strategies practiced, employee participation, and employee commute travel behavior were collected.

5. Vehicle trips reduced (VTR) at each worksite were calculated.

6. VTR were then distributed (pairs of origin-destination trips) on the traffic network.

7. The distributed trips were then assigned onto network links based on the shortest path between origins and destinations.

8. The already-calibrated microsimulation model was run with existing volumes (Scenario A: With TDM).

9. VTR were added to existing traffic counts on network links (Scenario B: Without TDM).

10. Scenarios A and B were run and data from output files were analyzed to compare the Scenarios.

\subsection{Report Organization}

Chapter 2 provides a literature review on performance measurement, TDM evaluation models, and traffic analysis tools. Chapter 3 details the procedures and methodologies followed to calculate trips reduced as a result of CTR programs implemented at worksites in the study area in Seattle. The chapter also explains how the reduced trips were distributed and assigned onto the traffic network as input to the simulation network of the study area. Chapter 4 documents the CORSIM analysis. Chapter 5 provides the comparison, in graphs and tables, of performance measures With TDM and Without TDM of the traffic network and presents some sensitivity analysis to show that even voluntary TDM programs that may result in modest vehicle trip reductions can contribute to improved transportation network performance. Chapter 6 discusses findings and provides recommendations for future research. 


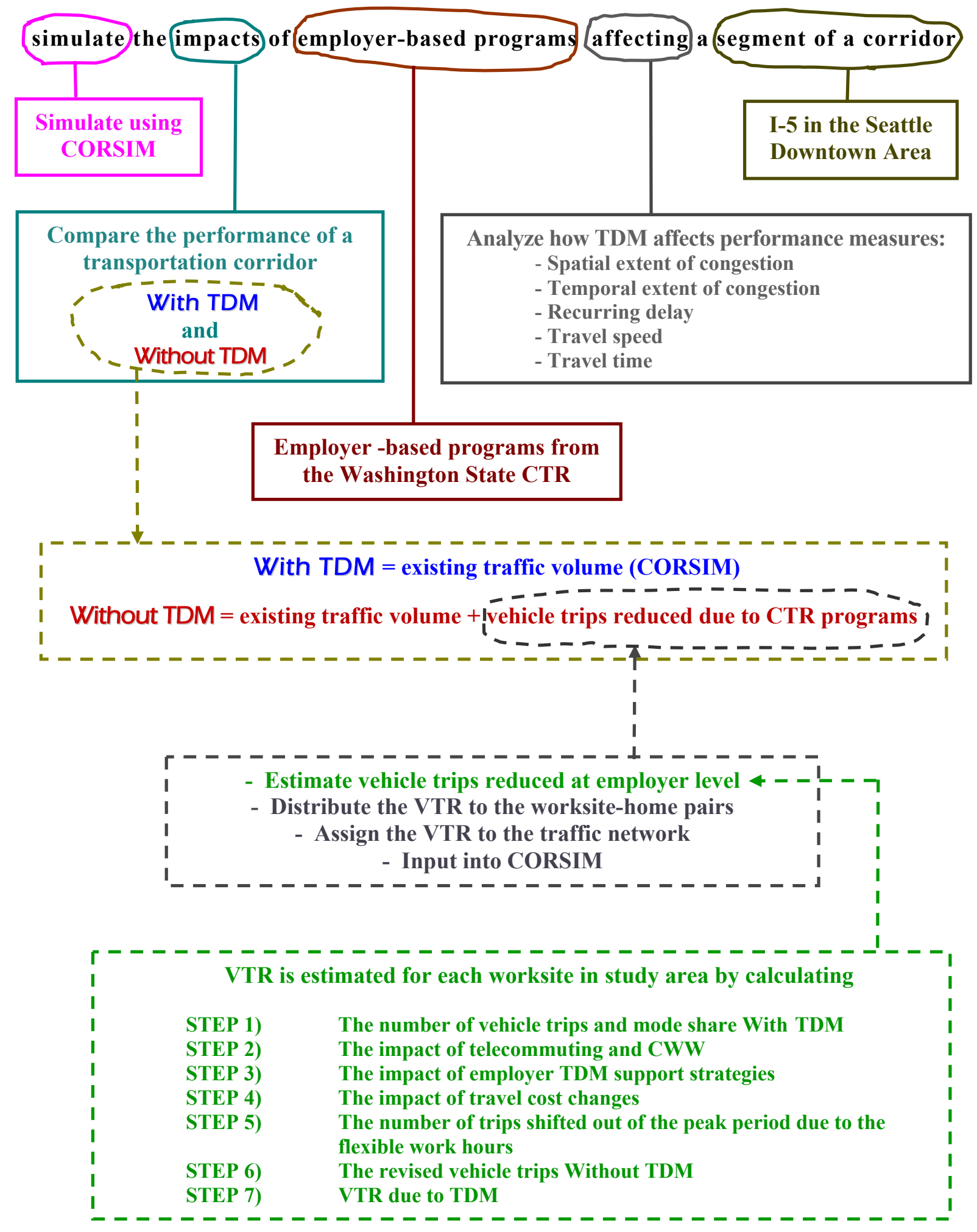

Figure 1: Research Methodology Framework 


\section{Chapter 2 - Literature Review}

\subsection{Introduction}

A comprehensive literature review was provided in Technical Memorandum \#1 of this project and included:

- The review of literature to identify Measures of Effectiveness (MOEs) and frameworks used for developing performance measurement systems used in the transportation industry, such as commuter assistance programs (CAP), intelligent transportation systems (ITS), and performance based planning.

- The review of documented assessments of employer-based programs at the worksite, transit system, set of intersections, activity center, corridor, and regional and system levels.

- The review of non-U.S. approaches to evaluation, specifically the Mobility Management Strategies for the next Decade (MOST) Monitoring and Evaluation Toolkit (MET) that outlines assessment levels and performance measures with the last level being system impacts.

- The review of findings and conclusions of both Transportation Research Board (TRB) conferences on "Performance Measures to Improve Transportation Systems and Agency Operations," 2000 and 2004. Other TRB research studies were also reviewed in the Memorandum.

- The research of the feasibility of using a corridor simulation tool, CORSIM, and the Washington State CTR program databases to prove the hypothesis that employer programs do affect the transportation system.

This chapter provides a summary of the literature reviewed and documents the research gaps highlighted in Technical Memorandum \#1 with remarks on how this research study fills these gaps.

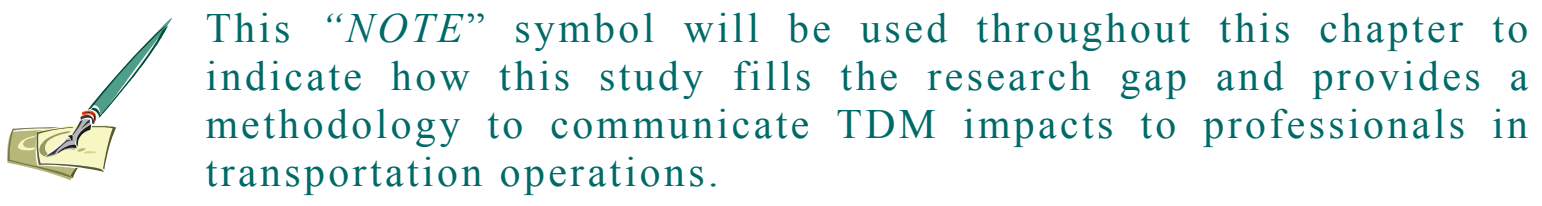

A review of literature on state, national, and international practice of performance measurement is provided in the next section. Section 2.3 compares evaluation models of TDM effectiveness including the Air Resources Board (California) Cost-Effective Model, the Washington State TDM Effectiveness Estimation Methodology (TEEM) Model, the Environmental Protection Agency (EPA) COMMUTER Model, and the Center for Urban Transportation Research (CUTR) Worksite Trip Reduction Model (WTRM). Section 2.4 reviews some tools used for the analysis of transportation network performance and presents how and why CORSIM was selected to account for the impacts of TDM employer-based programs on the transportation system. 


\subsection{Transportation Performance Measurement}

\subsubsection{State Efforts on Performance Measurement}

\section{Florida Commuter Assistance Programs}

The 1999 "Commuter Assistance Program Evaluation Manual" was developed by CUTR for FDOT to assist Florida's CAPs in their efforts to measure and evaluate their performance. The manual focuses on providing the information necessary for a CAP to devise and conduct its own evaluation program. It also provided guidance on how to report the results of that evaluation so that key CAP funding sources, elected officials, and the general public can understand and appreciate the efforts of the CAP in addressing traffic congestion, air quality, and mobility concerns. With the manual, transit and highway professionals are able to: 1) understand the concepts of CAP design and how TDM programs can be applied in diverse markets; 2) grasp what is needed to plan, design, implement, operate, and evaluate effective CAP projects successfully; and 3) use the guidance materials and technical tools compiled and developed in this effort for implementing effective CAP projects. "An Evaluation Toolkit for Florida's CAP: A Companion to the 1999 CAP Evaluation Manual" was later developed by CUTR to help implement the manual (4). For Florida CAPs, performance measures can be divided into three broad categories: A) required performance measures, B) optional performance measures; and C) other performance measures.

A) Required performance measures are those that the FDOT Central Office has mandated that all CAP offices in Florida track and report on at least an annual basis. The FDOT required performance measures are:

- Number of commuters requesting assistance

- Number of commuters switching modes

- Number of vans in service (where applicable)

- Number of vehicle trips eliminated

- Vehicle miles eliminated

- Employer contacts

- Parking spots saved/parking needs reduced

- Commuter costs saved

- Major accomplishments

For the purposes of evaluation, the data collection requirements can be divided into two distinct categories: those data elements collected by CAP staff, and those requiring surveys. To compile the information required to evaluate the program, a survey of database members is necessary.

B) District optional performance measures are those that FDOT has determined are appropriate for some of the CAP programs to show progress. District optional performance measures as defined by FDOT are:

- Gasoline saved

- Emissions reduced

- Information materials distributed 
- $\quad$ Special events

- Media/community relations

C) Other performance measures are those that can help a CAP illustrate the effectiveness of their programs in meeting program or regional objectives. These measures were developed to allow a CAP the flexibility to tailor an evaluation program that closely matches program goals and objectives and to measure CAP effects on markets and groups, like employers and the general public that directly or indirectly are influenced by CAP efforts. Some examples would be percent of employers with TDM programs, commuter costs saved, percent of employers wanting assistance from CAP, etc.

As evident by the required, optional, and other CAP
performance measures, there are many levels of TDM
evaluation, the last level being system performance. It does
seem rather logical that CAPs results would correlate to

\section{Washington State}

Documenting the changes in key performance measures such as travel delay, vehicle miles of travel, traffic volumes, and ridership levels for the transportation community may influence the support for such programs as a systems management strategy. Others face similar challenges in addressing how to relate the impact of worksite trip reduction programs on the system as well as on the worksite. For example, the CTR program in Washington State has used a variety of methods to help communicate the impacts in their biennial reports to the state legislature (5). In 1999, they used a lane-mileage reduction. In 2001, they used change in travel delay. In 2003, WSDOT used an analysis method developed by Texas Transportation Institute (TTI) for their 2003 Annual Urban Mobility Report (6). This methodology estimates the levels of congestion on roadways in major metropolitan areas throughout the country. TTI's 2003 report used a new methodology to estimate the delay reduction from five congestion remedies; ramp metering, incident management, signal coordination, public transportation, and high occupancy vehicle (HOV) lanes. These analysis techniques are experimental but provide a context for understanding the significance and value of travel delay reduction. TTI estimated that the total (morning and evening) annual delay reduction in 2003 for changes in commute choices at CTR sites to be 1.84 million hours and valued the savings at $\$ 24$ million each year. In addition, fuel savings from less stop-and-go traffic amounts to an estimated 3.6 million gallons, worth more than $\$ 5.8$ million per year. The TTI methodology for estimating delay and speed for various congestion mitigation strategies is based on a macroscopic approach. Travel delay is estimated from vehicle traffic per lane and traffic speed equations. 


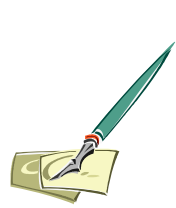

WSDOT corridor.

The fundamental challenge is to assess the bearings of TDM programs on the traffic system and to quantify speed, delay, and travel time after TDM programs are applied. This project addresses this challenge by using CORSIM to evaluate the impacts of employer-based programs from the developing strategies that increase transportation system efficiency particularly by reducing delays and bottlenecks during peak hours without added construction costs. This research provides a new tool that bridges the communication gap between the TDM and the traffic operations communities, both having a similar goal and that is tackling congestion by increasing the efficiency of the system.

\section{Florida's Mobility Management Process}

Florida DOT focused on "mobility" as the key system performance measure for "supporting investment decisions and policy analysis." Mobility is defined as the ease with which people and goods move throughout the community, state, and world. It is often measured as the quantity of travel served, quality of travel, accessibility, and use of transportation systems. Some example measures for each include the following:

Quantity:

- Person miles traveled

- $\quad$ Truck miles traveled

- Person trips

Quality:

- Ridership

- Average speed weighted by person miles traveled

- Average delay per vehicle

- Average door-to-door travel time

- Reliability (variance of average travel time or speed)

- Maneuverability (vehicles per hour per lane in peak hours)

- Auto or transit travel time ratio

Accessibility:

- Connectivity to intermodal facilities (percentage within 5 miles)

- Dwelling unit proximity

- Employment proximity

- Industrial warehouse facility proximity

- Percentage of miles of bicycle accommodation in right-of-way

- Percentage of miles of sidewalk coverage

- Transit coverage (percentage of person minutes served)

- Transit frequency (buses per hour)

- Span of service (hours per day)

Utilization:

- Percentage of system heavily congested (LOS E or F)

- Vehicles per lane mile 
- Percentage of travel heavily congested

- Duration of congestion (vehicles per hour per mile at LOS E or F)

- Transit load factor (percentage of seats occupied)

Mobility performance measures are used in systems planning and metropolitan planning to identify the location, scale, and nature of transportation problems to identify possible solutions to these problems. The measures may be applied statewide, in an area-wide analysis (e.g., the seven largest counties together), or by functional system (e.g., Florida Intrastate Highway System (FIHS)). Metropolitan planning organizations (MPOs) address many of the same issues at a metropolitan level.

Although TDM strategies are congestion management
solutions, they are not included in mobility evaluations. The
project's products should facilitate multimodal, performance
based planning for use by transportation planners and

\section{Florida ITS Performance Measures}

The Florida Transportation Commission (FTC) asked the Advisory Council of the ITS Florida Chapter (ITSFL) to identify suitable ITS performance measures. The ITS Performance Measures Committee evaluation effort involved workshops with extensive FDOT and private sector participation, (7). Preliminary (or interim) recommendations are included in Table 1.

The Committee recommended the addition of customer satisfaction survey question(s) for ITS (e.g., Road Ranger comment cards), account for the number (or percent) of traffic signals that are computerized and provide progression, and include case studies to document success stories in ITS deployment. 
Table 1: Florida Statewide ITS Performance Measures

\begin{tabular}{|c|c|}
\hline Program Area & Measurements \\
\hline $\begin{array}{l}\text { Operations and } \\
\text { Maintenance }\end{array}$ & $\begin{array}{l}\text { - Number of incident management (Road Ranger) responses } \\
\text { - Average time to clear incidents } \\
\text { - Number of } 511 \text { calls during times of incidents } \\
\text { - fumber (or percent) of lane-miles equipped with ITS components suitable } \\
\text { - Percenergency management } \\
\text { - Percent transit trips on-time } \\
\text { - Percent participation of commercial motor carriers in electronic screening } \\
\text { - Number (or percent) of commercial motor carriers that are electronically } \\
\text { by-passed at weigh stations }\end{array}$ \\
\hline Safety & $\begin{array}{l}\text { - Response time for incidents } \\
\text { - Clearance time for incidents } \\
\text { - Reduction in number of secondary incidents } \\
\text { - Reduction in work zone crashes (when ITS is applied) } \\
\text { - Reduction in pedestrian and bicycle crashes (when ITS is applied) }\end{array}$ \\
\hline Mobility & $\begin{array}{l}\text { - Percent person-hours of delay } \\
\text { - Percent truck-hours of delay } \\
\text { - Reliability measured by Buffer Time Index (95th percentile travel times } \\
\text { compared to average) } \\
\text { - Number of Road Ranger assists } \\
\text { - Number of media partnerships } \\
\text { - Frequency of } 511 \text { calls and related web site hits }\end{array}$ \\
\hline
\end{tabular}

The measures were then further refined in more extensive interviews with the FDOT Districts and Turnpike Enterprise. The following interim ITS performance measures were recommended, based on insight gained from workshops and review of pertinent literature including other state examples and current Federal priorities, to move forward into the Data Collection Phase:

- Number of 511 calls during times of incidents

- Number of Road Ranger responses during times of incidents

- Average incident response time

- Average incident clearance time

- Percent of actual versus planned ITS deployment (as defined by FDOT

- $\quad$ Ten-Year ITS Cost Feasible Plan), conducted on an annual basis

- Reliability of travel time, as measured by Buffer Time Index for top-ten travel corridors (in each District)

- Delay, as measured by passenger-miles of travel/vehicle-hours of travel

- (ITS versus non-ITS equipped corridors)

- Percent of electronic toll and/or transit payment transactions to total transactions

- $\quad$ Percent of electronic by-passes at truck weigh stations

Measures can be provided for top-ten commuting corridors, top-ten transit routes, top-ten Interstate corridors, or top-ten freight corridors, as desired. Standards and targets for 
mobility are needed to assess effects from ITS if congestion gets worse. Also under mobility, two other system measures for ITS versus non -ITS corridors have been suggested; speed index (vehicle-miles of travel/vehicle-hours of travel) and throughput index (passenger-miles of travel/vehicle-hours of travel).

This research may prove to be the first step in bringing to
traffic operations professionals a new perception and
understanding of TDM strategies. In the future, ITS can help
bolster the methodology of assessing the impacts of TDM not
only in a segment of a corridor, but regionally as well. ITS
systematically used for dynamic data collection can assist in before
and after TDM evaluations. One new research area as a result of this
project would be the practice of evaluating the combined impacts of
TDM strategies and selected ITS application in a corridor setting so
that blended alternatives are introduced and compared to increase
system efficiency.

\subsubsection{National Efforts on Performance Measures}

\section{Foundation for 21st Century Operations}

The Federal Highway Administration's (FHWA) Office of Operations started an initiative to reduce congestion through better operation of the highway network. The development of a foundation to diligently apply new technologies, better plan for operations, and chart success using key performance measures led to the creation of the Foundation for 21 st Century Operations (8). The Foundation started with collaborative activities in transportation operations that bring together jurisdictions and agencies such as State DOTs, Departments of Public Works, Transit Authorities, MPOs, and Public Safety/Security Agencies to plan for operations.

In general, it was agreed that a good measure:

- Is accepted by and meaningful to the customer

- Tells how well goals and objectives are being met

- Is simple, understandable, logical, and repeatable

- $\quad$ Shows a trend

- Is unambiguously defined

- Allows for economical data collection

- Is timely

- Is sensitive

According to the Foundation, a successful performance measurement system comprises a balanced set of a limited few vital measures, produces timely and useful reports at a reasonable cost, displays and makes readily available information that is shared, understood, and used by an organization, and supports the organization's values and the relationship the organization has with customers, suppliers, and stakeholders. 


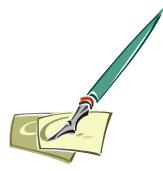

This project developed a methodology for measuring the impacts of employer-based TDM programs on transportation system performance, in particular from the traffic management and operations perspectives. This study investigated key performance measures, methods, and results in use today by the transportation community. It used familiar measures to communicate TDM impacts. Documentation of these impacts for that community should add TDM strategies to the range of management and operations solutions and ultimately may influence the support for such programs by traffic operations professionals and others as a costeffective systems management strategy.

\section{The National Transportation Operations Coalition (NTOC):}

The NTOC Action Team on Performance Measurement was convened to define and document "a few good measures" for transportation operations performance measurement (9). With the guidance of an oversight team comprised of transportation professionals and state and local government representatives, specific measures focused on the following issue areas:

- Non-recurring congestion (e.g., traffic incident management)

- Recurring congestion (e.g., arterial management, traffic signal timing)

- System-wide performance (e.g., travel time, reliability, congestion)

The oversight team identified and defined performance measures, Table 2, within each of the areas described above. Since the Performance Measures Initiative Report was finalized in the summer of 2005, the Performance Measures team has worked on identifying opportunities to work with states and MPOs to pilot some or all of the measures.

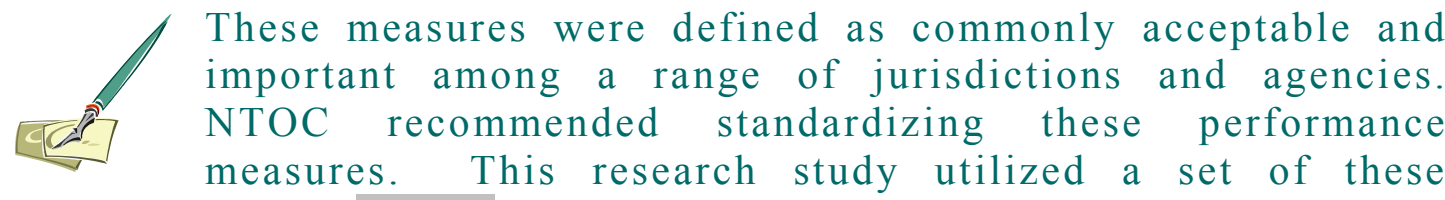
measures (rows shaded in Table 2) to communicate the impacts of TDM on the transportation system. With this research project completed, TDM impacts can now be presented to a variety of audiences making it possible for different agencies to consider TDM as one of the viable alternatives that reduces congestion, avoiding more concrete capacity additions. 
Table 2: Summary of Performance Measures from NTOC

\begin{tabular}{|c|c|c|}
\hline Measure & Definition & Sample Units of Measurement \\
\hline Customer satisfaction & $\begin{array}{l}\text { A qualitative measure of customers opinions related to the } \\
\text { roadway management and operations services provided in a } \\
\text { specified region }\end{array}$ & $\begin{array}{c}\text { Very satisfied } \\
\text { Somewhat satisfied } \\
\text { Neutral } \\
\text { Somewhat dissatisfied } \\
\text { Very dissatisfied } \\
\text { Don't know/not applicable }\end{array}$ \\
\hline $\begin{array}{l}\text { Extent of congestion - } \\
\text { spatial }\end{array}$ & $\begin{array}{l}\text { Miles of roadway within a predefined area and time period for } \\
\text { which average travel times are } 30 \% \text { longer than unconstrained } \\
\text { travel times }\end{array}$ & $\begin{array}{c}\text { Lane miles of congested conditions of } \\
\text { percent of congested roadways. } \\
\text { Calculated as a ratio }=100 \% x \text { (Congested } \\
\text { lane miles)/(total lane miles) }\end{array}$ \\
\hline $\begin{array}{l}\text { Extent of congestion - } \\
\text { temporal }\end{array}$ & $\begin{array}{l}\text { The time duration during which more than } 20 \% \text { of the roadway } \\
\text { sections in a predefined area are congested as defined by the } \\
\text { extent of congestion }\end{array}$ & Hours of congestion \\
\hline Incident duration & $\begin{array}{l}\text { The time elapsed from the notification of an incident until } \\
\text { evidence of the incident has been removed from the incident } \\
\text { scene }\end{array}$ & Median minutes per incident \\
\hline Non-recurring delay & $\begin{array}{l}\text { Vehicle delays in excess of recurring delay for the current time- } \\
\text { of-day, day-of-week, and day type }\end{array}$ & Vehicle-hours \\
\hline Recurring delay & $\begin{array}{l}\text { Vehicle delays that are repeatable for the current time-of-day, } \\
\text { day-of-week and day-type }\end{array}$ & Vehicle hours \\
\hline Speed & $\begin{array}{l}\text { The average speed of vehicles measured in a single lane for a } \\
\text { single direction of flow at a specific location on the roadway }\end{array}$ & $\begin{array}{l}\text { Miles per hour, feet per second or kilometers } \\
\text { per hour }\end{array}$ \\
\hline Throughput - person & $\begin{array}{l}\text { Number of persons including vehicle occupants, pedestrians, and } \\
\text { bicyclists traversing a roadway section in one direction per unit } \\
\text { time. May also be the number of persons traversing a screen line } \\
\text { in one direction per unit time }\end{array}$ & Persons per hour \\
\hline Throughput - vehicle & $\begin{array}{l}\text { Number of vehicles traversing a roadway section in one direction } \\
\text { per unit time. May also be the number of vehicles traversing a } \\
\text { screen line in one direction per unit time }\end{array}$ & Vehicles per hour \\
\hline Travel time-link & $\begin{array}{l}\text { The average time required to traverse a section of roadway in a } \\
\text { single direction }\end{array}$ & Minutes per trip \\
\hline $\begin{array}{l}\text { Travel time - reliability } \\
\text { (buffer time) }\end{array}$ & $\begin{array}{l}\text { The buffer time is the additional time added to a trip (measured } \\
\text { as defined b y travel time-trip) to ensure that travelers making the } \\
\text { trip will arrive at their destination at, or before, the intended time } \\
95 \% \text { of the time }\end{array}$ & $\begin{array}{l}\text { Minutes. This measure may also be } \\
\text { expressed as a percent of total trip time or as } \\
\text { an index }\end{array}$ \\
\hline Travel time - trip & $\begin{array}{l}\text { The average time required to travel from an origin to a } \\
\text { destination on a trip that might include multiple modes of travel }\end{array}$ & Minutes per trip \\
\hline
\end{tabular}

Shaded cells are measures used for evaluating TDM impacts on the performance of the transportation system in this study

Source: National Transportation Operations Coalition. "Performance Measure Initiative Final

Report.” July 2005, p. 4. Accessed Aug 21, 2006 at

http://www.ntoctalks.com/ntoc/ntoc final report.pdf 


\subsubsection{TRB and International Performance Measures}

\section{TRB Conferences and Research on Performance Measures}

In October 2000, more than 120 transportation and planning officials gathered in Irvine, California, for the TRB Conference, "Performance Measures to Improve Transportation Systems and Agency Operations" (10). The objective of the conference was to bring together a group of government, academic, and business leaders who had experience in transportation systems performance measures and performance based planning and programming. The group discussed organizational approaches to implementing and using performance measures in transportation systems, including the connection between measures and decision-making, implementation experience regarding the state of the practice as well as lessons and guidelines for moving forward, and customer perspectives of transportation system performance. Other issues included application of multimodal measures in the planning process and the assessment of system performance and technical issues involving data, number, and type of measures, and trade-off analysis. Next steps and research recommendations from the conference included:

- Clarify terminology of performance measures.

- Fund the synthesis of best practices and other mechanisms to share experience.

- Research new measures, in particular

- Soft measures such as quality of life,

- Mode-neutral measures, and

- System-wide measures.

- Identify strategies to better use existing data.

- Develop techniques to balance or weigh competing goals and measures.

- Provide staff training on performance measures, data collection and analysis, and presentation techniques.

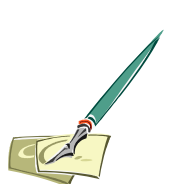

This study addressed the issue of communicating impacts of TDM strategies to traffic operations staff in familiar expressions on a second by second basis for each vehicle in a transportation network. Currently, most TDM evaluation programs report impacts on a daily or annual basis for the system as a whole. The CORSIM output file contains links and network-wide statistics providing a graphical interface to view the coded network allowing researchers, practitioners, and decision-makers to inspect visually the traffic conditions throughout the duration of the simulation. In addition to the output from the algorithm such as delay per vehicle, graphical interface can be used to visually compare the before and after scenarios for any improvements to the transportation network.

This research study fulfilled some of the conference recommendations by using data already collected (employer and employee surveys) and communicating conventional performance measures (delay, speed, 
throughput, etc.,) to more diverse stakeholders from different agencies or departments (planning, ITS, traffic operations, and TDM). In addition, one of the products of this study is an on-line training course that helps practitioners apply the same methodology to their respective areas of interest and calculate TDM impacts of a transportation system.

The 2003 National Cooperative Highway Research Program's "NCHRP Synthesis of Highway Practice 311: Performance Measures of Operational Effectiveness for Highway Segments and Systems" examined the use of performance measures for the monitoring and operational management of highway segments and systems (11). The current state of the practice includes a wide and varied approach to performance measures with more than 70 measures identified. The measures most commonly identified were conditions experienced by the traveler, such as travel time, speed, and delay. Measures that are derived from these basic units, primarily indices, were found to be less relevant to the operational environment, but very valuable for transportation planning, policy, and prioritization analysis. Based on the results of a survey of state DOTs and MPOs, the dimensions of operational performance that were the most relevant were the quantity of travel and the quality of travel. The following measures were recommended based on their ability to serve as foundations for other commonly reported measures, such as the congestion index.

A) Outcomes (Operational) Performance Measures

- Quantity of travel

- Person-miles traveled

- Truck-miles traveled

- Vehicle miles traveled

- Persons moved

- Trucks moved

- Vehicles moved

- Quality of travel (users' perspective)

- Average speed weighted by person-miles traveled

- Average door-to-door travel time

- Travel time predictability

- Travel time reliability (percent of trips that arrive in acceptable time)

- Average delay (total, recurring, and incident-based)

- Level of Service (LOS)

- Utilization of the system (agency's perspective)

- Percent of system heavily congested (LOS E or F)

- Density (passenger cars per hour per lane)

- Percentage of travel heavily congested

- Volume to Capacity (V/C) ratio

- Queuing (frequency and length)

- Percent of miles operating in desired speed range

- Vehicle occupancy (persons per vehicle)

- Duration of congestion (lane-mile-hours at LOS E or F)

- Safety

- Incident rate by severity (fatal, injury, or property damage), and type (stopped vehicles, rail crossing, weather, or crashes) 
- Incidents

- Incident induced delay

- Evacuation clearance time

B) Outputs (agency performance)

- Incident response time by type

- Stopped vehicle

- Rail crossing

- Weather

- Crashes

- Toll revenue

- Bridge condition

- Pavement condition

- Percent of ITS equipment operational

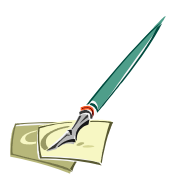

This research used well-defined performance measures for TDM impacts on the transportation system that are quantifiable, simple, and clear to technical and non-technical audiences. These measures were calculated from existing field data and are consistent with operations analysis. The research team used network traffic data and the CTR database available from WSDOT to evaluate the benefits of employer-based programs on the transportation system. The CTR database was used to estimate the peak period trips reduced because of employer-based TDM programs. These trips when added to current traffic conditions create a scenario assuming CTR programs were not in place. This scenario was evaluated against existing traffic conditions using CORSIM to show the benefits of implementing TDM programs. MOEs used for the evaluation included reductions in VMT and delays (listed above.) Although reduction in fuel consumptions and air quality improvements are not included in the list, they are used in this study, as they are extremely important and timely additions to performance measurement. Also, they are used as indicators for funding authorities to prove the effectiveness of the TDM programs.

When TRB convened the Second National Conference on Performance Measures in Irvine, California August 22-24, 2004, it brought together approximately 125 individuals from across the transportation planning communities, at national, state, regional, and local levels and from the public and private sectors and academia (12). More than 20 state DOTs participated in the conference, along with a similar number of local and regional agencies. The conference had two primary objectives: to explore the implementation and use of performance measures and to discuss how to monitor the impact of performance measures on the delivery and quality of transportation services. 
There is no recognized process for performance measurement that captures the actual impacts of employer-based TDM programs on a transportation system at local, corridor, and regional levels. Though the programs may in total substantially reduce VMT, the reductions are likely to be spread geographically and temporally so the "observed" impact may be difficult to discern. Rather than remove the need for "full lanes," the actual benefits to the transportation system in terms of reductions in lane capacity are likely to be only "slivers" of road capacity. There are many levels of TDM evaluation, the last level being system performance. Some evaluation efforts are taking a bottoms-up approach to evaluation by systematically conducting evaluations at the program level but designed to avoid double-counting and rolling the effects up to a regional level.

This research study combines a common goal of transportation agencies, relieving congestion while utilizing the efficiency of the transportation system. By monitoring and communicating TDM strategies and their combined impacts on the roadway system in a visual way, planners, traffic operations staff, TDM professionals, decision-makers, and elected officials can be on the same page choosing to combine/compare cost-effective measures to reduce congestion.

\section{Project MOST}

MOST is an organization overseeing the implementation of pilot TDM projects in 32 European cities. The scope of MOST is to improve access to transportation for all sectors and to foster positive attitudes about alternative options toward sustainable mobility (13). MOST programs focus a large amount of resources on educational programs to enhance public awareness and to attract schoolchildren to transportation alternatives, before commuting habits are formed. MOST also is involved in shaping policy decisions such as changing tax laws to favor alternative mode use, changing land use rules to favor car-free spaces, and alteration of existing infrastructure to improve car-free options.

MOST developed a thorough set of evaluation guidelines called the Monitoring and Evaluation Toolkit (MET). MET helps Mobility Management (MM) practitioners define objectives, select target groups, and select evaluation techniques. The first recommendation is to perform a before-and-after study to collect baseline data in order to have something to measure for follow-up. The most important information required before program implementation is the initial conditions at both a spatial and personal level. Table 3 provides an illustration of the MM Framework. 
Table 3: Mobility Management Framework

\begin{tabular}{|c|c|c|c|c|c|}
\hline $\begin{array}{c}\text { Evaluation } \\
\text { Framework }\end{array}$ & & $\begin{array}{l}\text { Assessment } \\
\text { Levels }\end{array}$ & Definition & Before & Study \\
\hline \multirow[t]{2}{*}{$\begin{array}{l}\text { Framework } \\
\text { Conditions }\end{array}$} & $\mathrm{S}$ & $\begin{array}{l}\text { Spatial } \\
\text { Framework } \\
\text { Conditions }\end{array}$ & $\begin{array}{l}\text { Refers to conditions like travel and traffic patterns that are } \\
\text { similar for all users. Evaluation in this category consists of } \\
\text { working times and frequency (may affect carpooling), parking } \\
\text { availability in relation to requirements, parking fees, and } \\
\text { conditions for cyclists. Collecting this information in a before } \\
\text { survey is important for factoring external influences later. }\end{array}$ & $*$ & $X$ \\
\hline & $\mathrm{P}$ & $\begin{array}{l}\text { Personal } \\
\text { Framework } \\
\text { Conditions }\end{array}$ & $\begin{array}{l}\text { Refers to information about personal information of individual } \\
\text { travel patterns. Evaluation in this category may consist of } \\
\text { distance between work and home, mode choice, etc. }\end{array}$ & $*$ & $X$ \\
\hline \multirow{3}{*}{ MM Services } & A & $\begin{array}{l}\text { Knowledge } \\
\text { of MM } \\
\text { Services }\end{array}$ & $\begin{array}{l}\text { Checks whether or not people know about MM and, if they do, } \\
\text { which programs or services. A technique would be to conduct } \\
\text { an awareness campaign and survey students or employees about } \\
\text { their knowledge of programs or services. }\end{array}$ & & $*$ \\
\hline & B & $\begin{array}{l}\text { Usage of } \\
\text { MM } \\
\text { Services }\end{array}$ & $\begin{array}{l}\text { Check whether or not people use MM programs or services and } \\
\text { if so, which ones. }\end{array}$ & & $*$ \\
\hline & $\mathrm{C}$ & $\begin{array}{l}\text { Satisfaction } \\
\text { with MM } \\
\text { Services }\end{array}$ & $\begin{array}{l}\text { Checks whether or not people are satisfied with MM programs } \\
\text { and services and how they would improve them. }\end{array}$ & & $*$ \\
\hline \multirow{3}{*}{$\begin{array}{l}\text { Travel } \\
\text { Services }\end{array}$} & $\mathrm{D}$ & $\begin{array}{l}\text { Acceptance } \\
\text { of Travel } \\
\text { Options }\end{array}$ & $\begin{array}{l}\text { Checks whether or not people have accepted proposed travel } \\
\text { options. }\end{array}$ & & $*$ \\
\hline & $\mathrm{E}$ & $\begin{array}{l}\text { Experiment } \\
\text { al } \\
\text { Individual } \\
\text { Travel } \\
\text { Behavior }\end{array}$ & $\begin{array}{l}\text { Checks whether or not people changed their individual travel } \\
\text { behavior to try an alternative. }\end{array}$ & & * \\
\hline & $\mathrm{F}$ & $\begin{array}{l}\text { Satisfaction } \\
\text { with Travel } \\
\text { Option }\end{array}$ & $\begin{array}{l}\text { Checks whether or not people are satisfied with the tested } \\
\text { alternative transport modes and how they could be changed to } \\
\text { meet their needs }\end{array}$ & & $*$ \\
\hline \multirow{2}{*}{$\begin{array}{l}\text { Mobility } \\
\text { Behavior }\end{array}$} & G & $\begin{array}{l}\text { Permanent } \\
\text { Individual } \\
\text { Travel } \\
\text { Behavior }\end{array}$ & $\begin{array}{l}\text { Checks whether or not people changed their travel behavior and } \\
\text { if so what they changed (mode, time, or destination choice or } \\
\text { trip frequency). }\end{array}$ & $\mathrm{X}$ & $*$ \\
\hline & $\mathrm{H}$ & $\begin{array}{l}\text { System } \\
\text { Impact }\end{array}$ & $\begin{array}{l}\text { Checks the changes in traffic flow, mode choice, emissions, and } \\
\text { energy consumption, etc. }\end{array}$ & $\mathrm{X}$ & $*$ \\
\hline
\end{tabular}

* denotes major focus; $\mathrm{X}$ notes focus

The MOST MET evaluation framework can be separated into categories of soft and hard evaluation findings. Soft results may include levels or awareness and satisfaction and hard results may include travel behavior changes or increased use of a sustainable mode of transportation. Levels $\mathrm{A}$ to $\mathrm{F}$ are classified as soft and $\mathrm{S}, \mathrm{P}, \mathrm{G}$, and $\mathrm{H}$ as hard evaluation methods. 
While MOST MET has standard forms and questionnaires for practitioners and participants to use for evaluations and comparisons of programs over time, further study of the impacts of MM on the transportation system was recommended. Most of the data used for MOST evaluation came from employee/resident/visitor surveys, number of riders, and direct measurements of air quality from monitoring stations. Despite the fact that evaluation results help monitor progress and provide good arguments for the decision-makers, not many MM projects were found to have integrated evaluations in their planning. The need for more investigations of long-term impacts of MM was recommended.

This study establishes direct correlation between employer-based strategies and the traditional transportation system performance measurement. Despite MOST success at evaluating TDM programs at worksites, it did not establish a methodology of assessing the impacts of these programs on the transportation system. This research made a stride towards successfully establishing a methodology to evaluate and communicate the impacts of TDM in terms of traffic operations.

\subsection{Notes on Literature Review on Performance Measurement}

The literature review revealed the gap between methodologies used to evaluate the effectiveness of employer-based TDM strategies at worksites in contrast to common measures used to evaluate the performance of the transportation system. This research study addressed this gap by developing a methodology that will help TDM professionals communicate the effectiveness of employer-based programs in terms of commonly used transportation performance measures including delay in vehicle-hours and seconds per vehicle, average speed in miles per hour (mph), spatial and temporal extent of congestion, in addition to fuel consumption in gallons and emissions in grams $/ \mathrm{mile}$.

\subsection{Review of Models for TDM Effectiveness Evaluation}

The following trip reduction models were reviewed:

1. Air Resources Board Cost-Effective Model (14)

2. Washington State TDM Effectiveness Estimation Methodology Model (15)

3. Environmental Protection Agency COMMUTER Model (16)

4. CUTR Worksite Trip Reduction Model (17)

\subsubsection{Air Resources Board (California) Cost-Effective Model}

This automated Access database was developed to assess the cost-effectiveness of TDM strategies implemented to reduce employee trips. The methodology used to calculate the trip reduction is relatively simple. Users are asked to perform a weeklong commute travel survey to collect the mode split and travel distance information. Then the following equation is used to calculate the current weekly vehicle trips per commute employee. The current weekly 
vehicle trips per commute employee are then compared with the national average or other user specified data to calculate the yearly trip reduction, (11). The model can be found at http://www.arb.ca.gov/planning/tsaq/eval/eval.htm

Vehicle trips per year reduced $=$

[Current weekly vehicle trips per commute employee][National average vehicle trips/employee/wk]) $x$ [weeks] $x$ [employees]

\subsubsection{Washington State TDM Effectiveness Estimation Methodology (TEEM) Model}

The TEEM model was developed by DKS Associates in 2003 for the WSDOT. The model was updated in 2005. The purpose of developing the model is to produce an analytical tool that can quantify the effectiveness of TDM and land use strategies in the Central Puget Sound Region, (12). The model and the documentations can be found at http://www.wsdot.wa.gov/mobility/TDM/sr520caseteem.htm

The model was created based on local data sources and can estimate the effectiveness of 20 TDM and land use strategies at a corridor or sub area level. Each strategy is evaluated separately using different methodologies. The combined impacts can be evaluated based on the assumption of the interaction of different strategies. The major TDM strategies that are included in the model and the methodologies applied to perform the evaluation are briefly reviewed in the following sections.

\section{Evaluating the Impact of Multiple Strategies}

The evaluation of the combined impacts of different strategies depends on the assumption of the interaction of the strategies. In some cases, the cumulative effect from combining most strategies can be found by sequentially predicting the effect of one, then adjusting the baseline data and applying the next one. Strategies such as these are referred to as multiplicatively additive. Other strategies, when combined, affect different markets and the results can be combined directly. These are referred to as directly additive. This could include a strategy affecting only employee trips being combined with a strategy affecting only residential non-work trips. A third type of combination is strategies that conflict in ways that are not accounted for by readjusting the base shares. These are referred to as conflicting strategies, and a correction factor must be specified to be able to estimate the combined effect of both. The final category of strategy combination is referred to as synergistic. When combined, they produce greater results because of their supportive nature than a direct addition of their impacts would suggest.

TEEM is designed to apply sensitivity factors to base mode shares incrementally when more than one strategy is being tested. By readjusting the base mode shares, the methodology can accurately represent the first two types of interactions above: directly additive and multiplicatively additive. If the strategies do not interact or affect the same markets and are directly additive, then no adjustment of the predicted changes is necessary at all. If they are multiplicatively additive, the re-adjusting of the base mode share provides an accurate assessment of the combined affect but the individual effects cannot be identified. The order in which they are tested does not affect the results. Only the conflicting and synergistic 
affects are not directly accounted for in TEEM. Users of TEEM need to be aware of when such interaction may be occurring and special adjustments need to be made.

\subsubsection{Environmental Protection Agency (EPA) COMMUTER Model}

This is a model developed by Cambridge System, Inc. for U.S. Environmental Protection Agency (EPA). The first version of the model was released in 2000, and the model was updated in 2005. The basic objective of the model is to assess or evaluate the emission impacts of various transportation control measure strategies. The methodology and procedure of the model are based on the Federal Highway Administration's Travel Demand Management Evaluation Model (FHWA TDM model), (13). The model can be accessed at http://www.epa.gov/otaq/stateresources/policy/transp/commuter/commuter-v20.zip

In the COMMUTER model, the TDM strategies are classified into four categories and the impacts of each category are analyzed using different methodology:

1. Employer TDM Support Strategies: Non-monetary inducements to encourage employees to use alternative modes rather than drive alone. These include rideshare matching services, vanpool formation assistance, on-site transit information and/or pass sales, transportation coordinators, guaranteed ride home.

2. Alternative Work Schedules: Arrangements such as flexible or staggered work hours, compressed workweeks, and telecommuting.

3. Travel Time Improvements: On-site or adjacent area modifications to improve access to work sites from transit, or by walking or biking. Also includes preferential (close-in/reserved) parking for carpools or vanpools, and improvements to transit service.

4. Travel Cost Changes: Measures such as imposition of parking fees, differential rates or discounts for carpools or vanpools, transit fare subsidies, or in specific modal incentives or disincentives to any or all modes.

The first two (Employer TDM Support Programs and Alternative Work Schedules) are analyzed using relational factors in look-up tables, with a normalization procedure applied to the adjusted shares to ensure that changes are proportionate across the available alternatives and do not allow final choices to exceed 100 percent. The strategies that involve changes to either travel time or cost (Travel Time Improvements and Travel Cost Changes) are analyzed through the more rigorous logit pivot-point procedure.

The COMMUTER model estimates the combined impacts of different TDM strategies by performing the calculation through a sequencing order. The order in which the COMMUTER model performs its calculations of travel changes is as follows:

It first calculates the changes due to Alternative Work Hours. This serves to re-adjust the travel population baseline to determine how many trips will be shifted to the off-peak, and how many will remain in the peak period and be subjected to application and analysis of the mode-choice oriented strategies. Next, mode shares of the remaining peak trips are 
readjusted to reflect the effects of the Employer TDM Support strategies. All time and cost related strategies are tallied up and brought into the logit pivot-point procedure, which is then applied to the revised mode share starting point from step 2.

\subsubsection{CUTR Worksite Trip Reduction Model (WTRM)}

This model was developed by CUTR in 2004 using worksite trip reduction data from three urban areas in the United States Los Angeles, Tucson, and Washington State that have had trip reduction requirements on employers for many years (14). Two approaches were used for the model building process: linear statistical regression model and non-linear neural network model. The linear statistical regression models were used as a benchmark for the validity and accuracy of the neural network models. Several phases were followed to build the models. Models were built for each of the three datasets using a variety of approaches of handling the data, including variable selection, grouping of incentives, and the treatment of outliers. Models were also built after combining the data from the three urban areas into a single dataset. The only model to get better results simultaneously on all three cities' validation sets was a neural network model built with no variable selection on equally sampled combined data. This model serves as the generalized model and is located at http://www.nctr.usf.edu/worksite/

Differing from the TEEM and COMMUTER models, the CUTR worksite trip reduction model chose the change in vehicle trip (VT) rate (e.g., reduction of 4.5 vehicles per 100 employees) as the dependent variable. The VT rate for each worksite was calculated from the following equation:

$$
\begin{gathered}
\text { VT rate }=100 \times(\text { CAR } 1+\text { MOTORCYCLE + CAR } 2 / 2+\mathrm{CAR} 3 / 3+\mathrm{CAR} 4 / 4+ \\
\text { CAR5/5 + CAR6/6 + VAN_CUTR/7 }) / \\
(\mathrm{CAR} 1+\mathrm{MOTORCYCLE} \mathrm{+} \mathrm{CAR2} \mathrm{+} \mathrm{CAR3} \mathrm{+} \mathrm{CAR4} \mathrm{+} \mathrm{CAR5} \mathrm{+} \mathrm{CAR6} \mathrm{+} \\
\text { VAN_CUTR + BUS + TRANSIT + WALK + BIKE + TELECOMMUTE + } \\
\text { CWW336 + CWW440 + CWW980 })
\end{gathered}
$$

where:

$\begin{array}{ll}\text { CAR1 }= & \text { Number of employees driving alone } \\ \text { MOTORCYCLE }= & \text { Number of employees commuting by motorcycle } \\ \text { CAR2 }= & \text { Number of employees commuting two together } \\ \text { CAR3 }= & \text { Number of employees commuting three together } \\ \text { CAR4 }= & \text { Number of employees commuting four together } \\ \text { CAR5 }= & \text { Number of employees commuting five together } \\ \text { CAR6 }= & \text { Number of employees commuting six together } \\ \text { VAN_CUTR }= & \text { Number of employees commuting in van } \\ \text { BUS }= & \text { Number of employees commuting by bus } \\ \text { TRANSIT }= & \text { Number of employees commuting using transit } \\ \text { WALK }= & \text { Number of employees commuting walking } \\ \text { BIKE }= & \text { Number of employees commuting by bike } \\ \text { TELECOMMUTE }= & \text { Number of employees telecommuting } \\ \text { CWW336 }= & \text { Number of 3/36 days off } \\ \text { CWW440 }= & \text { Number of } 4 / 40 \text { days off } \\ \text { CWW980 }= & \text { Number of } 9 / 80 \text { days off }\end{array}$


The change in VT rate for each worksite is calculated as the difference between the rate of the analyzed and the subsequent program year. For example, worksite "A" in 1999 had a VT rate of 90 and in 2000 had a VT rate of 85; the difference in VT rate $(85-90)$ of -5 was associated with the 1999 record for that worksite.

The travel impacts of TDM strategies are evaluated directly for different strategy combinations. The TDM strategies are first categorized into groups. Table 4 lists part of those variable groups. Based on those variables (Groups), various combinations are constructed to represent different TDM programs each worksite may implement. The neural network model is then applied to estimate (predict) the change in VT rate for each of those combinations. There are 1,671 distinct strategy combinations in total, and out of these, 50 combinations are implemented by at least 75 records.

Table 4: Combined Data Variable and Grouping

\begin{tabular}{|c|c|c|}
\hline Variables & Description & Grouping \\
\hline FACILITY_AMENITIES & Facilities and amenities & $\begin{array}{l}\text { - Passenger Loading Areas } \\
\text { - Other Facility Improvements } \\
\text { - Preferential Parking Areas } \\
\text { - Bike Racks and Bike Lockers } \\
\text { - Shower and Lockers }\end{array}$ \\
\hline GRH & $\begin{array}{l}\text { Guaranteed ride home } \\
\text { programs }\end{array}$ & $\begin{array}{l}\text { - TMA/TMO Provided Guaranteed Return Trip } \\
\text { - Company Vehicle Guaranteed Return Trip } \\
\text { - Emergencies Guaranteed Return Trip } \\
\text { - Other Guaranteed Return Trip Program } \\
\text { - Rental Car Guaranteed Return Trip } \\
\text { - Taxi Guaranteed Return Trip } \\
\text { - Unscheduled Overtime Guaranteed Return }\end{array}$ \\
\hline FLEX & Flexible timing & $\begin{array}{l}\text { - Flextime for Ridesharers (Work Shifts) } \\
\text { - Flextime for Ridesharers (Grace Period) }\end{array}$ \\
\hline ONSITE & Onsite incentives & $\begin{array}{l}\text { - On-Site Childcare Service } \\
\text { - Other On-Site Services } \\
\text { - Cafeteria, ATM's, Postal, Fitness Center } \\
\text { - Transit Information or Pass Sales }\end{array}$ \\
\hline FINANCIAL & Financial incentives & $\begin{array}{l}\text { - Transportation Allowances } \\
\text { - On-Going Bike-to-Work Subsidies } \\
\text { - On-Going Carpooling Subsidies } \\
\text { - Other Direct Financial Subsidies } \\
\text { - On-Going Walk-to-Work Subsidies }\end{array}$ \\
\hline
\end{tabular}

CUTR's WTRM is the only model of those reviewed that can predict increases in vehicle trips (i.e., sometimes factors resulted in more trips). It also was built and validated using actual worksite data. WTRM does not estimate travel delay or evaluate impacts on roadways. 


\subsection{Review of Analysis Tools}

TTI's 2003 Annual Urban Mobility Report estimated that the total (morning and evening) annual delay reduction in 2003 for changes in commute choices at CTR sites to be 1.84 million hours and values the savings at $\$ 24$ million each year. The methodology for estimation for delay and speed for various congestion mitigation strategies is based on a macroscopic approach as shown in Figure 2 (18). The speed and delay estimates are based on number of lanes and Average Daily Traffic (ADT). Travel delay is estimated from vehicle traffic per lane and traffic speed equations.

The TTI's macroscopic approach to estimate benefits of TDM impacts is useful for estimating a region-wide impact of TDM programs. However, microscopic simulation analysis (using CORSIM or other tools) can provide much deeper understanding of the impact of TDM programs on a corridor level. Macroscopic approach can provide average and total delay reduction in a region while the microscopic level approach on a corridor can show how delay reduction varies along a corridor and how it varies with the peak period. It can also show locations that were impacted more by these programs as well as the ones that were not at all impacted. Microscopic level analysis also considers interaction of a traffic flow (and not volume) with roadway capacity and vehicle interactions. These interactions are not considered in a macroscopic level analysis.

TTI's methodology provides a good estimate for a region-
wide reduction in delay and other saving. Further,
microscopic level of analysis is not feasible for region-wide
impact, as it requires large data collection efforts to input
various parameters required to conduct the analysis.
However, microscopic level study can be conducted on a few selected
corridors that form the backbone of the transportation network in the
region as it provides more detailed reports on when and where delays
were reduced. TTI's approach also estimates non-recurring delay
(delay incurred due to incidents or other non-recurring events) reduced
by the CTR program. This study will focus only on recurring delay
reductions due to CTR programs.




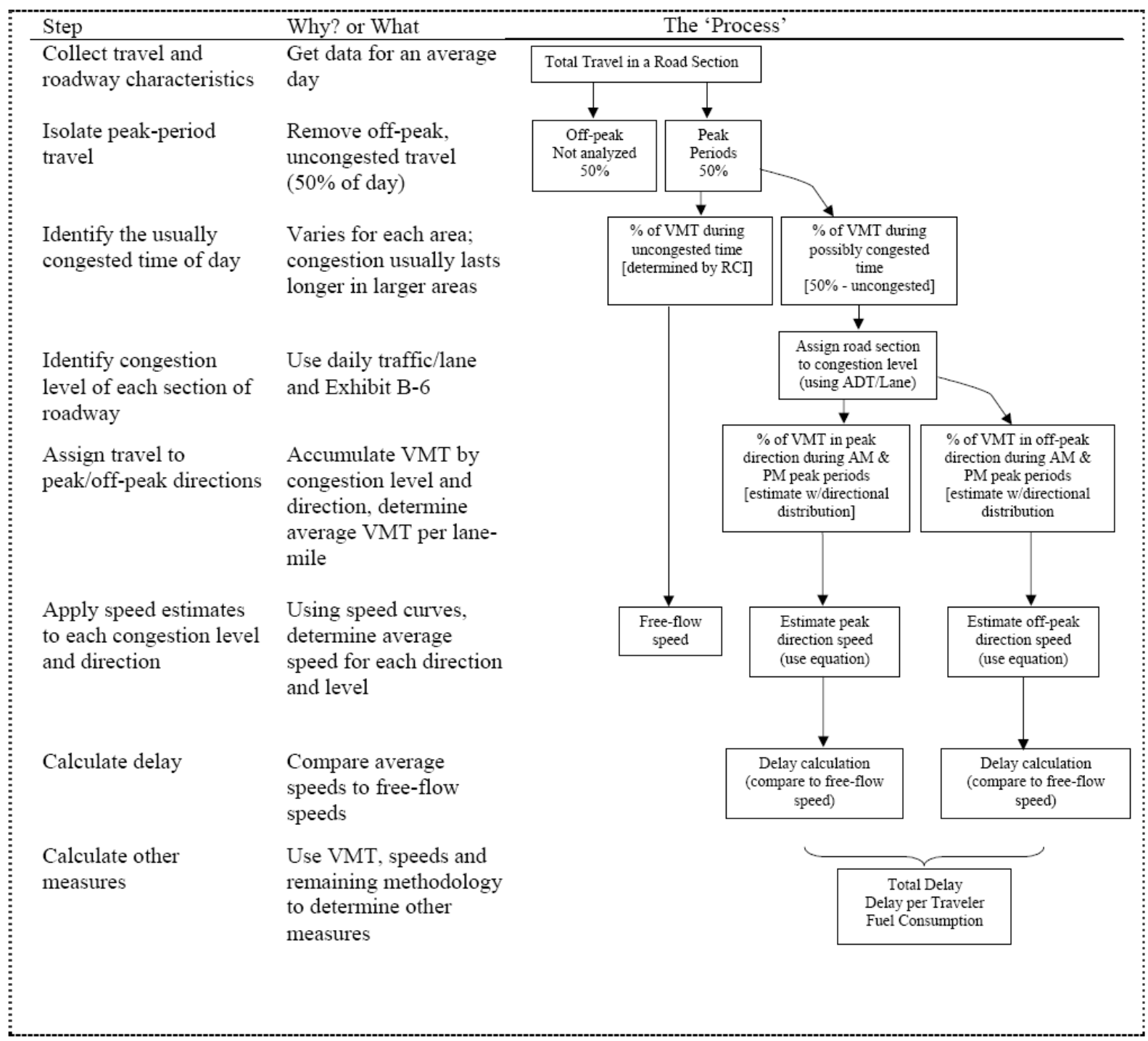

"2003 Annual Urban Mobility Report - Appendix B: Methodology,"

Texas Transportation Institute, p. 6

\section{Figure 2: Overview of TTI Methodology for Speed and Delay Estimation}

A literature review was conducted to select the appropriate tool for evaluating the impact of TDM programs and establishing performance measures. The FHWA Traffic Analysis Toolbox Volume I: Traffic Analysis Tools Primer, was developed by Cambridge Systematics, Inc., to assist traffic engineers, planners, and traffic operations professionals in the selection of the appropriate type of analysis tool for operational improvements (19). The Traffic Analysis Tools Primer categorizes these tools based on the objective, capability, and limitation as follows:

1. Sketch-planning tools evaluate specific projects or alternatives without conducting an in depth engineering analysis. Such techniques are primarily used to prepare preliminary budgets and proposals, and are not considered to be a substitute for detailed engineering analysis required for project design and implementation processes. 
2. Travel demand models are mathematical models that forecast future travel demand based on current traffic conditions and projections of socio-economic and demographics.

3. Analytical/deterministic tools (Highway Capacity Model-based) predict capacity, density, speed, delay, and queuing on transportation facilities and are validated with field data, laboratory test beds, or small-scale experiments.

4. Traffic signal optimization tools are primarily designed to develop optimal signalphasing and timing plans for isolated signal intersections, arterial streets, or signal networks.

5. Macroscopic simulation models simulate a section-by-section tracking rather than by individual vehicles. These models do not have the ability to analyze improvements in as much detail as the microscopic models.

6. Microscopic models simulate the movement of individual vehicles based on carfollowing and lane-changing theories. Typically, vehicles enter a transportation network using a statistical distribution of arrivals (a stochastic process) and are tracked through the network over small intervals (e.g., 1 second or a fraction of a second). Upon entry, each vehicle is assigned a destination, a vehicle type, and a driver type. Computer time and storage requirements for microscopic models are large, usually limiting the network size and the number of simulation runs that can be completed.

7. Mesoscopic simulation models combine the properties of both microscopic and macroscopic models. The mesoscopic models' unit of traffic flow is the individual vehicle providing less fidelity than the microsimulation tools, but is superior to the typical planning analysis techniques.

As each of these tools has its capabilities and limitations, a decision making tool is required to select an appropriate tool for a specific study. The FHWA Analysis Toolbox Volume II: Decision Support Methodology for Selecting Traffic Analysis Tools developed by Cambridge Systematics, Inc., has criterion for selecting analysis tools including (20):

1. Identification of the analytical context for the task - planning, design, or operations/construction

2. Ability to analyze the appropriate geographic scope or study area for the analysis, including isolated intersection, single roadway, corridor, or network.

3. Capability of modeling various facility types, such as freeways, high-occupancy vehicle (HOV) lanes, ramps, arterials, toll plazas, etc.

4. Ability to analyze various travel modes, such as single-occupancy vehicle (SOV), HOV, bus, train, truck, bicycle, and pedestrian traffic.

5. Ability to analyze various traffic management strategies and applications, such as ramp metering, signal coordination, incident management, etc.

6. Capability of estimating traveler responses to traffic management strategies, including route diversion, departure time choice, mode shift, destination choice, and induced/foregone demand.

7. Ability to directly produce and output performance measures, such as safety measures (crashes, fatalities), efficiency (throughput, volumes, vehicle-miles of travel (VMT)), mobility (travel time, speed, vehicle-hours of travel (VHT)), productivity (cost savings), and environmental measures (emissions, fuel consumption, noise). 
8. Tool/cost-effectiveness for the task, mainly from a management or operational perspective. Parameters that influence cost-effectiveness include tool capital cost, level of effort required, ease of use, hardware requirements, data requirements, animation, etc.

The decision-making toolbox provides a worksheet with predefined weights for each of the above criterion. This worksheet was used to determine the type of tool that can be used for evaluating the operational impacts of TDM programs on the selected transportation corridor.

Table 5 shows the weighted totals of the score for each type of analysis tool based on the criterion requirements for this study. The microscopic simulation tool had the maximum weighted total and was therefore selected for the corridor analysis in this study.

Table 5: Weighted Totals of Scores from the Decision Toolbox

\begin{tabular}{|c|c|c|c|c|c|c|c|}
\hline Criteria/Tool & $\begin{array}{c}\text { Sketch } \\
\text { Plan }\end{array}$ & TDM & Analytical & $\begin{array}{c}\text { Traffic } \\
\text { Opt }\end{array}$ & $\begin{array}{c}\text { Macro } \\
\text { Sim }\end{array}$ & $\begin{array}{c}\text { Micro } \\
\text { Sim }\end{array}$ & $\begin{array}{c}\text { Meso } \\
\text { Sim }\end{array}$ \\
\hline Analysis Context & 125 & 0 & 250 & 250 & 250 & 250 & 250 \\
\hline Geographic Scope & -643 & 33 & -297 & -280 & 83 & 83 & 67 \\
\hline Facility Type & 50 & 100 & 100 & 75 & 100 & 100 & 100 \\
\hline Travel Mode & 0 & 0 & 0 & 0 & 0 & 0 & 0 \\
\hline Management Strategy & 0 & 0 & 0 & 0 & 0 & 0 & 0 \\
\hline Traveler Response & 0 & 0 & 0 & 0 & 0 & 0 & 0 \\
\hline Performance Measures & 131 & 122 & 163 & 163 & 184 & 200 & 200 \\
\hline Tool/Cost Effectiveness & 75 & 75 & 94 & 94 & 113 & 131 & 113 \\
\hline Weighted Total & $\mathbf{- 2 6 2}$ & $\mathbf{3 3 0}$ & $\mathbf{3 1 0}$ & $\mathbf{3 0 1}$ & $\mathbf{7 3 0}$ & $\mathbf{7 6 5}$ & $\mathbf{7 2 9}$ \\
\hline
\end{tabular}

A complete feasibility analysis was conducted and reported in Technical Memorandum \#1 of this project. The decision to use the microsimulation tool CORSIM for this study was supported by the following factors:

- The decision toolbox exercise in Table 5 resulted in recommending the use of microscopic simulation software for this study.

- WSDOT has been using CORSIM software for evaluations on I-5 in the Seattle downtown area.

- $\quad$ The research team at CUTR had training and expertise using CORSIM.

- CORSIM is supported by FHWA and has been utilized for the past 30 years by several state agencies including WSDOT. 


\subsubsection{Input to CORSIM Model}

The validity of a simulation model relies greatly on the input to the algorithm. CORSIM requires accurate descriptions of the characteristics of the vehicles, the transportation network, and the traffic control system. These characteristics vary over the physical length of the network and over time. The geometric characteristics of the roadway may vary over the length of the network and at the same time, the volume entering the network and signaltiming plans can vary over time. To simulate this variability the network is divided into links to code different geometric changes and simulation duration is divided into different time periods to code the variability in traffic volume and other temporal changes.

\subsubsection{Output of CORSIM Model}

The CORSIM model does time step simulation of the transportation network. It records all the performance measures on a second by second basis for each vehicle in the transportation network. These performance measures can be delay per vehicle, fuel consumption, emissions, that are recorded in an output file. The output file also contains links and network-wide statistics. CORSIM also provides a graphical interface to view the coded network (Figure 3) which allows researchers, practitioners and decision-makers to visually inspect the traffic conditions throughout the duration of the simulation. In addition to the output from the algorithm such as delay per vehicle, the graphical interface can be used to visually compare the before-after scenarios for any improvement (example, signal retiming) to the transportation network.

The employee survey provides information on individual employee work schedule, mode of travel, job type, and employee's home zip code. The employee survey for the year 2003 provides the information to estimate the number of trips reduced by TDM programs (survey response), when these trips were made and the origin-destination of these trips. The reduced vehicle trips will be calculated from the existing mode share (With TDM) and the estimated mode share Without TDM. 


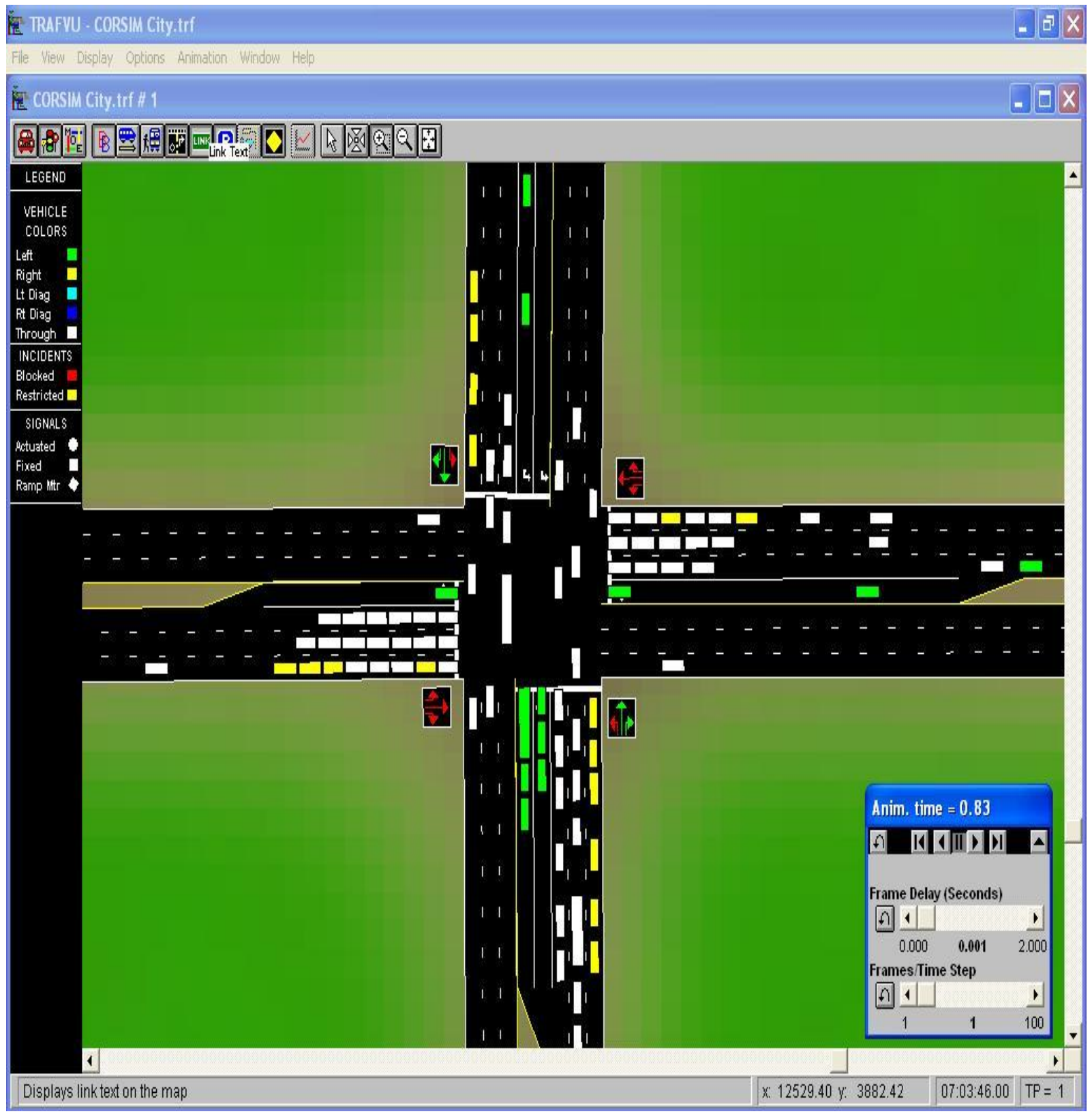

Figure 3: A Sample of Graphical Interface Provided by CORSIM 


\section{Chapter 3 - Groundwork for Microsimulation Analysis}

\subsection{Selection of Impact Area}

The impacts of TDM programs on the transportation corridor were evaluated by comparing the performance of a corridor With TDM and Without TDM. The study corridor was selected in the vicinity of a high concentration of CTR-participating employers where quality data are regularly collected. The Washington State CTR program database for the year 2003 was studied to establish the geographical concentration of participating employers. The database provided the list of cities and ZIP codes with high numbers of employers/employees participating in TDM programs. The WSDOT long-range plans were studied to determine where DOT has identified problem areas and planned future improvements. Based on these factors, I-5 in downtown Seattle was selected as the transportation corridor for this study. Figure 4 shows the extent of improvements planned for I-5 in the region.

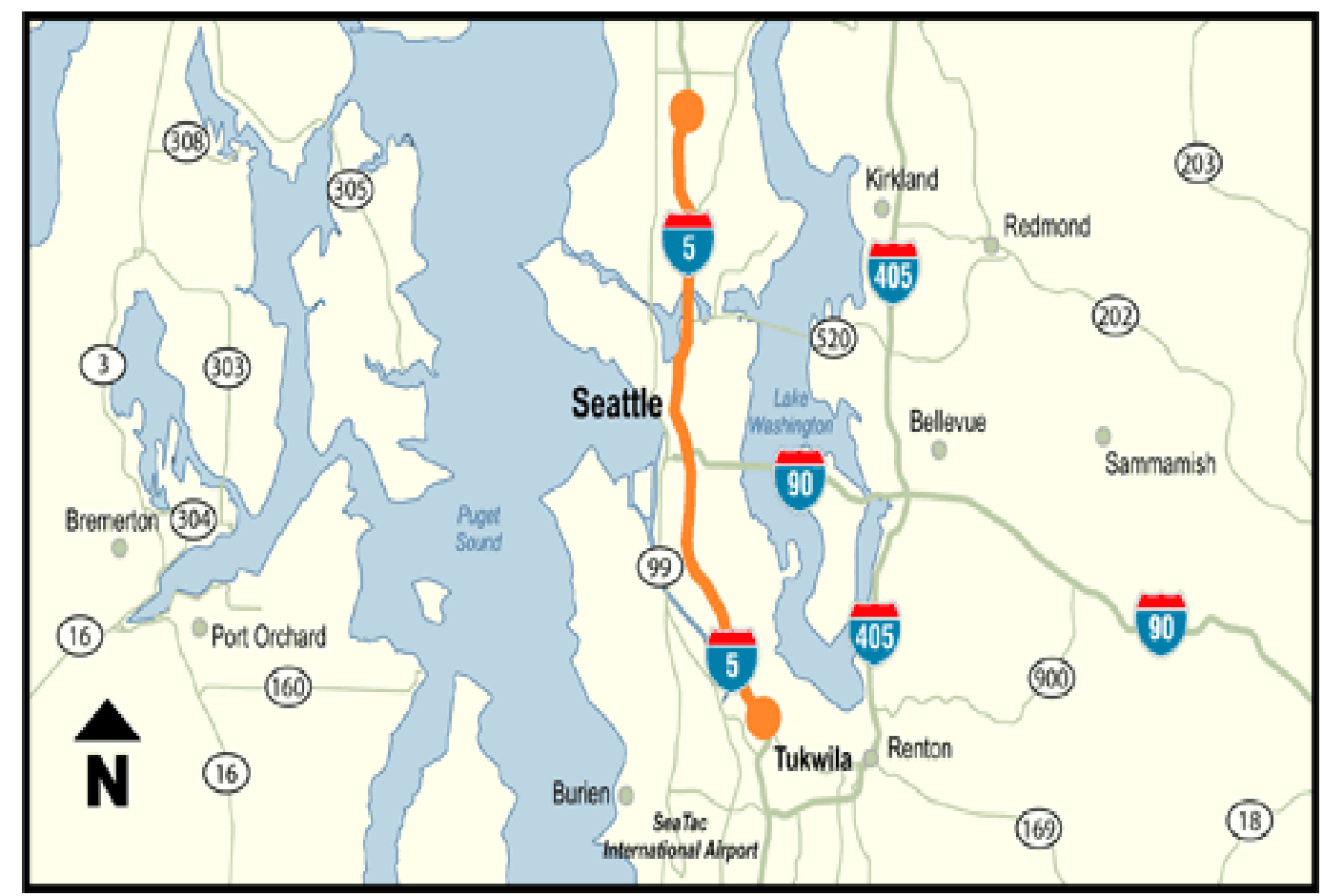

Figure 4: Pavement Reconstruction and Bottleneck Improvement Project for the I-5 Corridor

Source: WSDOT website

Figure 5 shows worksite locations on and around the I-5 study area. The area consists of 8.6 miles of I-5 from NE $45^{\text {th }}$ Street in the north to Corson Avenue in the south. The 67 lanemiles of interstate consist of 16 on-ramps and 19 off-ramps. Other major roadways in the area were I-90, SR 520, and SR 99. The I-5 reversible express lanes were not considered in the analysis as they provided limited entrance to and egress from the study area or provided access to HOV lanes only. The total volumes of the three-hour-AM-peak between 6:00 AM and 9:00 AM were 22,500 and 19,900 vehicles for the Northbound and Southbound I-5 
respectively for the year 2004. The three-hour-PM-peak volumes between 3:00 PM and 6:00 PM were 19,800 and 20,600 vehicles for Northbound and Southbound I-5 respectively. The study area had 189 employers participating in CTR programs, affecting 62,947 employees.

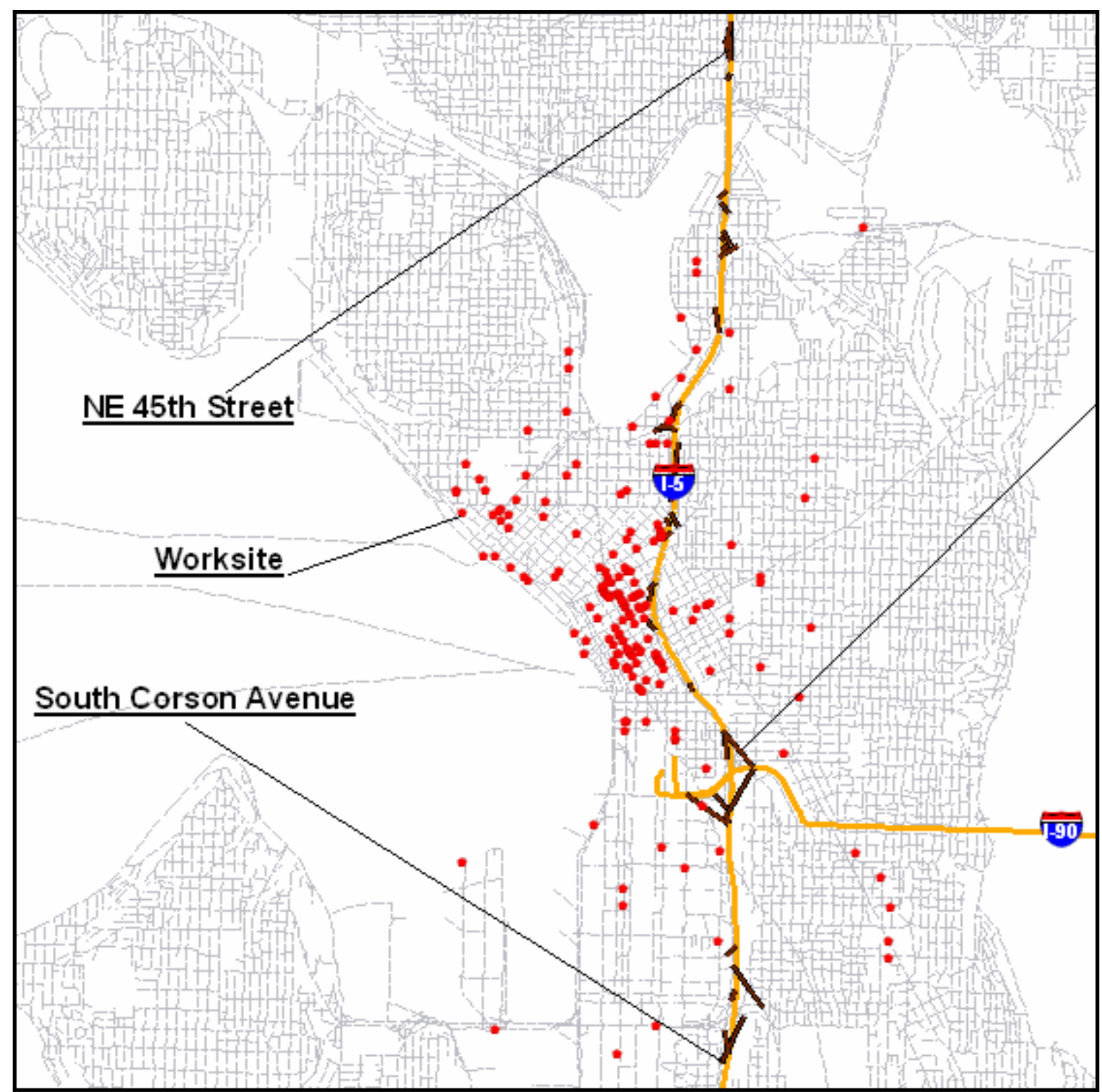

Figure 5: Worksites in Study Area of I-5

\subsection{Data Collection}

\subsubsection{CTR program database}

The CTR program is an employer-based regional TDM effort initiated in Washington in 1991. The CTR law requires employers to implement programs that encourage alternatives to drive-alone commuting to their worksites. The CTR law applies to all employers with 100 or more full-time employees arriving at work between 6:00 and 9:00 AM located in a county with a population greater than 150,000 . As a result of the law, by 2005, more than 1,110 employers had developed programs affecting over 560,000 employees in nine counties. The 
law requires that CTR employers submit an employer annual report and a program description form to report on TDM programs implemented. CTR employers are also required to survey employee commute behavior every two years to measure progress toward their CTR goals. The employer annual report and employee biennial survey compose two databases that provide detailed data on the employers' TDM performance and employees' travel behavior. The data are detailed, comprehensive and certified as correct for each employer. There were no identifiers linking employee records between surveys. The data was the basis for another project, the National Smart Transportation Archive Researcher (NSTAR), an online searchable TDM case studies database. WSDOT provided the electronic files of the database and the survey hard copies. However, the NSTAR research team found discrepancies in the database and worked to reconcile inconsistencies between survey hard copies, electronic files, and survey instrument changes across years for comparability purposes. The problems arose from database input errors, electronic file corruption, and difficulties of data interpretation. The NSTAR project team re-entered Washington State CTR employer plan data from survey hard copies for years that indicated data inconsistencies (21).

The annual employer report includes:

- Worksite and employer information including the organization name, worksite address, the Employer Transportation Coordinator's (ETC) information, total number of employees, total number of affected employees, etc.

- $\quad$ Program promotion information including a list of TDM programs implemented or promoted by the employer

- Worksite characteristics including information on the accessibility of the worksite to facilities such as bus stops, shops, and child care facilities, etc.

- Worksite parking information and/or parking management

- Financial incentive and subsidies

- $\quad$ Site amenities

- Work schedule policy

- Other TDM programs availability such as guaranteed ride home (GRH), internal ridematching, fleet vehicles, etc.

The individual employee survey includes:

- Work schedule

- Commute trip mode split

- Compressed work week schedule

- Teleworking schedule

- Commute travel distance

- Employee job title and home zip code

\subsubsection{CTR Data Summary}

The estimation of VTR due to TDM at worksites was performed based on 2003 Washington State CTR employer annual report and employee biennial travel behavior survey data. The 
selected study area for this project is the downtown area in Seattle between NE 45th Street and South Corson Avenue around I-5. The total number of valid worksites located within the study area is 189 , which includes 62,947 affected employees. A transportation network was created based on the 2000 Census Tiger/Line road data for five counties, including Island, Snohomish, Kitsap, King, and Pierce. The location of the worksite is geocoded based on their street address. The location of the employee's home as geocoded is represented by the centroid of the ZIP code. The map of the study area and the distribution of the worksites are shown in Figure 6. Figure 7 is the distribution of employee's home and the transportation network of five counties. The study period (peak period) is defined as 6:00 AM - 9:00 AM. The total number employees beginning to work between 6:00 AM-9:00 AM is 56,251.

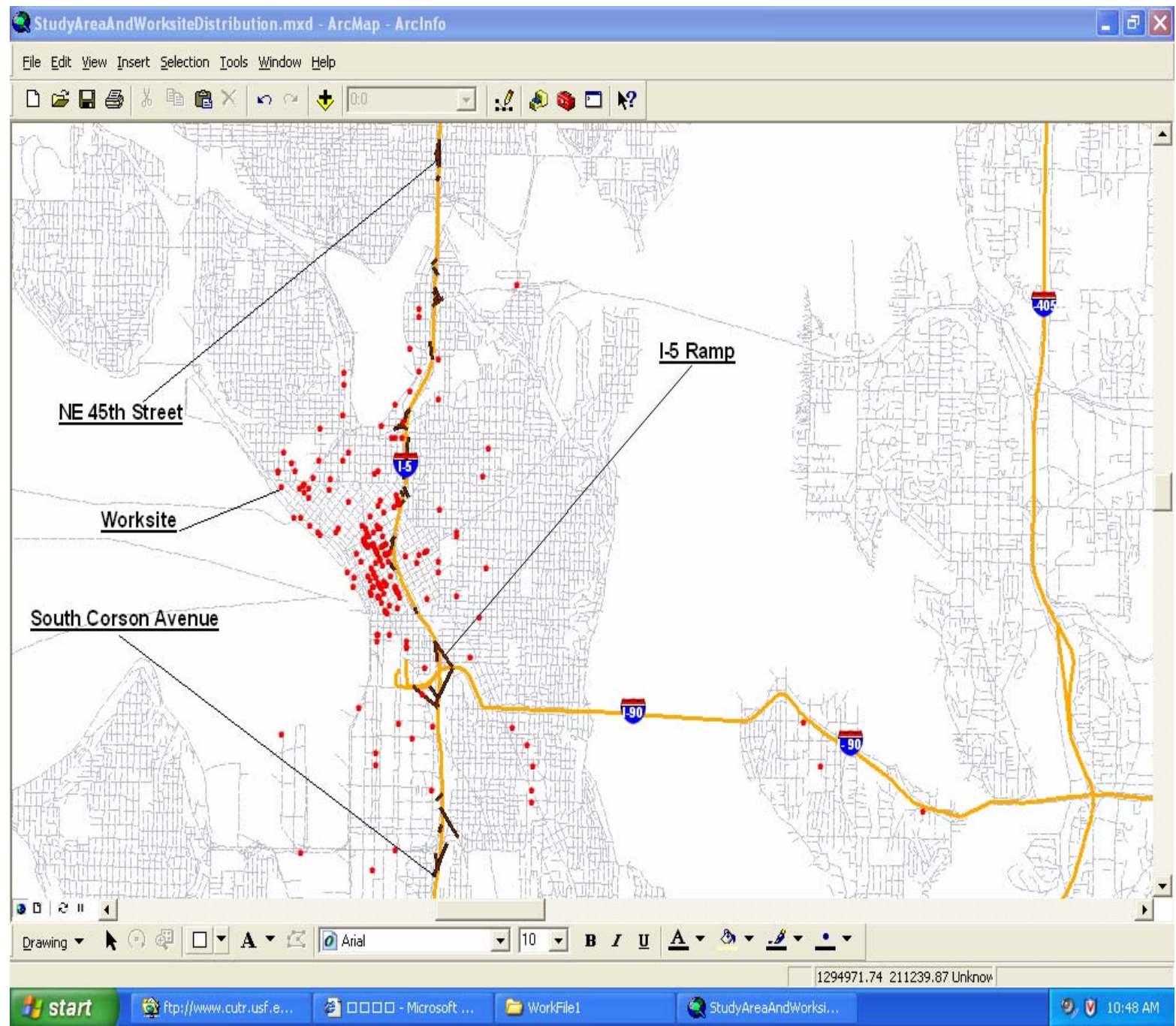

Figure 6: Study Area and Distribution of the Worksites 


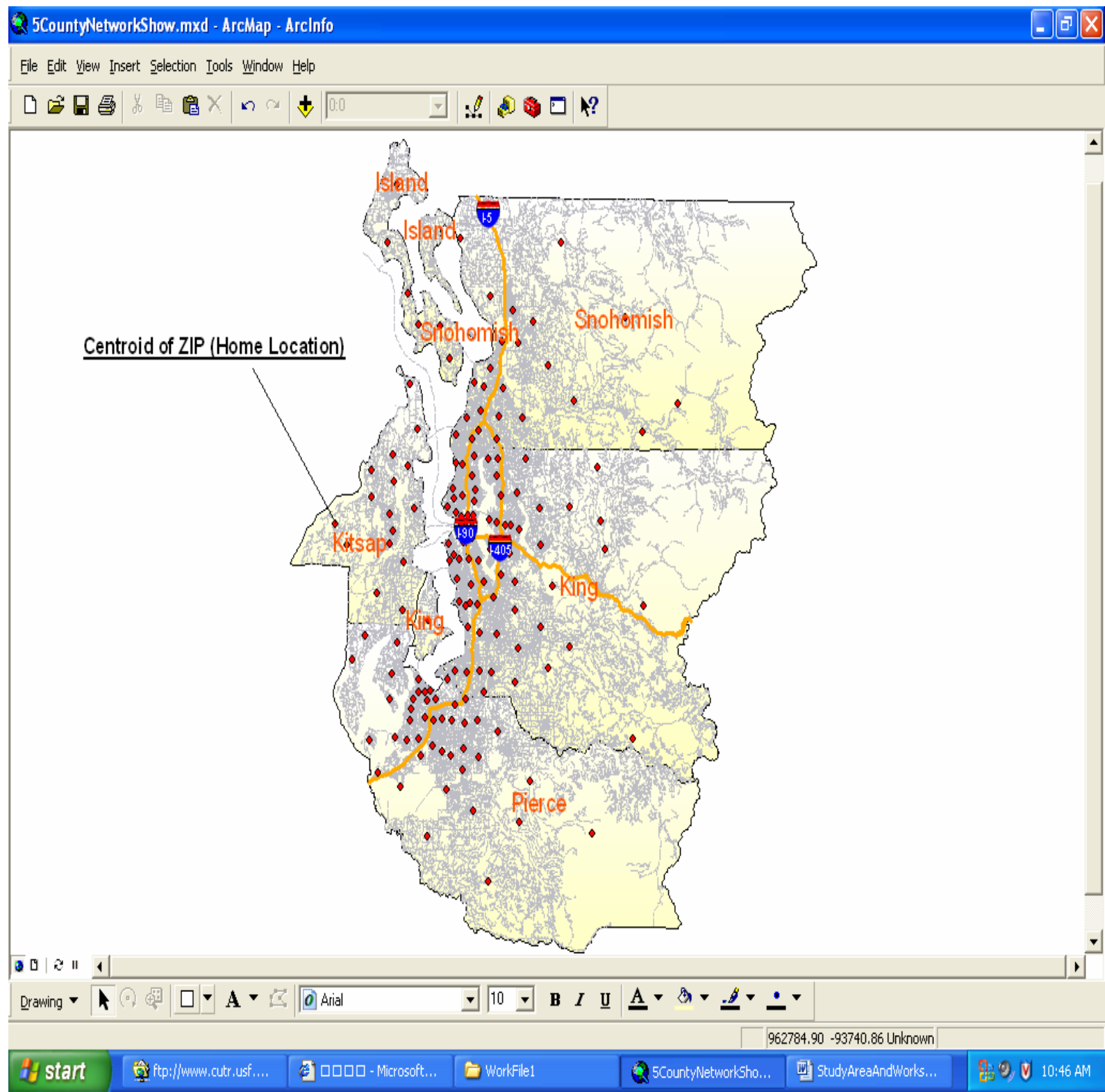

Figure 7: Transportation Network of Five Counties and the Distribution of the Employees' Homes

\subsubsection{CORSIM Network}

The CORSIM network model files for the AM and PM peak periods were obtained from the WSDOT with 2004 traffic volume data. The obtained network files were already calibrated to represent the traffic conditions that exist on the field. The traffic volumes were provided in 19 intervals of 15 minutes each from 5:30 AM to 10:15 AM for the AM peak and from 3:00 PM to 7:45 PM for the PM peak files. 


\subsection{Estimation of Vehicle Trips Reduced due to CTR Programs}

\subsubsection{VTR Estimation, Distribution, and Assignment - An Overview}

This section of the report summarizes the methodologies used to perform the worksite trip reduction estimation at the worksite level, how these trips were distributed on the study area network, and how the trips were assigned onto network links. To use CORSIM in evaluating the impacts of TDM, a course of action was developed to calculate changes in traffic flow due to the implementation of TDM program for each entry and exit ramp of the I-5 study area based on the Washington State CTR database.

1. A methodology was developed to estimate the volume of vehicle trips reduced (VTR) by TDM programs implemented at each worksite within the study area.

2. The percentage of non single-occupancy-vehicle (SOV) trips from each origin (Home) to all destinations (Worksites) was calculated based on the CTR employee survey data.

3. Each reduced trip at employer worksite was distributed between worksite and home traffic zones pairs based on the assumption that VTRs were derived from the non-SOV trips.

4. Based on the 2000 Tiger/Line road census data, a transportation network of five counties including King, Island, Snohomish, Kitsap, and Pierce was created to find the shortest path for each home-worksite pair and assign the reduced traffic onto network links based on the all-or-nothing traffic assignment approach.

The results included changes in traffic flow at each ramp and the ramp-ID for each reduced trip if using the I-5 portion of the study area.

\subsubsection{Introduction to Worksite Trip Reduction Estimation}

\section{Overview of TDM Models}

As previously mentioned, several TDM authoritative trip reduction models were reviewed to help address those questions; Air Resources Board (California) Cost-Effective Model, Washington State TEEM Model, EPA COMMUTER Model, and the CUTR WTRM.

Most of the above models are used to estimate future travel behavior changes resulting from the implementation of certain TDM programs. These models are not applicable to this research study since TDM has already been on going and supported by the 1991 CTR initiative. The traffic volume currently counted on I-5 reflects the impacts of the TDM strategies already in use by employees participating in CTR programs, (With TDM). In other words, if TDM were not practiced in this study area for a day, would there be a measurable difference in traffic flow on that portion of I-5? In order to estimate the quantitative impacts the TDM strategies have had on the corridor, the VTR due to the particular TDM programs practiced by the employees are to be calculated and added to the current volumes. Given the fact that the travel behavior of employees participating in the 
CTR program is observed and recorded, traffic conditions Without TDM can be re-created. Based on Washington State CTR database, the number of VTR at each worksite can be calculated. Added to the current traffic volume, the Without TDM traffic conditions can be analyzed.
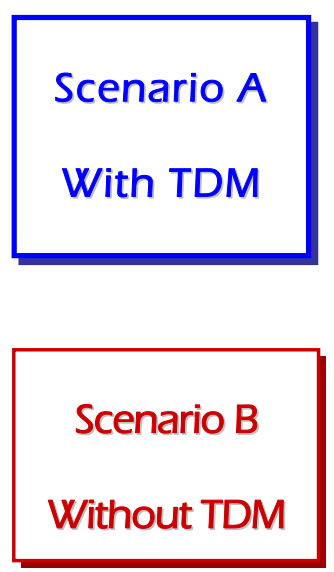

In Scenario A, employers offer options to their employees including telecommuting and/or compressed workweek (CWW). In addition, preferential spaces or subsidies for HOV parking may be offered. Additional financial subsidies or incentives may include fully or partially paid bus passes or the use of employer fleet vehicles to carpool or vanpool.

In Scenario B, the assumption was that TDM programs were not implemented by the employer. Since vehicle trips Without TDM cannot be measured directly, the research team introduced a new process based on the EPA's COMMUTER model utilizing the Washington State CTR data.

To estimate VTR at each worksite, the TDM program was first defined as four groups of strategies, including Alternative Work Schedules strategies, Employer TDM Support Strategies, Travel Cost Changes strategies, and Flexible Work Hours strategies. Then, it is assumed that there are two scenarios, With TDM and Without TDM, for each group of strategies.

For Alternative Work Schedules, it is assumed that Without TDM employees are not encouraged to telecommute or work on compressed workweeks. For Employer TDM Support Strategies, Without TDM for this group of strategies means all of the strategies are not implemented by employers. For Flexible Work Hours, Without TDM means employees are not encouraged to work on flexible work hours. For Travel Cost Changes, the definition of Without TDM is that is no financial subsidy for any modes are offered and parking for individual employee of all modes is free.

While the assumptions of Without TDM for the first three groups of TDM strategies are straightforward and consistent with the general understanding of TDM, the assumption for travel cost changes is arguable. The travel cost changes strategies include measures such as imposition of parking fees, differential rates, or discounts for carpool or vanpool parking, and financial incentives or subsidies to alternative modes. The differential rates or discounts for carpool or vanpool parking and the financial subsidies to alternative modes are inarguably considered direct results of TDM but there is disagreement on the imposition of parking fees as part of TDM strategies. The major concern is that, no matter With TDM or Without TDM, free parking does not widely exist, especially in Seattle in the downtown area. 
The assumption of free parking for individual employees only means employees do not have out-of-pocket costs for parking; it may or may not be free for employers. In other words, it assumes that the imposition of parking fees by the employer on individual employees has a direct impact on their commute mode choice. Employees park either on an employerprovided parking facility or at a facility that is not provided by the employer. The employer provided facility includes employer-leased parking space or employer-owned space. In both cases, if it is free for the employee, it is not for the employer. Free parking in the parking space that is not provided by the employer means the employee either receives a financial subsidy from the employer to cover the parking cost or enjoys free public parking space. Only the free public parking space is free for both the employee and employer, which is a rare case. According to the 2003 Washington State CTR employer annual report, 50.8 percent of employers charge for SOV parking, 31.2 percent charge for carpool parking, and 11.1 percent charge for vanpool parking.

If only differential rates or discounts for carpool or vanpool parking and financial incentives or subsidies to alternative modes were taken into account, based on the TDM reduced vehicle trip calculation procedure, the average percentage of reduced vehicle trip is 11.3 percent. Compared with the original 14.2 percent, it suggests the impact of the imposition of parking fees is about 3 percent.

Since the CTR employee biennial survey is conducted after the CTR program is implemented, it is assumed for this study that individual employee commute travel behavior information in the survey is of the With TDM scenario. However, since the implementation of TDM programs vary across the employers, the definition of With TDM is not consistent. In other words, the scenario of With TDM for one employer may differ from another. It is therefore possible to define the scenario of With TDM assuming all target employers implement the same level of TDM program. The shortcoming of this assumption would be the unavailability of the corresponding employee commute travel behavior data. The reality is that employers comply with the same CTR law in various degrees.

While TDM is a broad application of different strategies aimed at reducing and/or eliminating SOVs, for the purposes of this research, these strategies are combined into four different groups and only the impact of these groups will be evaluated (Table 6). 
Table 6: Combined Groups of TDM Strategies for Scenarios A and B

\begin{tabular}{|c|c|c|c|c|}
\hline Group & Strategies & Purposes & $\begin{array}{l}\text { Scenario A } \\
\text { With TDM }\end{array}$ & $\begin{array}{c}\text { Scenario B } \\
\text { Without TDM }\end{array}$ \\
\hline A & $\begin{array}{l}\text { Alternative } \\
\text { Work } \\
\text { Schedules }\end{array}$ & CWW and telecommuting. & $\begin{array}{l}\text { This group of strategies } \\
\text { functions to reduce } \\
\text { person trips. }\end{array}$ & $\begin{array}{l}\text { Employees are not } \\
\text { allowed to } \\
\text { telecommute or } \\
\text { participate in CWW. }\end{array}$ \\
\hline B & $\begin{array}{l}\text { Employer } \\
\text { TDM } \\
\text { Support } \\
\text { Strategies }\end{array}$ & $\begin{array}{l}\text { Non-monetary promotions to } \\
\text { encourage the use of alternative } \\
\text { modes. These include rideshare } \\
\text { matching services, vanpool } \\
\text { formation assistance, on-site transit } \\
\text { information and/or pass sales, ETCs, } \\
\text { and guaranteed ride home. }\end{array}$ & $\begin{array}{l}\text { This group of strategies } \\
\text { functions to reduce the } \\
\text { driving alone trips by } \\
\text { encouraging } \\
\text { employees to take } \\
\text { alternative modes. }\end{array}$ & $\begin{array}{l}\text { Employers do not } \\
\text { assist in any way to } \\
\text { encourage modes } \\
\text { other than SOV }\end{array}$ \\
\hline $\mathrm{C}$ & $\begin{array}{l}\text { Travel Cost } \\
\text { Changes }\end{array}$ & $\begin{array}{l}\text { Measures such as imposition of } \\
\text { parking fees, differential rates or } \\
\text { discounts for carpool or vanpool } \\
\text { parking, transit fare subsidies }\end{array}$ & $\begin{array}{l}\text { This group of strategies } \\
\text { functions to reduce } \\
\text { SOVs by increasing } \\
\text { SOV costs or } \\
\text { decreasing that of } \\
\text { alternative modes. }\end{array}$ & $\begin{array}{l}\text { There is no financial } \\
\text { subsidy for any } \\
\text { alternative mode and } \\
\text { SOV or other mode } \\
\text { parking is free. }\end{array}$ \\
\hline $\mathrm{D}$ & $\begin{array}{l}\text { Flexible } \\
\text { Work Hours }\end{array}$ & $\begin{array}{l}\text { A relaxation in the official daily } \\
\text { hours of business allows employees } \\
\text { the flexibility to adjust their personal } \\
\text { work schedules to either come } \\
\text { early/leave early, or come late/leave } \\
\text { late in order to avoid the most } \\
\text { congested portion of daily commute } \\
\text { periods. }\end{array}$ & $\begin{array}{l}\text { This group functions to } \\
\text { shift vehicle trips out of } \\
\text { peak period. }\end{array}$ & $\begin{array}{l}\text { Employees are not } \\
\text { allowed to work on } \\
\text { flexible work hour } \\
\text { schedules. }\end{array}$ \\
\hline
\end{tabular}

\subsubsection{Process for the Calculation of VTR due to TDM}

The process of estimating VTR was developed based on the COMMUTER model. The impact of each group of strategies is evaluated separately using different methods:

A) The impact of alternative work hours is evaluated by adding participants of telecommuting and CWW back to SOVs, then calculating the revised person trips.

B) The employer TDM support programs are analyzed using relational factors in lookup tables, along with a normalization procedure applied to the adjusted shares to ensure that changes are proportionate across the available alternatives and final choices do not exceed 100 percent.

C) The travel cost changes strategies are analyzed through the more rigorous logit pivotpoint procedure.

D) The impact of flexible work hours is evaluated by estimating the number of vehicle trips shifted out of the peak period due to the program. 
The total impact of TDM for each worksite is the cumulative results of the above groups of strategies. The VTR as a result of CTR is estimated for each worksite within the study area by calculating the following:

$\begin{array}{ll}\text { STEP 1) } & \text { The number of vehicle trips and mode share With TDM } \\ \text { STEP 2) } & \text { The impact of telecommuting and CWW } \\ \text { STEP 3) } & \text { The impact of employer TDM support strategies } \\ \text { STEP 4) } & \text { The impact of travel cost changes } \\ \text { STEP 5) } & \text { The number of trips shifted out of the peak period due to the } \\ & \text { flexible work hours } \\ \text { STEP 6) } & \text { The revised vehicle trips Without TDM } \\ \text { STEP 7) } & \text { VTR due to TDM }\end{array}$

An Example will be used throughout these steps to illustrate the process of calculation. The Example is a record in the Case Study Database in the NCTR HelpDesk found at http://www.nctr.usf.edu/helpdesk/casestudies.htm. The case study is that of the U.S. Social Security Administration in Seattle, Washington. The detailed record of this case study as extracted from the CTR database is included in Appendix A.

\section{STEP 1) Number of vehicle trips and mode share with TDM}

These are calculated for each worksite within the study area based on 2003 Washington State CTR employee travel behavior survey data. The non-respondents are counted as SOVs based on the assumption that they are less likely affected by employer-based TDM programs. The response rate for people working between 6:00 AM - 9:00 AM and that of the employee population is assumed identical for each worksite. The procedure of calculation is as follows:

1. Calculate the total response rate for each worksite

2. Divide the total number of reported trips between 6:00 AM - 9:00 AM by the response rate to get the total number of employees working between 6:00 AM - 9:00 AM.

3. Treat all non-respondents as SOV, then calculate the original mode share, vehicle trip, and the percentage of employees that carpool by the occupancy in vehicle using following formulas:

$$
\begin{aligned}
& \text { VehicleTrip } \text { WithTDM }_{\text {ind }}=\text { Non-respondents }+\mathrm{SOV}+\text { Motorcycle }+ \\
& \mathrm{Carpool}_{2} / 2+\mathrm{Carpool}_{3} / 3+\mathrm{Carpool}_{4} / 4+\mathrm{Carpool}_{5} / 5+\mathrm{Vanpool} 6 \\
& \text { PCarpool }_{\mathrm{N}}=\mathrm{Carpool}_{\mathrm{N}} /\left(\mathrm{Carpool}_{2}+\mathrm{Carpool}_{3}+\mathrm{Carpool}_{4}+\mathrm{Carpool}_{5}\right)
\end{aligned}
$$




\section{Example}

\begin{tabular}{|c|c|c|c|c|c|c|c|c|c|c|c|c|}
\hline Total & $\begin{array}{c}\text { Drive } \\
\text { Alone }\end{array}$ & Carpool & Vanpool & Motorcycle & Transit & Bicycle & Walk & Tele & CWW & $\begin{array}{c}\text { Business } \\
\text { Trip }\end{array}$ & $\begin{array}{c}\text { Do } \\
\text { not } \\
\text { work }\end{array}$ & Other \\
\hline 152 & 24 & 29 & 2 & 0 & 80 & 0 & 2 & 2 & 0 & 0 & 5 & 8 \\
\hline
\end{tabular}

\begin{tabular}{|c|c|c|c|c|}
\hline \multicolumn{1}{c}{} & \multicolumn{2}{c}{ Total affected employees starting to work between 6 AM-9 AM } \\
\hline $\begin{array}{c}\text { Total Affected } \\
\text { Employees }\end{array}$ & $\begin{array}{c}\text { Total } \\
\text { Responds }\end{array}$ & $\begin{array}{c}\text { Total Responds } \\
\text { Between 6am-9am }\end{array}$ & $\begin{array}{c}\text { Total Response } \\
\text { Rate }\end{array}$ & $\begin{array}{c}\text { Total Affected Employees } \\
\text { between 6am-9am }\end{array}$ \\
\hline 211 & 146 & 152 & $\begin{array}{c}165 / 211 \\
=78.20 \%\end{array}$ & $\begin{array}{c}152 / 78.20 \% \\
=194\end{array}$ \\
\hline
\end{tabular}

Mode shares (Treat non-respondents as SOV)

\begin{tabular}{|c|c|c|c|c|c|c|c|c|c|}
\hline & Drive Alone & Carpool & Vanpool & Motorcycle & Transit & Bicycle & Walk & Total \\
\hline Number & 66 & 29 & 2 & 0 & 80 & 0 & 2 & 179 \\
\hline Percentage & $36.87 \%$ & $16.20 \%$ & $1.11 \%$ & 0 & $44.69 \%$ & 0 & $1.11 \%$ & $100 \%$ \\
\hline
\end{tabular}

\begin{tabular}{|c|c|c|c|c|c|c|c|}
\hline \multicolumn{8}{|c|}{ Carpool percentage by number of passenger } \\
\hline \multicolumn{4}{|c|}{ Number } & \multicolumn{4}{|c|}{ Percentage } \\
\hline Carpool $_{2}$ & Carpool $_{3}$ & Carpool $_{4}$ & $\mathrm{Car}_{5}$ & $\mathrm{Car}_{2}$ & $\mathrm{Car}_{3}$ & $\mathrm{Car}_{4}$ & $\mathrm{Car}_{5}$ \\
\hline 24 & 4 & 1 & 0 & $81.58 \%$ & $15.79 \%$ & $2.56 \%$ & 0 \\
\hline
\end{tabular}

$$
\begin{aligned}
& \text { VehicleTrip WithTDM }=(194-152)+24+0+24 / 2+4 / 3+1 / 4+0 / 5+2 / 6 \\
& =80 \text { vehicle trips }
\end{aligned}
$$

STEP 2) The impact of telecommuting and $C W W$

The telecommuting and CWW impacts are assumed to be the direct results of employerbased TDM programs. Participants of these programs are added back to calculate the revised person trips:

$$
\begin{aligned}
& \text { Revised Person Trips }=\text { Non-respondents }+ \text { SOV }+ \text { Motorcycle }+ \\
& \mathrm{Carpool}_{2}+\mathrm{Carpool}_{3}+\mathrm{Carpool}_{4}+\mathrm{Carpool}_{5}+ \\
& \text { Transit }+ \text { Bicycle }+ \text { Walk }+ \\
& \text { Vanpool + CWW + Telecommuter } \\
& =181 \text { Person Trips }
\end{aligned}
$$

\section{Example}


The impact of employer TDM support strategies is estimated based on the COMMUTER model as follows:

1. Determine the level of implementation of employer support strategies based on Table 7 and the information provided in CTR employer annual report on carpool, vanpool, transit, and bicycle.

2. Determine the type of employment. Those in construction, mining, manufacturing, and utility are defined as non-office workers; all others are office workers.

3. Calculate the impact of support strategies on each alternative mode for each employer, based on the coefficients reported in Table 8. Apply the normalization procedure to the adjusted shares to ensure that changes are proportionate across the available alternatives, not allowing final choices to exceed 100 percent.

Table 7: Composition of Modal Support Strategy Program

\begin{tabular}{|c|c|c|}
\hline Mode & Level & Strategies included in levels \\
\hline \multirow{4}{*}{ Carpool } & 1 & Carpool information activities (tied in with area wide matching), quarter-time transportation coordinator \\
\hline & 2 & All the above, PLUS in-house carpool matching service and/or personalized carpool candidate get-togethers \\
\hline & 3 & $\begin{array}{l}\text { All the above, PLUS preferential parking (reserved, indoor, and/or close-in), flexible work schedule policy to } \\
\text { accommodate carpool schedules. Half-time transportation coordinator }\end{array}$ \\
\hline & 4 & All the above, PLUS full-time transportation coordinator \\
\hline \multirow{4}{*}{ Vanpool } & 1 & $\begin{array}{l}\text { Vanpool information activities (tied in with area wide vanpool matching and/or third party vanpool programs), } \\
\text { quarter-time transportation coordinator }\end{array}$ \\
\hline & 2 & $\begin{array}{l}\text { All the above, PLUS in-house vanpool matching services and/or personalized vanpool candidate get-togethers, non- } \\
\text { monetary vanpool development assistance, policy of flexible work schedules to accommodate vanpool schedule }\end{array}$ \\
\hline & 3 & $\begin{array}{l}\text { All the above, PLUS vanpool development and operating assistance, including financial assistance such as vanpool } \\
\text { purchase loan guarantees, consolidate purchase of insurance, and a startup subsidy; supporting services such as van } \\
\text { washing and fueling; half-time transportation coordinator }\end{array}$ \\
\hline & 4 & $\begin{array}{l}\text { All the above, PLUS major financial assistance for development and operations, such as employer purchase of vans } \\
\text { with favorable leaseback, continuing subsidy, free maintenance, free insurance; full-time transportation coordinator }\end{array}$ \\
\hline \multirow{4}{*}{ Transit } & 1 & Transit information center, quarter-time transportation coordinator \\
\hline & 2 & All the above, PLUS policy of work hours flexibility to accommodate transit schedules/delays \\
\hline & 3 & All the above, PLUS on -site transit pass sales, half-time transportation coordinator \\
\hline & 4 & All the above, PLUS guaranteed ride home, full-time transportation coordinator \\
\hline \multirow{4}{*}{ Bicycle } & 1 & Provision of on-site bicycle parking (racks or lockers) \\
\hline & 2 & All the above, PLUS shower and change facilities \\
\hline & 3 & $\begin{array}{l}\text { All the above, PLUS provision of secure bicycle parking (storage lockers or indoor storage), development of local } \\
\text { bike-friendly infrastructure }\end{array}$ \\
\hline & 4 & All the above, PLUS workplace information and promotional activities \\
\hline
\end{tabular}

Source: Procedures manual for the COMMUTER Model v 2.0, Cambridge Systematics, Inc., October 2005 
Table 8: Increase Using Model by Support Program Level

\begin{tabular}{|c|c|c|c|c|c|}
\hline \multirow{2}{*}{ Program } & $\begin{array}{c}\text { Type of } \\
\text { Workplace }\end{array}$ & $\begin{array}{c}\text { Program } \\
\text { Level 1 }\end{array}$ & $\begin{array}{c}\text { Program } \\
\text { Level 2 }\end{array}$ & $\begin{array}{c}\text { Program } \\
\text { Level 3 }\end{array}$ & $\begin{array}{c}\text { Program } \\
\text { Level 4 }\end{array}$ \\
\hline \multirow{2}{*}{ Carpool } & Office & $0.40 \%$ & $1.00 \%$ & $2.00 \%$ & $4.00 \%$ \\
\cline { 2 - 6 } & Non-Office & $0.20 \%$ & $0.40 \%$ & $1.40 \%$ & $2.00 \%$ \\
\hline \multirow{2}{*}{ Vanpool } & Office & $0.40 \%$ & $1.00 \%$ & $2.00 \%$ & $4.00 \%$ \\
\cline { 2 - 6 } & Non-Office & $0.20 \%$ & $0.40 \%$ & $1.40 \%$ & $2.00 \%$ \\
\hline \multirow{2}{*}{ Transit } & Office & $0.20 \%$ & $0.50 \%$ & $1.50 \%$ & $2.00 \%$ \\
\cline { 2 - 6 } & Non-Office & $0.20 \%$ & $0.50 \%$ & $1.50 \%$ & $2.00 \%$ \\
\hline \multirow{2}{*}{ Bicycle } & Office & $0.20 \%$ & $0.50 \%$ & $1.50 \%$ & $2.00 \%$ \\
\cline { 2 - 6 } & Non-Office & $0.10 \%$ & $0.25 \%$ & $0.75 \%$ & $1.00 \%$ \\
\hline
\end{tabular}

Sources: Procedures manual for the COMMUTER model v2.0, Cambridge Systematics, Inc., October 2005.

Table 9 presents the mode share change calculation process based on the TDM program level for each alternative mode. .

Table 9: Mode Share With TDM and Without TDM

\begin{tabular}{|c|c|c|c|c|}
\hline $\begin{array}{c}\text { TDM Support } \\
\text { Program } \\
\end{array}$ & $\begin{array}{c}\text { Starting Mode Share } \\
\text { With TDM }\end{array}$ & Program Level & $\Delta$ Share & $\begin{array}{c}\text { Revised Mode Share } \\
\text { Without TDM } \\
\end{array}$ \\
\hline \multirow{4}{*}{ Carpool } & & 1 & $-1.50 \%$ & \\
\hline & $11.00 \%$ & 2 & $-2.00 \%$ & $9.00 \%$ \\
\hline & & 3 & $-3.00 \%$ & \\
\hline & & 4 & $-5.00 \%$ & \\
\hline \multirow{4}{*}{ Vanpool } & & 1 & $-0.50 \%$ & \\
\hline & $5.00 \%$ & 2 & $-1.00 \%$ & $4.00 \%$ \\
\hline & & 3 & $-1.50 \%$ & \\
\hline & & 4 & $-2.00 \%$ & \\
\hline \multirow{4}{*}{ Transit } & & 1 & $-1.00 \%$ & \\
\hline & $15.00 \%$ & 2 & $-2.00 \%$ & $13.00 \%$ \\
\hline & & 3 & $-4.00 \%$ & \\
\hline & & 4 & $-5.00 \%$ & \\
\hline \multirow{4}{*}{ Bicycle } & $3.00 \%$ & 1 & $-0.10 \%$ & $2.00 \%$ \\
\hline & & 2 & $-0.30 \%$ & \\
\hline & & 3 & $-0.50 \%$ & \\
\hline & & 4 & $-1.00 \%$ & \\
\hline
\end{tabular}

Table 10 shows the normalization procedure used to adjust the revised shares to ensure that changes are proportionate across the available alternatives so that final mode choices are less than or equal 100 percent. 
Table 10: Mode Share Adjustment Process

\begin{tabular}{|c|c|c|c|c|c|}
\hline & Base & $\Delta$ & Revised & Adjustment Factor & Final Share \\
\hline Drive alone & $62 \%$ & & $62 \%$ & 1.064 & $66.00 \%$ \\
\hline Carpool & $11 \%$ & $-2 \%$ & $9 \%$ & 1.064 & $9.60 \%$ \\
\hline Vanpool & $5 \%$ & $-1 \%$ & $4 \%$ & 1.064 & $4.30 \%$ \\
\hline Transit & $15 \%$ & $-2 \%$ & $13 \%$ & 1.064 & $13.80 \%$ \\
\hline Walk & $-2 \%$ & & $-2 \%$ & 1.000 & $2.00 \%$ \\
\hline Bicycle & $3 \%$ & $-1 \%$ & $2 \%$ & 1.064 & $2.13 \%$ \\
\hline Other & $2 \%$ & & $2 \%$ & 1.064 & $2.13 \%$ \\
\hline Total & $\mathbf{1 0 0 \%}$ & & $\mathbf{9 4 \%}$ & & $\mathbf{1 0 0 \%}$ \\
\hline
\end{tabular}

\section{Example}

\section{Employer TDM Support Strategies}

\begin{tabular}{|l|r|}
\hline Quarter Time ETC & Yes \\
\hline Half Time ETC & No \\
\hline Full Time ETC & No \\
\hline Flexible Work Schedule & Yes \\
\hline Transit Information Center & Yes \\
\hline Reserved HOV Parking & Yes \\
\hline Carpool Information Activity & Yes \\
\hline Vanpool Information Activity & Yes \\
\hline Vanpool Financial Assistance & Yes \\
\hline Company Provided Vehicle for Vanpool & No \\
\hline Carpool Information Activity & Yes \\
\hline Vanpool Information Activity & Yes \\
\hline Vanpool Financial Assistance & Yes \\
\hline Company Provided Vehicle for Vanpool & No \\
\hline
\end{tabular}

Program Promotion Level and Mode Share change

\begin{tabular}{|l|c|c|c|}
\hline \multicolumn{3}{|c|}{ Program Promotion Level } \\
\hline Carpool & Vanpool & Transit & Bicycle \\
\hline 1 & 1 & 2 & 1 \\
\hline & & & \\
\hline & & \\
\hline
\end{tabular}




\begin{tabular}{|l|c|c|c|c|c|}
\hline \multicolumn{1}{|c|}{ Mode Share Adjustment Process } \\
\hline Drive alone & Base & $\Delta$ & Revised & Adjustment & Final Share \\
\hline Carpool & $36.87 \%$ & $0.0 \%$ & $36.87 \%$ & 1.0134 & $37.36 \%$ \\
\hline Vanpool & $16.20 \%$ & $-0.4 \%$ & $15.80 \%$ & 1.0134 & $16.01 \%$ \\
\hline Motorcycle & $1.11 \%$ & $-0.4 \%$ & $0.71 \%$ & 1.0134 & $0.72 \%$ \\
\hline Transit & $0.00 \%$ & $0.0 \%$ & $0.00 \%$ & & $0.00 \%$ \\
\hline Walk & $44.69 \%$ & $-0.5 \%$ & $44.19 \%$ & 1.0134 & $44.78 \%$ \\
\hline Bicycle & $1.11 \%$ & & $1.11 \%$ & 1.0000 & $1.11 \%$ \\
\hline Other & $0.00 \%$ & $-0.2 \%$ & $0.00 \%$ & 1.0134 & $0.00 \%$ \\
\hline Total & $0.00 \%$ & & $0.00 \%$ & 1.0134 & $0.00 \%$ \\
\hline & $100 \%$ & & $98.68 \%$ & & $100 \%$ \\
\hline
\end{tabular}

STEP 4) The impact of travel cost changes

The definition of Without TDM for parking fees or financial subsidies assumes no financial subsidy for any mode of transportation and market price parking for each employee regardless of mode. Based on this assumption, any charge to parking is a positive change to travel cost while any subsidy to alternative mode is a negative change to travel cost. With TDM, the parking fees or financial subsidies function to reduce the SOV trips by increasing its travel cost or decreasing that of other modes. Based on the COMMUTER model, a modified logit pivot point method is applied to evaluate the impacts of changed travel time and travel cost on mode choice.

Travel cost changes data are available from the Washington CTR employer annual report in the form of parking charges and alternative mode subsidies. Information on travel time changes is not available. However, the change in travel time is assumed to be zero, which yields a conservative estimate of the With TDM scenario. The original mathematical expression of the logit pivot point used to calculate the changed modal share due to the travel time and cost changes is as follows:

$$
p^{\prime}(m)=\frac{p(m) * e^{-\nabla U(m)}}{\left[\left(e^{-\nabla U(m)}-1\right) * p(m)\right]+1}
$$

where:

$p^{\prime}(m)=$ the new share of mode $m$ (With TDM)

$p(m)=$ original share of mode $m$ (Without TDM)

$\Delta U(m)=$ the change in disutility of mode $\mathrm{m}$

$=\left[a^{*}(\right.$ changed travel time $)+b^{*}($ changed travel cost $\left.)\right]$

The mode share p'(m) after imposing parking fees and financial subsidies, can be calculated from the CTR individual employee survey data. The $p^{\prime}(m)$ is the mode shares before the imposition of parking fees and parking and financial subsidies. After re-arranging the original logit pivot point model, $p(m)$ can be estimated through the following formula: 


$$
p(m)=\frac{p^{\prime}(m)}{\left[e^{-\nabla U(m)}\left(1-p^{\prime}(m)\right)\right]+p^{\prime}(m)}
$$

The results of mode shares in STEP 3) will serve as the input for $p^{\prime}(m)$. The coefficients of the utility function $(\Delta U(m))$ for the Seattle area can be found in Table 11. The normalization procedure is applied to the adjusted shares to ensure that changes are proportionate across the available alternatives and does not allow final choices to exceed 100 percent.

Table 11: Logit Mode-Choice Coefficients for Individual Urban Areas

\begin{tabular}{|l|c|c|c|c|c|c|}
\hline \multicolumn{2}{|c|}{} & $\begin{array}{c}\text { In-Vehicle Travel Time } \\
\text { (min) }\end{array}$ & \multicolumn{2}{|c|}{$\begin{array}{c}\text { Out-of-Vehicle Travel Time } \\
\text { (min) }\end{array}$} & $\begin{array}{c}\text { Out-of-Pocket Travel } \\
\text { Cost (cents) }\end{array}$ \\
\hline Location & Year & All Modes & Walk Time & Transit Wait & $\begin{array}{c}\text { Auto } \\
\text { Parking }\end{array}$ & Transit Fare \\
\hline Seattle & $\mathbf{1 9 9 0}$ & -0.0176 & -0.0206 & -0.0155 & -0.0024 & -0.0024 \\
\hline
\end{tabular}

Source: Procedures manual for the COMMUTER model v2.0, Cambridge Systematics, Inc., October 2005

\section{Example}

Parking Charge

\begin{tabular}{|c|c|c|}
\hline $\begin{array}{c}\text { Carpool Parking Charge } \\
\text { (\$/Day) }\end{array}$ & $\begin{array}{c}\text { Sanpool Parking Charge } \\
(\$ / \text { Day) }\end{array}$ \\
\hline 0 & 0 & (\$/Day) \\
\hline
\end{tabular}

Alternative Mode Financial Subsidy

\begin{tabular}{|c|c|c|c|c|}
\hline $\begin{array}{c}\text { Carpool Subsidy } \\
\text { (\$/Day) }\end{array}$ & $\begin{array}{c}\text { Vanpool Subsidy } \\
\text { (\$/Day) }\end{array}$ & $\begin{array}{c}\text { Transit Subsidy } \\
\text { (\$/Day) }\end{array}$ & $\begin{array}{c}\text { Bicycle Subsidy } \\
\text { (\$/Day) }\end{array}$ & $\begin{array}{c}\text { Walk Subsidy } \\
\text { (\$/Day) }\end{array}$ \\
\hline 1 & 1 & 1 & 0 & 0 \\
\hline
\end{tabular}

Mode Share Without Financial Subsidy and Parking Management

\begin{tabular}{|l|c|c|c|c|}
\hline & Base & Revised & Adjustment & Final Share \\
\hline Drive alone & $37.36 \%$ & $37.36 \%$ & 1.1 & $41.10 \%$ \\
\hline Carpool & $16.01 \%$ & $12.98 \%$ & 1.1 & $14.28 \%$ \\
\hline Vanpool & $0.72 \%$ & $0.56 \%$ & 1.1 & $0.62 \%$ \\
\hline Motorcycle & $0.00 \%$ & $0.00 \%$ & & $0.00 \%$ \\
\hline Transit & $44.78 \%$ & $38.82 \%$ & 1.1 & $42.70 \%$ \\
\hline Walk & $1.11 \%$ & $1.11 \%$ & 1.1 & $1.22 \%$ \\
\hline Bicycle & $0.00 \%$ & $0.00 \%$ & 1.1 & $0.00 \%$ \\
\hline Other & $0.00 \%$ & $0.00 \%$ & 1.1 & $0.00 \%$ \\
\hline Total & $100 \%$ & $90.83 \%$ & & $100 \%$ \\
\hline
\end{tabular}


The impact of flexible work hours depends on the definition of the peak period and the percentage of office employment type. Based on the COMMUTER model definitions of job types, the CTR employee surveys were categorized into administrative support, management, professional/technical, and customer service, all of which are defined as office employment. Non-office employment was defined as craft/production/labor and sales/marketing. Following the FHWA TDM model, the number of vehicle trips shifted out of the peak period (defined from 6:00 AM to 9:00 AM for this study) at worksites allowing employee participation in flexible work hours is calculated using the following equation:

\author{
Number Daily Vehicle Trips Shifted, Peak to Off-peak \\ $=$ \\ Total Affected Employment \\ $x$ \\ $22 \%$ Participating in Program \\ $x$ \\ Percent of Trips Shifted, based on length of peak period \\ $\boldsymbol{x}$ \\ Current Private Vehicle Mode Share
}

The 22 percent is a default from the COMMUTER model statistics based on previous studies. The percent of trips shifted actually depends on the definition of peak period and can be found in Table 12 .

Table 12: Percent of Trips Shifted by Length of Peak Period

\begin{tabular}{|c|c|}
\hline Length of peak period (hrs) & Percent of trips shifted \\
\hline 2.0 & 28.7 \\
\hline 2.5 & 19.2 \\
\hline 3.0 & 13.9 \\
\hline 3.5 & 10.6 \\
\hline 4.0 & 8.5 \\
\hline 4.5 & 7.1 \\
\hline 5.0 & 6.0 \\
\hline
\end{tabular}

Source: Estimating the Effect of Alternative Work Schedules on Travel Activity and Emissions, FHWA TDM Evaluation Model, 1993.

\title{
Example
}

Number of Daily Vehicle Trips Shifted Peak Period to Off-peak Period

$$
\begin{gathered}
=211 \times 97 \% \times 22 \% \times 13.9 \% \times 41.10 \% \\
=3 \text { Vehicle trips }
\end{gathered}
$$


The revised vehicle trip number can be calculated from the revised mode share from STEP 4), the total person trips including the participants of CWW and Telecommuting from STEP 2 ), and the percentage of employees on carpool divided by the number of passenger in vehicle from STEP 1). The total number of vehicle trips Without TDM is the revised vehicle trips plus the number of vehicle trips shifted out of the peak period due to the flexible work hours.

$$
\begin{aligned}
& \text { Vehicle Trip } \text { Without TDM }=\text { Person Trip } \text { Without TDM } \\
& x \\
& \text { [SOV Share }+ \text { Carpool Share } x\left(\mathrm{PCarpool}_{2} / 2+\mathrm{PCarpool}_{3} / 3+\mathrm{PCarpool}_{4} / 4+\right. \\
& \text { PCarpool } \left._{5} / 5\right)+ \text { VanpoolShare/6] } \\
& +
\end{aligned}
$$

Vehicle Trips Shifted Out From the Peak Period

\title{
Example
}

$$
\begin{aligned}
\text { Vehicle Trip without TDM = } \quad & 181 \times\{41.10 \%+0+[14.28 \% \times(81.58 \% / 2+ \\
15.79 \% / 3+2.56 \% / 4+0 \% / 5)]+0.62 \% / 6\} & =88 \text { Vehicle Trips }
\end{aligned}
$$

STEP 7) VTR due to TDM

The VTR due to TDM is the difference between the number of vehicle trips With TDM and Without TDM.

\author{
Vehicle trips reduced \\ $=$ \\ vehicle trips Without TDM from STEP 6 \\ vehicle trips With TDM from STEP 1 \\ Example \\ Total Number of TDM Reduced Vehicle Trips = \\ $88+3-80=11$ Vehicle Trips
}




\subsection{Distribution of Vehicle Trips Reduced}

The trip distribution implemented is based on an assumption that the number of reduced trips is derived from the non-SOV modes. In other words, when TDM programs are implemented, some people will shift modes from driving alone to carpooling or vanpooling, or from carpooling or vanpool to transit, bicycling, and walking and so on. Therefore, reduced vehicle trips are comprised of commuters that switched back to their original mode of choice in the Without TDM scenario.

Based on this concept, all non-SOV trips at each worksite and the percentage of trips for each home-worksite (origin-destination or O-D) pair can be calculated from the CTR employee travel behavior survey database. Then, the VTR is distributed to those home-worksite pairs proportionally according to the trip percentage. To avoid decimals and round up trip numbers, each pair was multiplied by 100 (to account for rounding up, after the trips are assigned to the network, the final link flow change will be divided by 100). Table 13 presents an example to illustrate the procedure of reduced trips distribution.

Table 13: Illustration of the TDM Reduced Trip Distribution Procedure

\begin{tabular}{|c|c|c|c|c|c|c|c|}
\hline & Worksite & $\begin{array}{c}\text { Home } \\
\text { ZIP }\end{array}$ & $\begin{array}{l}\text { Number of Non } \\
\text { Drive Alone } \\
\text { Trips By Home } \\
\text { ZIP }\end{array}$ & $\begin{array}{c}\text { Total Non Drive } \\
\text { Alone Trips by } \\
\text { Worksite }\end{array}$ & $\begin{array}{c}\text { Percentage } \\
\text { by } \\
\text { Home ZIP }\end{array}$ & $\begin{array}{c}\text { Reduced } \\
\text { Vehicle } \\
\text { Trips }\end{array}$ & $\begin{array}{c}100 x \\
\text { Distributed } \\
\text { Reduced } \\
\text { Trips }\end{array}$ \\
\hline 1 & E80000 & 98031 & 7 & 100 & $7 \%$ & 10 & 70 \\
\hline 2 & E80000 & 98125 & 5 & 100 & $5 \%$ & 10 & 50 \\
\hline 3 & E80000 & 98023 & 5 & 100 & $5 \%$ & 10 & 50 \\
\hline 4 & E80000 & 98422 & 5 & 100 & $5 \%$ & 10 & 50 \\
\hline 5 & E80000 & 98107 & 4 & 100 & $4 \%$ & 10 & 40 \\
\hline 6 & E80000 & 98006 & 4 & 100 & $4 \%$ & 10 & 40 \\
\hline 7 & & & & & & & \\
\hline & & & & & & & \\
\hline & & & & & & & \\
\hline 74 & $\nabla$ & $\dot{v}$ & $\nabla$ & $\nabla$ & 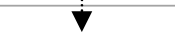 & $\nabla$ & $\nabla$ \\
\hline 75 & E80000 & 98108 & 1 & 100 & $1 \%$ & 10 & 1000 \\
\hline
\end{tabular}

\subsection{Assignment of Vehicle Trips Reduced}

With the Origin-Destination (O-D) for each reduced vehicle trip, it can then be assigned to the transportation network to estimate the number of trips that take I-5 and which ramp is used. The transportation network created was based on the Census 2000 Tiger/Line road data for five counties; Island, Snohomish, Kitsap, King, and Pierce. Worksite locations are geocoded based on the street address. The location of the employee's home is represented by the centroid of the ZIP code (assumed to be the traffic zone) and geocoded. The shortest path for each O-D pair was determined based on the length of the link from home to worksite and vice versa. The reduced trips were assigned to the shortest path based on the all-or-nothing traffic assignment approach to calculate traffic flow changes for each link on the network. 


\subsection{CORSIM Data Inputs}

After the VTR due to TDM was calculated for each worksite within the study area, the trips were distributed and assigned to the transportation network to obtain link traffic flow changes. The CORSIM network With TDM was that obtained from WSDOT with 2004 traffic volumes. The network Without TDM was created by subtracting the link traffic flow change from CORSIM network With TDM. At the same time, the percentages of traffic from each origin node to all destination nodes were modified by changing the $<$ Entry Properties $>$ of each node by selecting the time period and changing the corresponding traffic flow on the links. The percentages of traffic from each origin node to all destination nodes can be modified from the CORSIM main menu. Figures 8 and 9 represent the traffic flow and O-D percentages input for CORSIM model analyses.

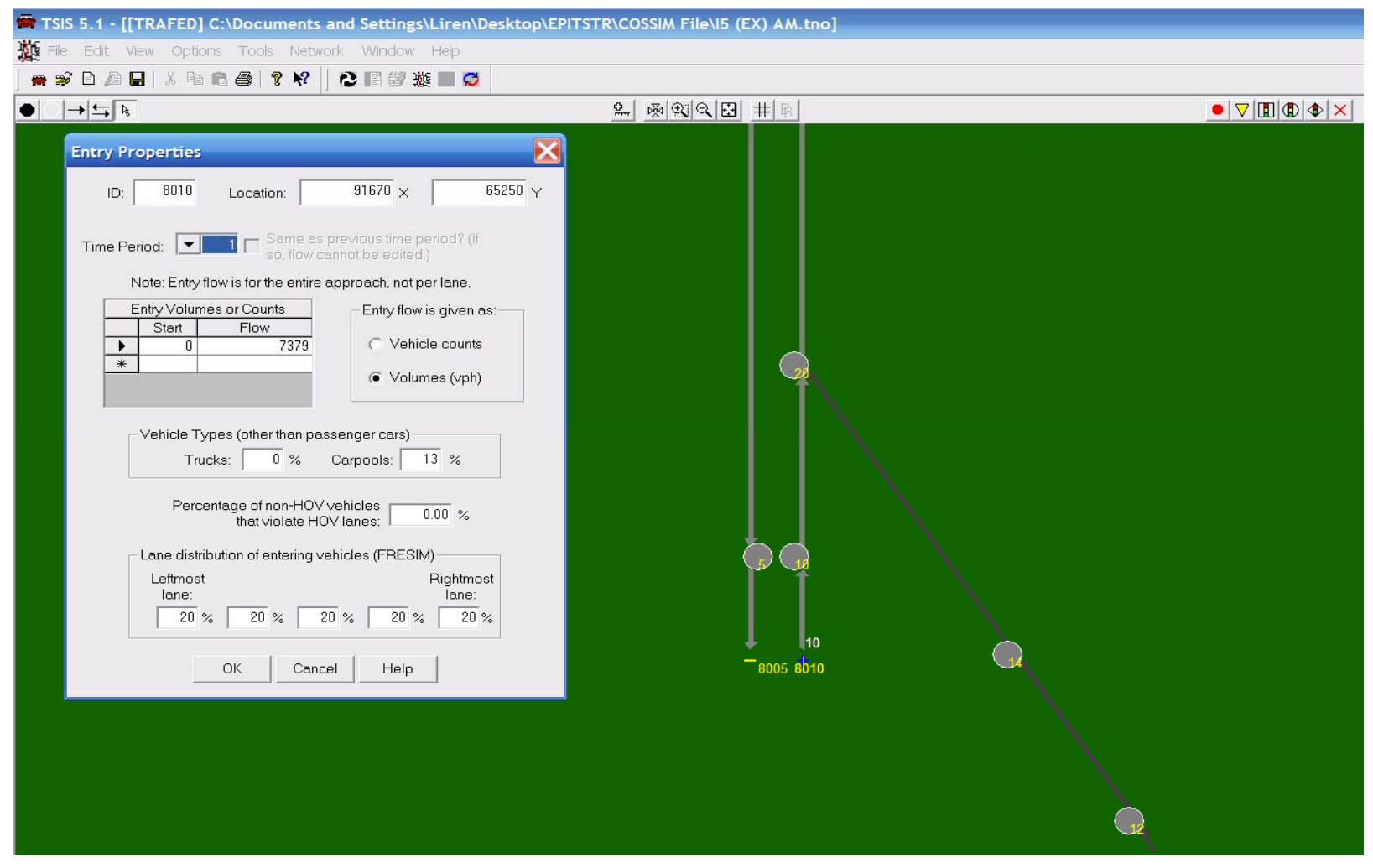

Figure 8: CORSIM Traffic Flow Input and Modification Interface 


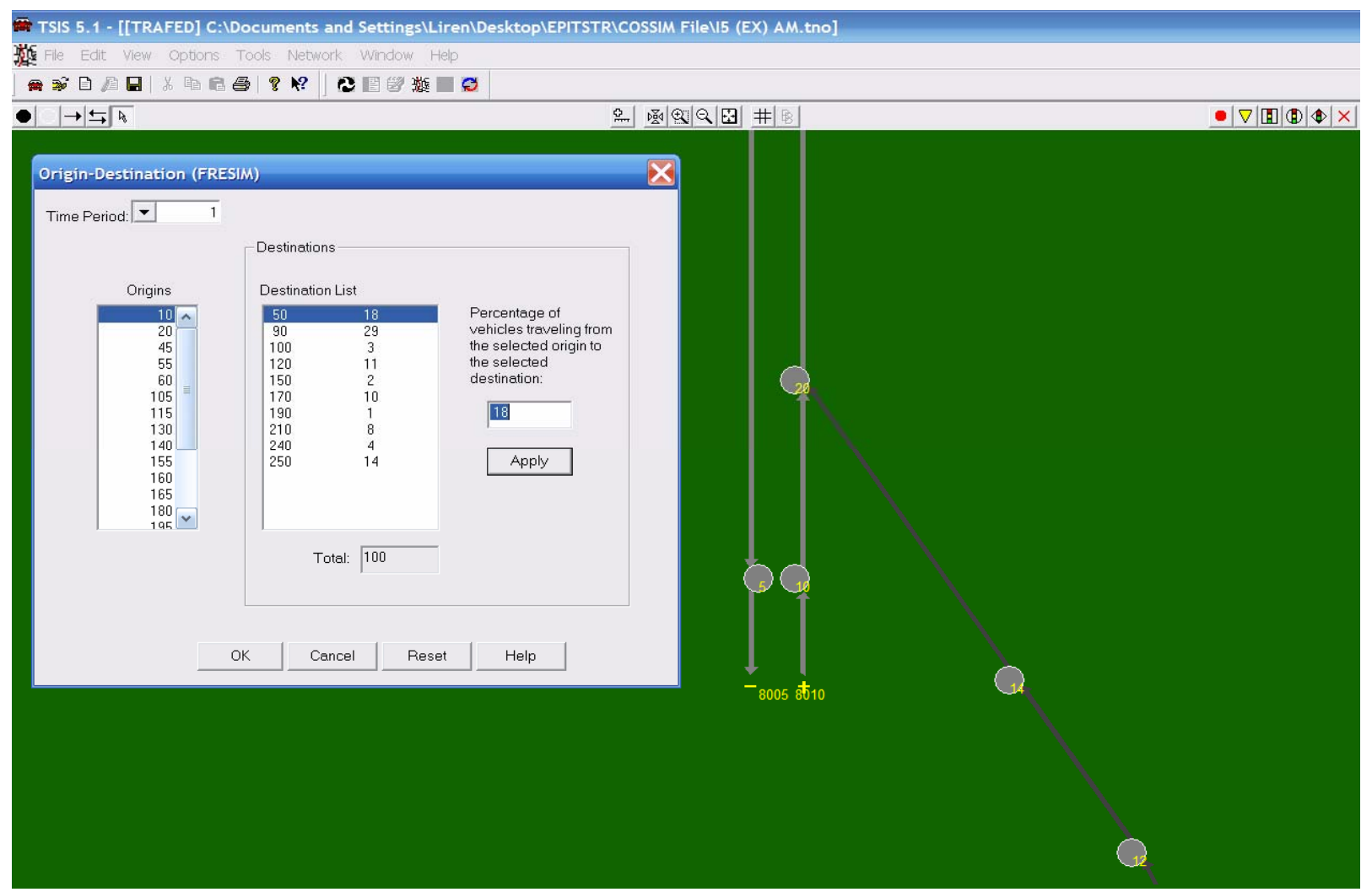

Figure 9: CORSIM Traffic O-D Percentage Input and Modification Interface

\subsubsection{Statistics of CTR Employer Support Strategies}

A brief overview of general statistics of CTR employers support strategies at program levels 0 to 4 is presented in Table 14 .

Table 14: Statistics of Employer TDM Support Strategies

\begin{tabular}{|c|c|c|c|c|}
\hline Program level & Transit & Carpool & Vanpool & Bicycle \\
\hline 0 & $1.06 \%$ & $1.06 \%$ & $1.06 \%$ & $7.41 \%$ \\
\hline 1 & $11.64 \%$ & $60.85 \%$ & $64.02 \%$ & $28.57 \%$ \\
\hline 2 & $77.78 \%$ & $31.75 \%$ & $25.93 \%$ & $3.17 \%$ \\
\hline 3 & $5.82 \%$ & $3.70 \%$ & $6.88 \%$ & $8.47 \%$ \\
\hline 4 & $3.70 \%$ & $2.65 \%$ & $2.12 \%$ & $52.38 \%$ \\
\hline Total & $\mathbf{1 0 0 . 0 0 \%}$ & $\mathbf{1 0 0 . 0 0 \%}$ & $\mathbf{1 0 0 . 0 0 \%}$ & $\mathbf{1 0 0 . 0 0 \%}$ \\
\hline
\end{tabular}

An overview of CTR employers strategies on the imposition of parking fees, and parking and financial subsidies is presented in Table 15. 
Table 15: Statistics of Employer Parking and Financial Subsidies

\begin{tabular}{|c|c|c|c|c|c|c|}
\hline & SOV & Carpool & Vanpool & Transit & Bicycle & Walk \\
\hline $\begin{array}{c}\text { Percentage of Employers } \\
\text { Charging for Parking }\end{array}$ & $50.8 \%$ & $31.2 \%$ & $11.1 \%$ & N/A & N/A & N/A \\
\hline $\begin{array}{c}\text { Average Parking Charge } \\
\text { (Dollars/Month) }\end{array}$ & $\$ 135.7$ & $\$ 108.6$ & $\$ 129.2$ & N/A & N/A & N/A \\
\hline $\begin{array}{c}\text { Percentage of Employers } \\
\text { Subsidizing Alternative Modes }\end{array}$ & $0.0 \%$ & $21.7 \%$ & $47.1 \%$ & $69.3 \%$ & $12.7 \%$ & $15.3 \%$ \\
\hline $\begin{array}{c}\text { Average Subsidy } \\
\text { (Dollars/Month) }\end{array}$ & $\$ 0.0$ & $\$ 36.3$ & $\$ 53.7$ & $\$ 47.8$ & $\$ 25.5$ & $\$ 25.6$ \\
\hline
\end{tabular}

\subsubsection{Statistics of the Data Input into CORSIM}

While the average traffic flow change of an I-5 ramp is about 4 percent, the distribution of the change is not even. At the AM peak period, work trips flow from north and south to the downtown area. The traffic flow changes for on-ramps at the north or south ends and for offramps in the downtown area are significant. The biggest flow change for on-ramp is more than 10 percent and for off-ramp is almost 50 percent. The average traffic flow change for off-ramp at the downtown area is more than 30 percent. At the PM peak period, people going home from the downtown are traveling to both north and south ends. The traffic flow changes for off-ramps at south and north ends and for on-ramps in the downtown area are significant. The biggest flow change for on-ramps is more than 55 percent and is more than 10 percent for off-ramp. The average traffic flow change for on-ramp at the downtown area is more than 20 percent. An overview of CORSIM inputs is presented in Table 16.

Table 16: CORSIM Inputs

\begin{tabular}{|l|c|c|}
\hline Total number of worksites & \multicolumn{2}{|c|}{189} \\
\hline Total number of affected employees working 6am-9am & \multicolumn{2}{|c|}{56,251} \\
\hline Total number of reduced vehicle trips & \multicolumn{2}{|c|}{14.149} \\
\hline Average percentage of TDM vehicle trip reduction & With TDM & Without TDM \\
\hline & $56.91 \%$ & $64.49 \%$ \\
\hline Average share of SOV & $28.08 \%$ & $20.39 \%$ \\
\hline Average share of transit & 54,459 & 54,997 \\
\hline Total number of person trips & 34,860 & 40,009 \\
\hline Total number of vehicle trips & AM Peak Period & PM Peak Period \\
\hline & 4,142 & 3,815 \\
\hline Total number of reduced vehicle trips on I-5 & 99,648 & 109,437 \\
\hline Total I-5 ramp traffic flow & $\mathbf{4 . 1 6 \%}$ & $3.49 \%$ \\
\hline Average percentage of I-5 ramp traffic flow change & & \\
\hline
\end{tabular}


The detailed traffic flow changes of all on-ramps and off-ramps are in Table 17 for AM and Table 18 for PM peak period respectively.

Table 17: I-5 Ramp Traffic Flow Change for AM Peak Period (Home-Worksite)

\begin{tabular}{|c|c|c|c|c|c|c|c|}
\hline On-ramp & Original Flow & $\begin{array}{c}\text { Flow } \\
\text { Change }\end{array}$ & $\begin{array}{l}\text { Percent } \\
\text { Change }\end{array}$ & Off-ramp & $\begin{array}{l}\text { Original } \\
\text { Flow }\end{array}$ & $\begin{array}{c}\text { Flow } \\
\text { Change }\end{array}$ & $\begin{array}{l}\text { Percent } \\
\text { Change }\end{array}$ \\
\hline I-5 NB South End & 20981 & 1347 & $6.42 \%$ & I-5 SB South End & 17147 & 0 & $0.00 \%$ \\
\hline I-5 SB North End & 18594 & 1884 & $10.13 \%$ & I-5 NB North End & 14200 & 0 & $0.00 \%$ \\
\hline Corson NB & 2358 & 153 & $6.49 \%$ & Spokane NB & 5376 & 35 & $0.65 \%$ \\
\hline Spokane NB & 6564 & 132 & $2.01 \%$ & I-90 NB & 9262 & 36 & $0.39 \%$ \\
\hline I-90 NB & 7054 & 308 & $4.37 \%$ & $4^{\text {th }} \mathrm{NB}$ & 443 & 213 & $48.08 \%$ \\
\hline University NB & 778 & 5 & $0.64 \%$ & Seneca NB & 3641 & 1431 & $39.30 \%$ \\
\hline Oliver NB & 2743 & 0 & $0.00 \%$ & Oliver NB & 1854 & 187 & $10.09 \%$ \\
\hline Mercer NB & 2927 & 7 & $0.24 \%$ & Mercer NB & 3408 & 0 & $0.00 \%$ \\
\hline SR520 NB & 2188 & 0 & $0.00 \%$ & Lakeview NB & 942 & 42 & $4.46 \%$ \\
\hline Harvard NB & 1414 & 0 & $0.00 \%$ & SR520 NB & 4168 & 10 & $0.24 \%$ \\
\hline Spokane SB & 803 & 0 & $0.00 \%$ & 45th NB & 3713 & 0 & $0.00 \%$ \\
\hline 6th SB & 2686 & 4 & $0.15 \%$ & Corson SB & 2764 & 0 & $0.00 \%$ \\
\hline 4th SB & 8844 & 0 & $0.00 \%$ & Spokane SB & 4247 & 20 & $0.47 \%$ \\
\hline Yale SB & 2826 & 2 & $0.07 \%$ & Forest SB & 983 & 2 & $0.20 \%$ \\
\hline Mercer SB & 2715 & 39 & $1.44 \%$ & I-90 SB & 8170 & 37 & $0.45 \%$ \\
\hline Boylston SB & 1312 & 113 & $8.61 \%$ & $6^{\text {th }} \mathrm{SB}$ & 4820 & 300 & $6.22 \%$ \\
\hline SR520 SB & 7506 & 151 & $2.01 \%$ & Union SB & 2726 & 1073 & $39.36 \%$ \\
\hline \multirow[t]{4}{*}{ 45th SB } & 1847 & 0 & $0.00 \%$ & Stewart SB & 2477 & 491 & $19.82 \%$ \\
\hline & & & & Mercer SB & 2995 & 164 & $5.48 \%$ \\
\hline & & & & SR520 SB & 4323 & 104 & $2.41 \%$ \\
\hline & & & & Boylston SB & 1992 & 0 & $0.00 \%$ \\
\hline Total & 94137 & 4142 & $4.40 \%$ & Total & 99648 & 4142 & $4.16 \%$ \\
\hline
\end{tabular}


Table 18: I-5 Ramp Traffic Flow Change for PM Peak Period (Worksite-Home)

\begin{tabular}{|c|c|c|c|c|c|c|c|}
\hline On-ramp & $\begin{array}{c}\text { Original } \\
\text { Flow }\end{array}$ & $\begin{array}{c}\text { Flow } \\
\text { Change }\end{array}$ & $\begin{array}{l}\text { Percent } \\
\text { Change }\end{array}$ & Off -ramp & $\begin{array}{c}\text { Original } \\
\text { Flow }\end{array}$ & $\begin{array}{c}\text { Flow } \\
\text { Change }\end{array}$ & $\begin{array}{l}\text { Percent } \\
\text { Change }\end{array}$ \\
\hline I-5 NB South End & 19186 & 0 & $0.00 \%$ & I-5 SB South End & 21745 & 1343 & $6.18 \%$ \\
\hline I-5 SB North End & 19563 & 0 & $0.00 \%$ & I-5 NB North End & 17689 & 1867 & $10.55 \%$ \\
\hline Corson NB & 3417 & 0 & $0.00 \%$ & Spokane NB & 3965 & 0 & $0.00 \%$ \\
\hline Spokane NB & 6284 & 20 & $0.32 \%$ & $\mathrm{I}-90 \mathrm{NB}$ & 8761 & 3 & $0.03 \%$ \\
\hline I-90 NB & 9959 & 73 & $0.73 \%$ & 4th NB & 448 & 0 & $0.00 \%$ \\
\hline University NB & 2192 & 1214 & $55.83 \%$ & Seneca NB & 2197 & 8 & $0.36 \%$ \\
\hline Oliver NB & 4712 & 510 & $10.82 \%$ & Oliver NB & 1648 & 0 & $0.00 \%$ \\
\hline Mercer NB & 3637 & 272 & $7.48 \%$ & Mercer NB & 3270 & 0 & $0.00 \%$ \\
\hline SR520 NB & 4575 & 35 & $0.77 \%$ & Lakeview NB & 987 & 148 & $14.99 \%$ \\
\hline Harvard NB & 2152 & 90 & $4.18 \%$ & SR520 NB & 6459 & 176 & $2.72 \%$ \\
\hline Spokane SB & 1527 & 35 & $2.29 \%$ & 45th NB & 5039 & 0 & $0.00 \%$ \\
\hline 6th SB & 4278 & 1019 & $23.82 \%$ & Corson SB & 2421 & 149 & $6.15 \%$ \\
\hline 4th SB & 10594 & 0 & $0.00 \%$ & Spokane SB & 4619 & 37 & $0.80 \%$ \\
\hline Yale SB & 4099 & 469 & $11.44 \%$ & Forest SB & 469 & 0 & $0.00 \%$ \\
\hline Mercer SB & 4535 & 55 & $1.21 \%$ & $\mathrm{I}-90 \mathrm{SB}$ & 6951 & 71 & $1.02 \%$ \\
\hline Boylston SB & 1197 & 20 & $1.67 \%$ & 6th SB & 3181 & 4 & $0.13 \%$ \\
\hline SR520 SB & 4784 & 3 & $0.06 \%$ & Union SB & 1486 & 6 & $0.40 \%$ \\
\hline \multirow[t]{4}{*}{ 45th SB } & 2547 & 0 & $0.00 \%$ & Stewart SB & 2502 & 0 & $0.00 \%$ \\
\hline & & & & Mercer SB & 3969 & 3 & $0.08 \%$ \\
\hline & & & & SR520 SB & 2910 & 0 & $0.00 \%$ \\
\hline & & & & Boylston SB & 2018 & 0 & $0.00 \%$ \\
\hline Total & 109437 & 3815 & $3.49 \%$ & Total & 102732 & 3815 & $3.71 \%$ \\
\hline
\end{tabular}

Table 19 shows a sample of the on-ramps and off-ramps for each reduced vehicle trip if the trip takes I-5. The location of the on-ramps and off-ramps with significant traffic flow change are presented in Figure 10 and Figure 11 for AM and PM peak periods, respectively. 
Table 19: Samples of Ramp ID for Each VTR

\begin{tabular}{|c|c|c|c|}
\hline Worksite CTR ID & Home ZIP & On-ramp & Off-Ramp \\
\hline E84244 & 98,388 & 303 & 1,020 \\
\hline E84245 & 98,321 & 303 & 1,020 \\
\hline E84246 & 98,328 & 303 & 1,020 \\
\hline E84247 & 98,329 & 105 & 506 \\
\hline E84248 & 98,465 & 105 & 1,030 \\
\hline E84249 & 98,466 & 105 & 506 \\
\hline E84250 & 98,405 & 303 & 1,020 \\
\hline E84251 & 98,409 & 303 & 1,020 \\
\hline E84252 & 98,498 & N/A & N/A \\
\hline E84253 & 98,499 & N/A & N/A \\
\hline E84254 & 98,402 & 303 & 1,020 \\
\hline E84255 & 98,444 & 303 & 1,020 \\
\hline E84256 & 98,424 & N/A & N/A \\
\hline E84257 & 98,354 & N/A & N/A \\
\hline E84258 & 98,371 & N/A & N/A \\
\hline E84259 & 98,373 & 105 & 1,030 \\
\hline E84260 & 98,374 & N/A & N/A \\
\hline E84261 & 98,335 & 105 & 506 \\
\hline E84262 & 98,407 & 105 & 1,030 \\
\hline
\end{tabular}




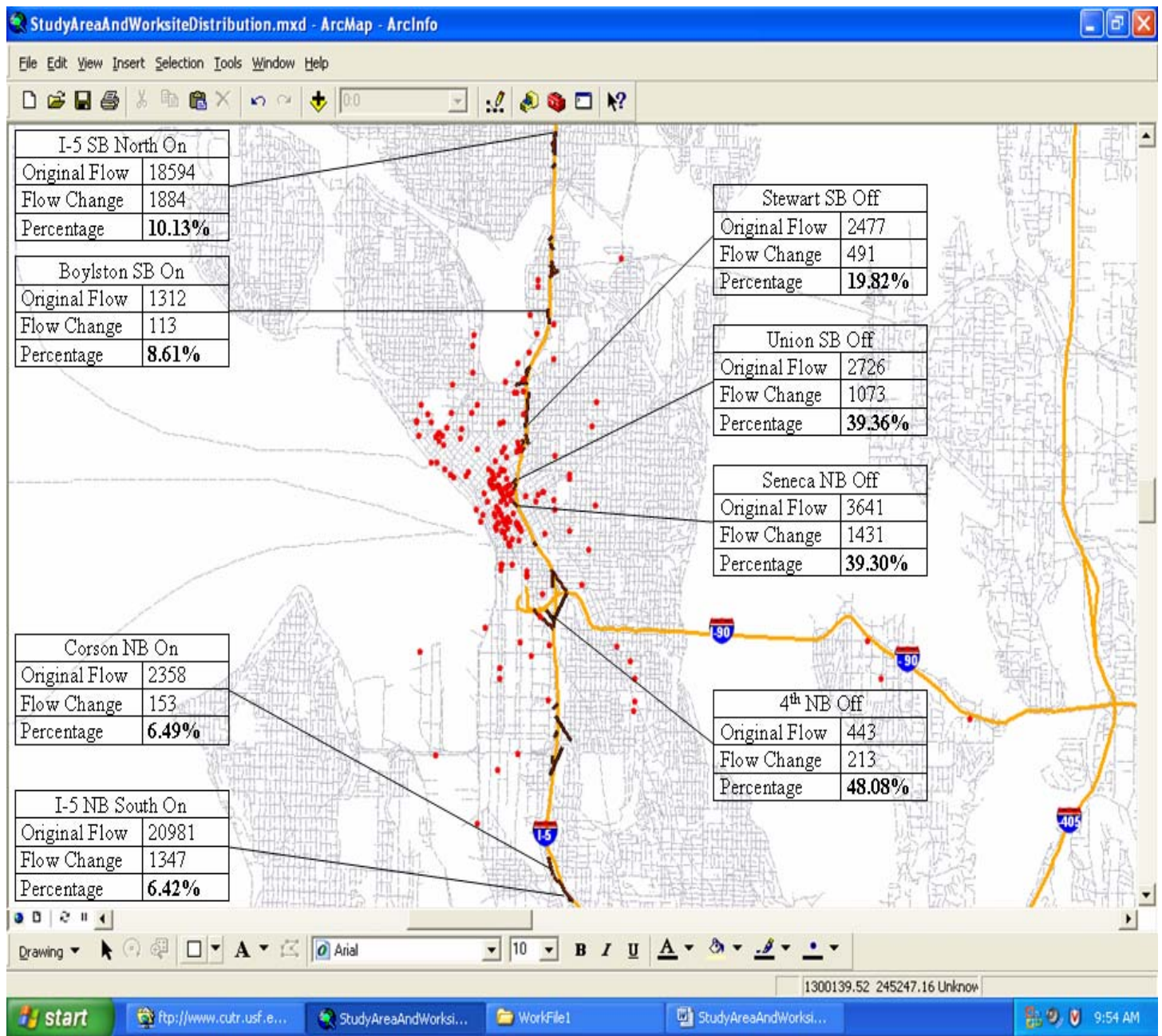

Figure 10: Locations of On-ramps and Off-ramps with Significant Flow Change at AM Peak 
Q StudyAreaAndWorksiteDistribution.mxd - Archap - Arclnfo

Elle Edit Vew Insert Selection Iools Window Help

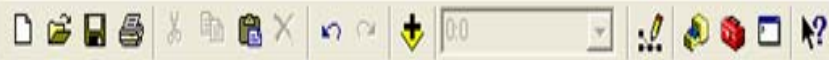

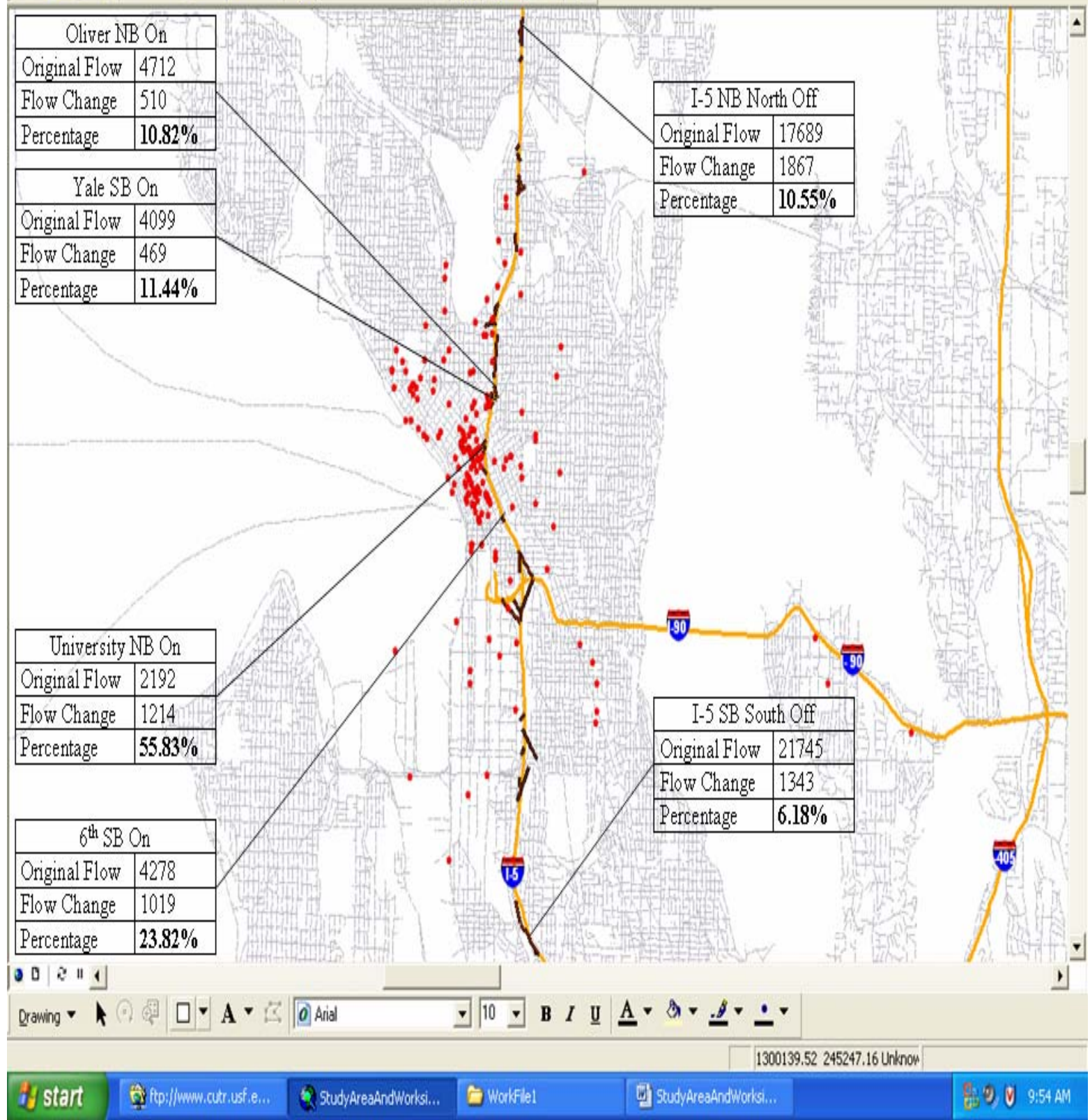

Figure 11: Locations of On-ramps and Off-ramps

with Significant Flow Change at PM Peak 


\section{Chapter 4 - Microsimulation Analysis}

As previously mentioned, the CTR program in Washington maintains comprehensive databases of employer-based TDM programs and employees survey data. These databases were used to calculate VTR due to TDM programs implemented at employer worksites in the Seattle downtown area on a segment of I-5. Two scenarios were compared; Scenario A represented existing traffic conditions on the network (With TDM) while Scenario B (Without TDM) represented traffic conditions with reduced trips added to Scenario A. The comparison was conducted using CORSIM, a microscopic simulation model, as the assessment tool to evaluate the impacts of TDM programs on the traffic network. This chapter provides the analysis process used for this comparison and the evaluation of performance measures for the two scenarios.

\subsection{CORSIM Review}

CORSIM is a microsimulation tool that applies time step simulation of one second to analyze traffic conditions on a corridor. Each vehicle is a distinct object in a simulated environment that is moved every second. Similarly, each variable control device (such as traffic signals) and each event (incident) is updated every second. CORSIM is a stochastic model that assigns random numbers to drivers, vehicle characteristics, and decision-making processes simulating the randomness of the actual traffic conditions. The model has different driver types, depending on the aggressiveness of driving, various vehicle types, and vehicle fleets depending on the acceleration capability, weight, and size of vehicles. All proportions of these driver types and vehicle types can be adjusted to simulate the existing driver and vehicle mix. Several calibration parameters can be modified to adjust the model for the existing traffic conditions. These parameters include mean start-up delay at ramp meters, incident rubbernecking factors, car-following sensitivity factors, lane change gap acceptance dynamics, and factors affecting discretionary lane changes.

The validity of a simulation model relies greatly on the input to the algorithm. CORSIM requires accurate descriptions of the characteristics of the vehicles, the transportation network, and the traffic control system. These characteristics vary over the physical length of the network and over time. The geometric characteristics of a roadway may vary over the length of the network and at the same time, the volume entering the network and signaltiming plans can also vary with time. To simulate this variability, the network is divided into links that code different geometric changes. The simulation duration is divided into different time periods that code the variability in traffic volume and other temporal changes.

The CORSIM model does time step simulation of the transportation network. It records all the performance measures on a second-by-second basis for each vehicle in the transportation network. These performance measures can be delay per vehicle, fuel consumption, and emissions, which are recorded in an output file. The output file also contains links and network-wide statistics. CORSIM also provides a graphical interface to view the coded network that allows researchers, practitioners, and decision-makers to visually inspect the traffic conditions throughout the duration of the simulation. In addition to the output from 
the algorithm, a graphical interface can be used to visually compare before and after scenarios for any improvement to the transportation network. The measures that will be used for comparing the performance of the I-5 corridor With TDM and Without TDM programs will be a subset of the NTOC performance measures previously discussed in Chapter 2 of this report and other standards provided by CORSIM. The performance measures used for this research study include the following:

1. Recurring delay in vehicle-minutes

2. Average recurring delay in seconds/vehicle

3. Average speed in $\mathrm{mph}$

4. Vehicle miles traveled

5. Spatial extent of congestion

6. Temporal extent of congestion

7. Fuel consumption in gallons

8. Emissions - hydrocarbon ( $\mathrm{HC})$, carbon monoxide ( $\mathrm{CO})$ and nitrogen oxides (NOx)

Several of these measures are used frequently by traffic operations professionals to assess the performance of a corridor, and therefore, considered appropriately familiar to communicate the operational impacts of TDM programs. By comparing these measures for the With TDM and Without TDM scenarios, the impacts of TDM programs on the I-5 corridor can be illustrated.

\subsection{CORSIM Network}

The CORSIM network model files for the AM and PM peak periods were obtained from the WSDOT with traffic volume data for the year 2004. The network files were already calibrated to represent the traffic conditions that exist on the field. The volumes were provided in 19 time intervals of 15 minutes each from 5:30 AM to 10:15 AM for the AM peak and from 3:00 PM to 7:45 PM for the PM peak file. The transportation network consists of nodes and links in the CORSIM network file where nodes are intersections, location of exits on interstate, or location of merge on interstates; and links are actual roadways between two nodes. An 8.6 mile segment of the I-5 corridor was divided into 49 links in CORSIM to simulate the changes in the roadway geometry and add or drop lanes/ ramps on the interstate. The nodes on the northbound I-5 are numbered from 10 to 250 in increments of 10 , and the nodes on southbound I-5 are numbered from 5 to 255 in increments of 10. The schematic sketch of the corridor is shown in Figure 12. 

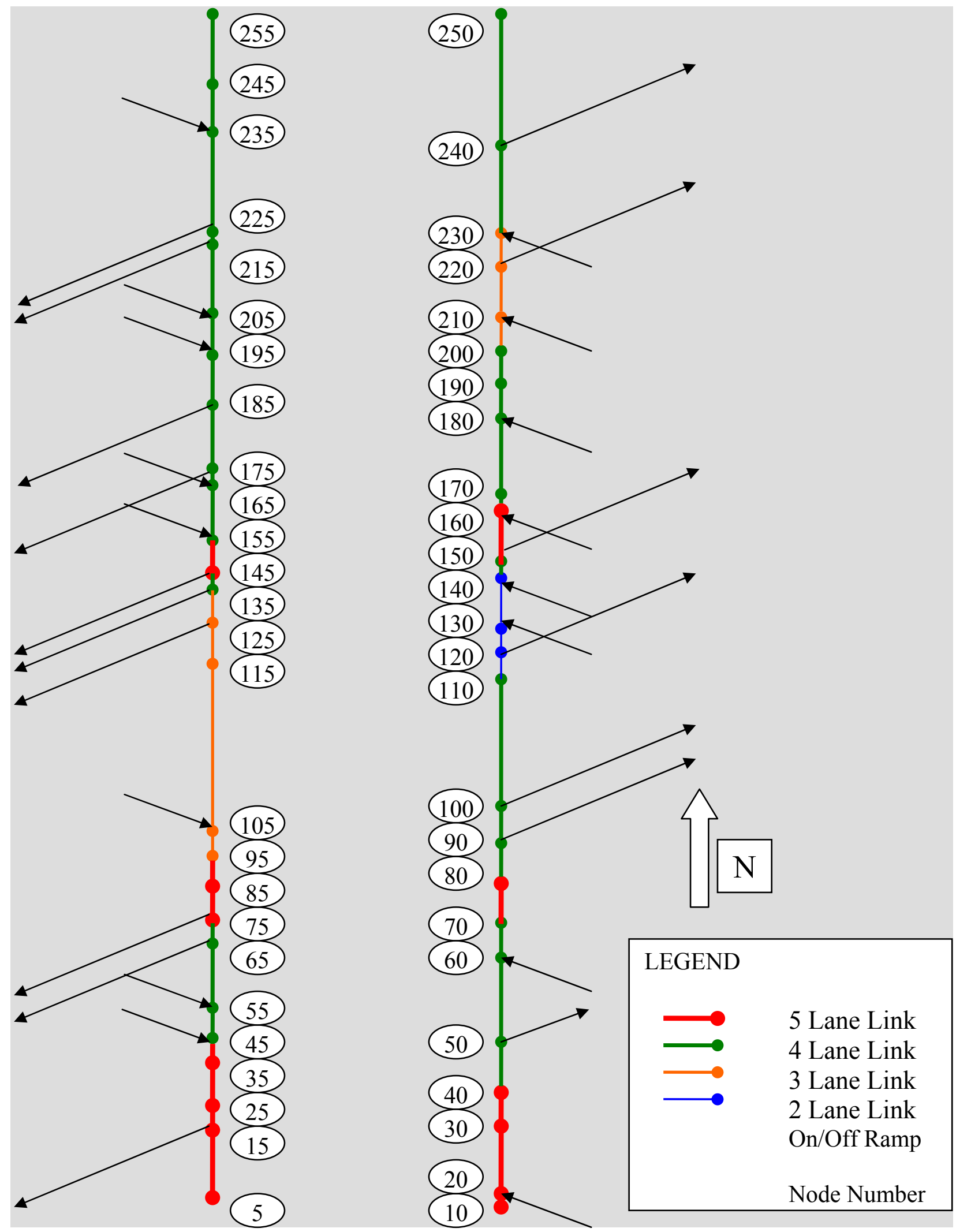

Figure 12: Schematic Sketch of the Study Area Segment of I-5 
Table 20 shows the length of each of these links, the number of through lanes, and whether HOV lanes are present. Node 10 is the southern-most node on the NB I-5 and Node 5 is the southern-most node of the SB I-5. The links are referred by the preceding node (Node A) in the entire report, for example, the link formed by node 10 and node 20 is referred to as link 10. Note that the links are neither equal in length nor have the same number of lanes

Table 20: Network Link Data

\begin{tabular}{|c|c|c|c|c|c|c|c|c|c|}
\hline \multicolumn{5}{|c|}{ NORTHBOUND I-5 } & \multicolumn{5}{|c|}{ SOUTHBOUND I-5 } \\
\hline \multicolumn{2}{|c|}{ Links } & \multirow{2}{*}{$\begin{array}{c}\begin{array}{c}\text { Link } \\
\text { Length } \\
\text { (feet) }\end{array} \\
\end{array}$} & \multirow{2}{*}{$\begin{array}{c}\text { Number } \\
\text { of Non- } \\
\text { HOV } \\
\text { Lanes } \\
\end{array}$} & \multirow{2}{*}{$\begin{array}{c}\text { Number } \\
\text { of } \\
\text { HOV } \\
\text { Lanes }\end{array}$} & \multicolumn{2}{|c|}{ Links } & \multirow{2}{*}{$\begin{array}{c}\text { Link } \\
\text { Length } \\
\text { (feet) }\end{array}$} & \multirow{2}{*}{$\begin{array}{c}\text { Number } \\
\text { of Non- } \\
\text { HOV } \\
\text { Lanes }\end{array}$} & \multirow{2}{*}{$\begin{array}{c}\text { Number } \\
\text { of } \\
\text { HOV } \\
\text { Lanes }\end{array}$} \\
\hline Node A & Node B & & & & Node A & Node B & & & \\
\hline 10 & 20 & 280 & 4 & 1 & 255 & 245 & 2800 & 4 & 0 \\
\hline 20 & 30 & 2520 & 4 & 1 & 245 & 235 & 2205 & 4 & 0 \\
\hline 30 & 40 & 1300 & 4 & 1 & 235 & 225 & 4000 & 4 & 0 \\
\hline 40 & 50 & 1780 & 3 & 1 & 225 & 215 & 332 & 4 & 0 \\
\hline 50 & 60 & 3538 & 3 & 1 & 215 & 205 & 2510 & 4 & 0 \\
\hline 60 & 70 & 1192 & 3 & 1 & 205 & 195 & 1500 & 4 & 0 \\
\hline 70 & 80 & 1628 & 4 & 1 & 195 & 185 & 1780 & 4 & 0 \\
\hline 80 & 90 & 1242 & 3 & 1 & 185 & 175 & 2550 & 4 & 0 \\
\hline 90 & 100 & 1200 & 4 & 0 & 175 & 165 & 650 & 4 & 0 \\
\hline 100 & 110 & 5210 & 4 & 0 & 165 & 155 & 2050 & 3 & 1 \\
\hline 110 & 120 & 1070 & 2 & 0 & 155 & 145 & 1315 & 4 & 1 \\
\hline 120 & 130 & 850 & 2 & 0 & 145 & 135 & 645 & 3 & 1 \\
\hline 130 & 140 & 1800 & 2 & 0 & 135 & 125 & 1300 & 2 & 1 \\
\hline 140 & 150 & 315 & 4 & 0 & 125 & 115 & 1600 & 2 & 1 \\
\hline 150 & 160 & 2150 & 5 & 0 & 115 & 105 & 6500 & 2 & 1 \\
\hline 160 & 170 & 400 & 4 & 0 & 105 & 95 & 1064 & 2 & 1 \\
\hline 170 & 180 & 3000 & 4 & 0 & 95 & 85 & 1013 & 4 & 1 \\
\hline 180 & 190 & 1400 & 4 & 0 & 85 & 75 & 1073 & 4 & 1 \\
\hline 190 & 200 & 1250 & 4 & 0 & 75 & 65 & 800 & 3 & 1 \\
\hline 200 & 210 & 1100 & 3 & 0 & 65 & 55 & 2480 & 3 & 1 \\
\hline 210 & 220 & 1800 & 3 & 0 & 55 & 45 & 1000 & 3 & 1 \\
\hline 220 & 230 & 1150 & 3 & 0 & 45 & 35 & 746 & 4 & 1 \\
\hline 230 & 240 & 3500 & 4 & 0 & 35 & 25 & 1544 & 4 & 1 \\
\hline 240 & 250 & 5380 & 4 & 0 & 25 & 15 & 950 & 4 & 1 \\
\hline- & - & - & - & - & 15 & 5 & 2650 & 4 & 1 \\
\hline
\end{tabular}

The corridor consists of 16 on-ramps and 19 off-ramps that provide access to the downtown region. The locations of the ramps on the corridor are referenced by node number. The node numbers in Table 21 correspond to those on I-5 where ramps connect onto the interstate. 
Table 21: Network Ramp Data

\begin{tabular}{|c|c|c|c|c|c|}
\hline \multicolumn{3}{|c|}{ NORTHBOUND I-5 } & \multicolumn{3}{c|}{ SOUTHBOUND I-5 } \\
\hline Node & On-ramp & Off- ramp & Node & On-ramp & Off- ramp \\
\hline 20 & Corson & - & 235 & NE 45 ${ }^{\text {th }}$ & - \\
\hline 50 & - & Spokane & 225 & - & Boylston \\
\hline 60 & Spokane & - & 215 & - & SR 520 \\
\hline 90 & - & I-90 & 205 & SR 520 & - \\
\hline 100 & - & $4^{\text {th }}$ Avenue & 195 & Boylston & - \\
\hline 120 & - & Seneca & 185 & - & Mercer \\
\hline 130 & I-90 & - & 175 & - & Stewart \\
\hline 140 & University & - & 165 & Mercer & - \\
\hline 150 & - & Olive & 155 & Yale & - \\
\hline 160 & Olive & - & 145 & - & Union \\
\hline 170 & - & Mercer & 135 & - & $6^{\text {th }}$ Avenue \\
\hline 180 & Mercer & - & 125 & - & I-90 \\
\hline 190 & - & Lakeview & 105 & I-90 & - \\
\hline 210 & SR 520 & - & 75 & - & Forest \\
\hline 220 & - & SR 520 & 65 & - & Spokane \\
\hline 230 & Harvard & - & 55 & $6^{\text {th }}$ Avenue & - \\
\hline 240 & - & NE 45 & 45 & Spokane & - \\
\hline & & & 15 & - & Corson \\
\hline
\end{tabular}

The reversible lanes on I-5 were treated as on-ramps and off-ramps, and the analysis was confined to non-reversible lanes of the network. The free-flow speed for the freeway mainline was assumed to be $65 \mathrm{mph}$, which was $5 \mathrm{mph}$ above the posted speed limit on the corridor. Further, the terminal links on NB I-5 and SB I-5 were extended by 1 mile to capture the visual impact of queues that may form due to congestion.

\subsection{Analysis of the With TDM and Without TDM Scenarios}

An assessment of the impact of TDM programs was conducted by comparing the performance of the transportation network With TDM and Without TDM programs. As previously stated, Scenario A, With TDM, represents traffic volumes on the network for the year 2004. Scenario B, Without TDM, represents traffic conditions that would exist if the TDM programs were not implemented. Scenario B has the 2004 traffic volumes plus VTR due to TDM programs implemented by 189 employers.

The analysis was conducted for the duration of the AM and PM peak period and the 75minute interval following each peak period. The additional 75-minute intervals were analyzed to capture the impacts of added trips beyond peak periods. Each analysis period consisted of 3-hour peak period (12 fifteen-minute intervals) followed by 5 fifteen-minute intervals (75 minutes), for a total of 17 time periods. 
The next two sub-sections will describe the traffic volumes for the year 2004 and the traffic volume after trips reduced by the TDM program were added.

\subsubsection{Scenario A - With TDM}

The traffic volumes on a CORSIM freeway network consist of the numbers of vehicles entering a link during a time period, the number of vehicles exiting the link during that time period, and the percentage of HOV vehicles. Each vehicle on the network has a defined origin and destination on the network. The calibrated CORSIM network file obtained from WSDOT had the volumes of vehicles entering the network during each 15-minute interval, the number of vehicles going through and taking an exit, the percentage of HOV vehicles, and the origin-destination of the traffic volume for each time period.

The 2004 traffic volumes on the network for the 17 15-minute intervals for the AM period for northbound and southbound I-5 are shown in Table 22 and Table 23, respectively. This AM period starts at 6:00 AM and ends at 10:15 AM. Similarly, the traffic volumes for the PM period, which starts at 3:00 PM and ends at 7:15 PM, are shown in Tables 24 and 25. 
Table 22: I-5 Volumes NB During the AM Peak

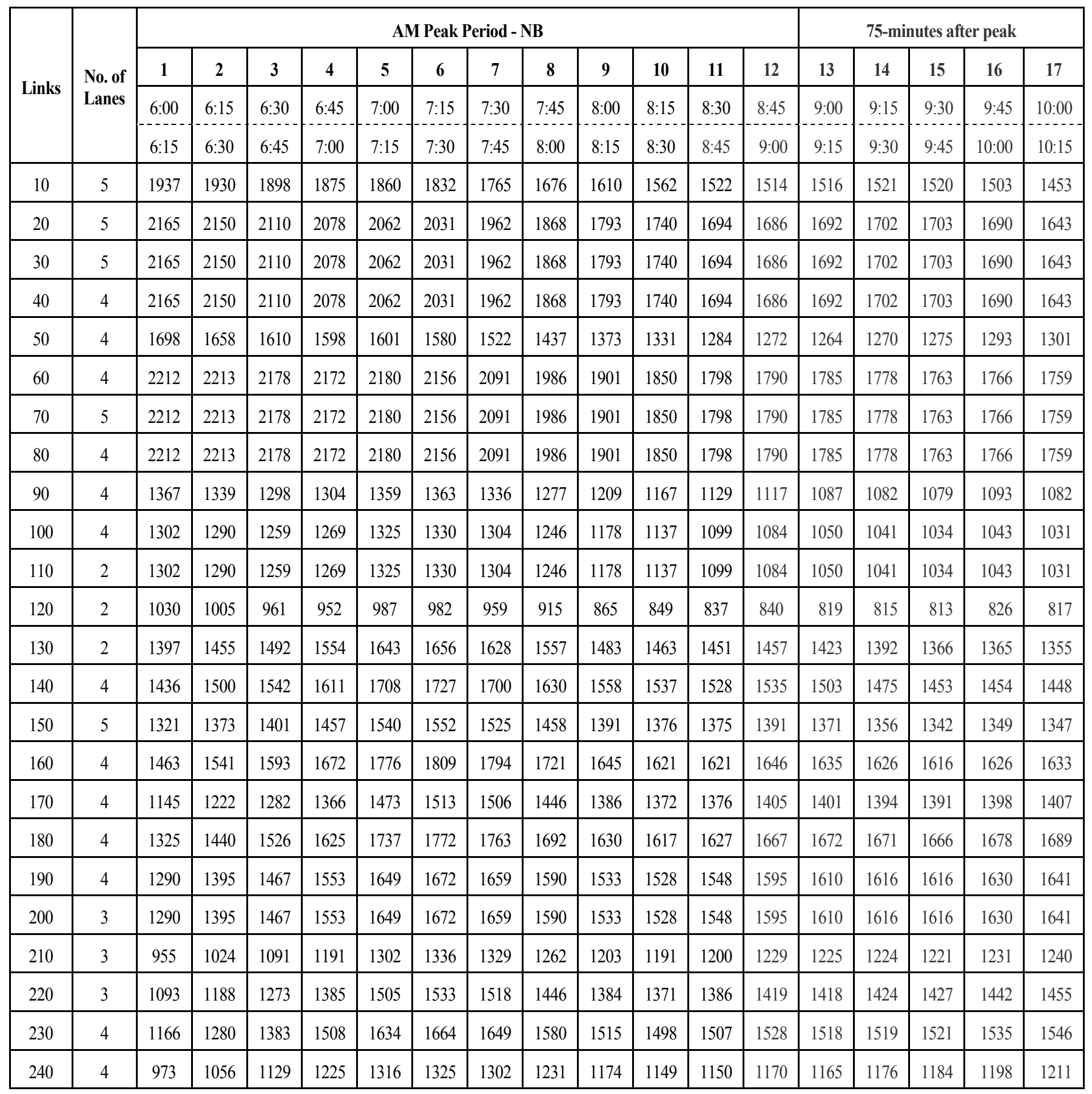


Table 23: I-5 Volumes SB During the AM Peak

\begin{tabular}{|c|c|c|c|c|c|c|c|c|c|c|c|c|c|c|c|c|c|c|}
\hline \multirow{4}{*}{ Links } & \multirow{4}{*}{$\begin{array}{l}\text { No. of } \\
\text { Lanes }\end{array}$} & \multicolumn{12}{|c|}{ AM Peak Period - SB } & \multicolumn{5}{|c|}{ 75-minutes after peak } \\
\hline & & 1 & 2 & 3 & 4 & 5 & 6 & 7 & 8 & 9 & 10 & 11 & 12 & 13 & 14 & 15 & 16 & 17 \\
\hline & & 6:00 & $6: 15$ & $6: 30$ & $6: 45$ & 7:00 & $7: 15$ & 7:30 & $7: 45$ & $8: 00$ & $\begin{array}{c}8: 15 \\
-\end{array}$ & $8: 30$ & $8: 45$ & 9:00 & $\begin{array}{c}9: 15 \\
-\end{array}$ & $9: 30$ & 9:45 & $10: 00$ \\
\hline & & $6: 15$ & $6: 30$ & $6: 45$ & 7:00 & $7: 15$ & $7: 30$ & $7: 45$ & $8: 00$ & $8: 15$ & $8: 30$ & $8: 45$ & 9:00 & $9: 15$ & $9: 30$ & $9: 45$ & $10: 00$ & $10: 15$ \\
\hline 255 & 4 & 1694 & 1725 & 1738 & 1706 & 1631 & 1550 & 1500 & 1475 & 1450 & 1400 & 1375 & 1350 & 1325 & 1313 & 1288 & 1288 & 1275 \\
\hline 245 & 4 & 1694 & 1725 & 1738 & 1706 & 1631 & 1550 & 1500 & 1475 & 1450 & 1400 & 1375 & 1350 & 1325 & 1313 & 1288 & 1288 & 1275 \\
\hline 235 & 4 & 1811 & 1855 & 1878 & 1854 & 1786 & 1710 & 1662 & 1635 & 1610 & 1564 & 1545 & 1531 & 1511 & 1500 & 1474 & 1479 & 1472 \\
\hline 225 & 4 & 1679 & 1710 & 1714 & 1669 & 1596 & 1518 & 1472 & 1455 & 1436 & 1408 & 1397 & 1396 & 1379 & 1369 & 1342 & 1344 & 1335 \\
\hline 215 & 4 & 1264 & 1261 & 1275 & 1259 & 1230 & 1189 & 1148 & 1135 & 1118 & 1093 & 1082 & 1073 & 1058 & 1056 & 1040 & 1048 & 1046 \\
\hline 205 & 4 & 1817 & 1893 & 1977 & 1999 & 1982 & 1905 & 1804 & 1745 & 1690 & 1632 & 1607 & 1583 & 1551 & 1537 & 1510 & 1513 & 1508 \\
\hline 195 & 4 & 1872 & 1962 & 2066 & 2108 & 2110 & 2043 & 1945 & 1881 & 1818 & 1749 & 1713 & 1678 & 1638 & 1616 & 1582 & 1582 & 1573 \\
\hline 185 & 4 & 1673 & 1745 & 1831 & 1858 & 1854 & 1783 & 1682 & 1615 & 1550 & 1489 & 1452 & 1419 & 1380 & 1358 & 1326 & 1323 & 1314 \\
\hline 175 & 4 & 1523 & 1575 & 1640 & 1646 & 1635 & 1564 & 1461 & 1394 & 1327 & 1269 & 1236 & 1203 & 1164 & 1141 & 1109 & 1107 & 1102 \\
\hline 165 & 4 & 1685 & 1762 & 1853 & 1885 & 1883 & 1817 & 1709 & 1628 & 1562 & 1500 & 1470 & 1435 & 1393 & 1367 & 1330 & 1326 & 1317 \\
\hline 155 & 5 & 1827 & 1941 & 2066 & 2128 & 2145 & 2090 & 1983 & 1895 & 1820 & 1750 & 1708 & 1662 & 1611 & 1576 & 1536 & 1531 & 1524 \\
\hline 145 & 4 & 1672 & 1764 & 1864 & 1902 & 1901 & 1836 & 1722 & 1632 & 1559 & 1506 & 1480 & 1452 & 1421 & 1400 & 1375 & 1381 & 1382 \\
\hline 135 & 3 & 1361 & 1420 & 1495 & 1511 & 1493 & 1412 & 1282 & 1182 & 1109 & 1074 & 1066 & 1063 & 1059 & 1058 & 1051 & 1069 & 1084 \\
\hline 125 & 3 & 734 & 737 & 765 & 756 & 731 & 658 & 555 & 488 & 450 & 448 & 475 & 502 & 525 & 556 & 570 & 605 & 636 \\
\hline 115 & 3 & 1217 & 1228 & 1254 & 1241 & 1211 & 1125 & 1012 & 933 & 885 & 881 & 901 & 919 & 917 & 909 & 882 & 878 & 885 \\
\hline 105 & 3 & 1864 & 1957 & 2044 & 2078 & 2074 & 1972 & 1818 & 1672 & 1563 & 1525 & 1531 & 1552 & 1554 & 1544 & 1509 & 1506 & 1524 \\
\hline 95 & 5 & 1864 & 1957 & 2044 & 2078 & 2074 & 1972 & 1818 & 1672 & 1563 & 1525 & 1531 & 1552 & 1554 & 1544 & 1509 & 1506 & 1524 \\
\hline 85 & 5 & 1864 & 1957 & 2044 & 2078 & 2074 & 1972 & 1818 & 1672 & 1563 & 1525 & 1531 & 1552 & 1554 & 1544 & 1509 & 1506 & 1524 \\
\hline 75 & 4 & 1804 & 1888 & 1969 & 1999 & 1988 & 1882 & 1727 & 1582 & 1474 & 1437 & 1446 & 1471 & 1479 & 1473 & 1441 & 1439 & 1458 \\
\hline 65 & 4 & 1554 & 1559 & 1619 & 1649 & 1638 & 1532 & 1372 & 1218 & 1094 & 1048 & 1054 & 1084 & 1100 & 1099 & 1071 & 1072 & 1093 \\
\hline 55 & 4 & 1708 & 1738 & 1811 & 1831 & 1844 & 1781 & 1628 & 1450 & 1359 & 1306 & 1318 & 1332 & 1346 & 1332 & 1339 & 1320 & 1364 \\
\hline 45 & 5 & 1757 & 1791 & 1873 & 1901 & 1922 & 1859 & 1706 & 1522 & 1427 & 1371 & 1381 & 1398 & 1410 & 1394 & 1399 & 1380 & 1424 \\
\hline 35 & 5 & 1757 & 1791 & 1873 & 1901 & 1922 & 1859 & 1706 & 1522 & 1427 & 1371 & 1381 & 1398 & 1410 & 1394 & 1399 & 1380 & 1424 \\
\hline 25 & 5 & 1757 & 1791 & 1873 & 1901 & 1922 & 1859 & 1706 & 1522 & 1427 & 1371 & 1381 & 1398 & 1410 & 1394 & 1399 & 1380 & 1424 \\
\hline 15 & 5 & 1536 & 1558 & 1631 & 1655 & 1673 & 1612 & 1471 & 1300 & 1212 & 1156 & 1165 & 1178 & 1195 & 1187 & 1199 & 1185 & 1233 \\
\hline
\end{tabular}


Table 24: I-5 Volumes NB During the PM Peak

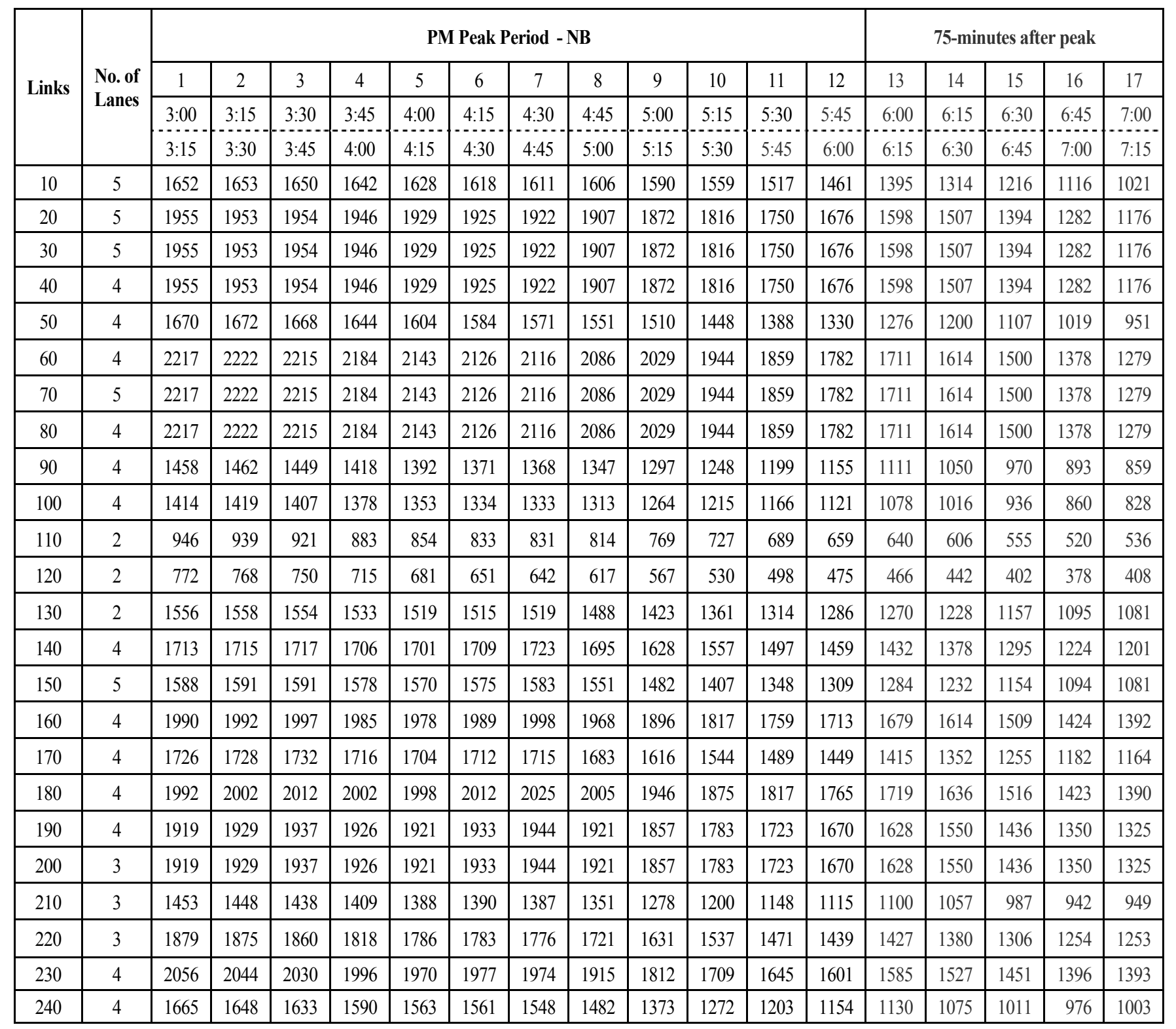


Table 25: I-5 Volumes SB During the PM Peak

\begin{tabular}{|c|c|c|c|c|c|c|c|c|c|c|c|c|c|c|c|c|c|c|}
\hline \multirow{4}{*}{ Links } & \multirow{4}{*}{$\begin{array}{l}\text { No. of } \\
\text { Lanes }\end{array}$} & \multicolumn{12}{|c|}{ PM Peak Period -SB } & \multicolumn{5}{|c|}{ 75-minutes after peak } \\
\hline & & 1 & 2 & 3 & 4 & 5 & 6 & 7 & 8 & 9 & 10 & 11 & 12 & 13 & 14 & 15 & 16 & 17 \\
\hline & & $3: 00$ & $3: 15$ & $3: 30$ & $3: 45$ & 4:00 & $4: 15$ & $4: 30$ & $4: 45$ & 5:00 & $5: 15$ & $5: 30$ & $5: 45$ & $6: 00$ & $6: 15$ & $6: 30$ & $6: 45$ & $7: 00$ \\
\hline & & $3: 15$ & $3: 30$ & $3: 45$ & 4:00 & $4: 15$ & $4: 30$ & $4: 45$ & $5: 00$ & $5: 15$ & $5: 30$ & $5: 45$ & $6: 00$ & $6: 15$ & $6: 30$ & $6: 45$ & 7:00 & $7: 15$ \\
\hline 255 & 4 & 1645 & 1652 & 1659 & 1666 & 1674 & 1666 & 1659 & 1645 & 1617 & 1588 & 1560 & 1532 & 1503 & 1475 & 1418 & 1376 & 1333 \\
\hline 245 & 4 & 1645 & 1652 & 1659 & 1666 & 1674 & 1666 & 1659 & 1645 & 1617 & 1588 & 1560 & 1532 & 1503 & 1475 & 1418 & 1376 & 1333 \\
\hline 235 & 4 & 1864 & 1867 & 1868 & 1875 & 1881 & 1876 & 1874 & 1859 & 1830 & 1801 & 1772 & 1744 & 1718 & 1689 & 1631 & 1586 & 1538 \\
\hline 225 & 4 & 1713 & 1704 & 1689 & 1695 & 1712 & 1707 & 1710 & 1694 & 1664 & 1633 & 1599 & 1574 & 1562 & 1536 & 1480 & 1432 & 1380 \\
\hline 215 & 4 & 1472 & 1464 & 1441 & 1445 & 1464 & 1457 & 1463 & 1448 & 1419 & 1393 & 1366 & 1352 & 1347 & 1322 & 1269 & 1225 & 1179 \\
\hline 205 & 4 & 1975 & 1948 & 1901 & 1869 & 1864 & 1844 & 1845 & 1814 & 1775 & 1737 & 1701 & 1695 & 1698 & 1676 & 1621 & 1566 & 1501 \\
\hline 195 & 4 & 2066 & 2040 & 1996 & 1966 & 1965 & 1950 & 1955 & 1925 & 1884 & 1839 & 1795 & 1783 & 1780 & 1752 & 1691 & 1630 & 1559 \\
\hline 185 & 4 & 1765 & 1735 & 1679 & 1639 & 1630 & 1612 & 1615 & 1586 & 1540 & 1494 & 1455 & 1447 & 1449 & 1425 & 1374 & 1320 & 1263 \\
\hline 175 & 4 & 1554 & 1528 & 1478 & 1442 & 1435 & 1416 & 1414 & 1380 & 1326 & 1275 & 1230 & 1215 & 1209 & 1182 & 1133 & 1085 & 1042 \\
\hline 165 & 4 & 1910 & 1888 & 1854 & 1827 & 1829 & 1823 & 1822 & 1785 & 1719 & 1649 & 1584 & 1540 & 1510 & 1452 & 1375 & 1309 & 1251 \\
\hline 155 & 5 & 2244 & 2224 & 2191 & 2164 & 2169 & 2165 & 2170 & 2134 & 2069 & 2000 & 1928 & 1870 & 1819 & 1738 & 1638 & 1549 & 1473 \\
\hline 145 & 4 & 2119 & 2101 & 2071 & 2048 & 2055 & 2050 & 2052 & 2013 & 1943 & 1868 & 1791 & 1729 & 1673 & 1588 & 1488 & 1405 & 1344 \\
\hline 135 & 3 & 1830 & 1825 & 1802 & 1789 & 1797 & 1789 & 1786 & 1747 & 1678 & 1608 & 1537 & 1473 & 1418 & 1341 & 1251 & 1184 & 1143 \\
\hline 125 & 3 & 1320 & 1306 & 1272 & 1245 & 1236 & 1209 & 1183 & 1123 & 1045 & 974 & 917 & 882 & 862 & 825 & 776 & 751 & 743 \\
\hline 115 & 3 & 1320 & 1306 & 1272 & 1245 & 1236 & 1209 & 1183 & 1123 & 1045 & 974 & 917 & 882 & 862 & 825 & 776 & 751 & 743 \\
\hline 105 & 3 & 2207 & 2196 & 2162 & 2138 & 2139 & 2113 & 2086 & 2019 & 1927 & 1842 & 1767 & 1707 & 1662 & 1605 & 1536 & 1488 & 1453 \\
\hline 95 & 5 & 2207 & 2196 & 2162 & 2138 & 2139 & 2113 & 2086 & 2019 & 1927 & 1842 & 1767 & 1707 & 1662 & 1605 & 1536 & 1488 & 1453 \\
\hline 85 & 5 & 2207 & 2196 & 2162 & 2138 & 2139 & 2113 & 2086 & 2019 & 1927 & 1842 & 1767 & 1707 & 1662 & 1605 & 1536 & 1488 & 1453 \\
\hline 75 & 4 & 2152 & 2146 & 2116 & 2097 & 2103 & 2082 & 2056 & 1988 & 1894 & 1807 & 1729 & 1664 & 1611 & 1549 & 1481 & 1439 & 1413 \\
\hline 65 & 4 & 1782 & 1779 & 1749 & 1727 & 1729 & 1705 & 1674 & 1600 & 1496 & 1402 & 1321 & 1254 & 1201 & 1138 & 1072 & 1036 & 1019 \\
\hline 55 & 4 & 2177 & 2183 & 2165 & 2132 & 2121 & 2088 & 2049 & 1955 & 1827 & 1706 & 1593 & 1498 & 1423 & 1337 & 1252 & 1198 & 1166 \\
\hline 45 & 5 & 2291 & 2306 & 2296 & 2266 & 2260 & 2227 & 2189 & 2091 & 1956 & 1830 & 1706 & 1603 & 1519 & 1423 & 1330 & 1270 & 1232 \\
\hline 35 & 5 & 2291 & 2306 & 2296 & 2266 & 2260 & 2227 & 2189 & 2091 & 1956 & 1830 & 1706 & 1603 & 1519 & 1423 & 1330 & 1270 & 1232 \\
\hline 25 & 5 & 2291 & 2306 & 2296 & 2266 & 2260 & 2227 & 2189 & 2091 & 1956 & 1830 & 1706 & 1603 & 1519 & 1423 & 1330 & 1270 & 1232 \\
\hline 15 & 5 & 2083 & 2099 & 2087 & 2055 & 2048 & 2016 & 1979 & 1884 & 1758 & 1637 & 1524 & 1431 & 1352 & 1265 & 1180 & 1127 & 1097 \\
\hline
\end{tabular}




\subsubsection{Scenario B - Without TDM}

VTR due to TDM programs implemented by 189 employers were distributed and assigned to the network as discussed in Section 3.4 and 3.5 of the report. The trips reduced because of CTR programs were distributed across the 12 time periods of each 3-hour peak. These trips were 4.16 percent of the total trips made during the AM peak within the network and 3.48 percent of the total trips during the PM peak. Tables 26 and 27 show the distribution of the added trips for the AM and PM peak periods. The distribution of these trips was in proportion of the traffic volume during the peak period and provided the number of trips entering and exiting the network in each time period and their location on the network. The percentage of HOV vehicles and origin-destination of trips was calculated after adding the additional trips (reduced by TDM program) to the network.

Table 26: Origin-Destination of Reduced Trips in AM Peak

\begin{tabular}{|c|c|c|c|c|c|c|c|c|c|c|c|c|}
\hline \multirow{2}{*}{$\begin{array}{c}\text { NB } \\
\text { On-ramps }\end{array}$} & \multicolumn{12}{|c|}{ NB Off-ramps } \\
\hline & Spokane & I-90 & $4^{\text {th }}$ Ave & Seneca & Olive & & Mercer & $\begin{array}{l}\text { Lake- } \\
\text { view }\end{array}$ & SR 520 & $\mathrm{NE} 45^{\text {th }}$ & $\mathrm{I}-5$ & Total \\
\hline $\mathrm{I}-5$ & 34 & 28 & 186 & 947 & 120 & & 0 & 25 & 6 & 0 & 0 & 1346 \\
\hline Corson & 0 & 4 & 18 & 108 & 17 & & 0 & 5 & 2 & 0 & 0 & 154 \\
\hline Spokane & - & 4 & 9 & 99 & 17 & & 0 & 3 & 0 & 0 & 0 & 132 \\
\hline $\mathrm{I}-90$ & - & - & - & - & 305 & & 0 & 2 & 1 & 0 & 0 & 308 \\
\hline University & - & - & - & - & 4 & & 0 & 1 & 0 & 0 & 0 & 5 \\
\hline Olive & - & - & - & - & - & & 0 & 0 & 0 & 0 & 0 & 0 \\
\hline Mercer & - & - & - & - & - & & - & 6 & 1 & 0 & 0 & 7 \\
\hline SR 520 & - & - & - & - & - & & - & - & - & 0 & 0 & 0 \\
\hline Harvard & - & - & - & - & - & & - & - & - & 0 & 0 & 0 \\
\hline Total & 34 & 36 & 213 & 1154 & 463 & & 0 & 42 & 10 & 0 & 0 & 1952 \\
\hline \multirow{2}{*}{$\begin{array}{c}\text { SB } \\
\text { On-ramps }\end{array}$} & \multicolumn{12}{|c|}{ SB Off-ramps } \\
\hline & Boylston & $\begin{array}{l}\text { SR } \\
520\end{array}$ & Mercer & Stewart & Union & $\begin{array}{l}6^{\text {th }} \\
\text { Ave }\end{array}$ & I-90 & Forest & Spokan & Corson & $\mathrm{I}-5$ & Total \\
\hline $\mathrm{I}-5$ & 0 & 104 & 135 & 428 & 913 & 255 & 31 & 1 & 15 & 0 & 0 & 1882 \\
\hline $\mathrm{NE} 45^{\text {th }}$ & 0 & 0 & 0 & 0 & 0 & 0 & 0 & 0 & 0 & 0 & 0 & 0 \\
\hline SR 520 & - & - & 18 & 33 & 84 & 17 & 0 & 0 & 0 & 0 & 0 & 152 \\
\hline Boylston & - & - & 12 & 30 & 55 & 14 & 2 & 0 & 0 & 0 & 0 & 113 \\
\hline Mercer & - & - & - & - & 20 & 14 & 3 & 0 & 1 & 0 & 0 & 38 \\
\hline Yale & - & - & - & - & 0 & 0 & 1 & 0 & 1 & 0 & 0 & 2 \\
\hline $\mathrm{I}-90$ & - & - & - & - & - & - & - & 0 & 0 & 0 & 0 & 0 \\
\hline $6^{\text {th }}$ Ave & - & - & - & - & - & - & - & - & - & 4 & 0 & 0 \\
\hline Spokane & - & - & - & - & - & - & - & - & - & 0 & 0 & 4 \\
\hline Total & 0 & 104 & 165 & 491 & 1072 & 300 & 37 & 1 & 17 & 4 & 0 & 2191 \\
\hline
\end{tabular}


As seen in Table 26, approximately 69 percent of total trips (1346 of 1952) enter the network from the south end of NB I-5 while 86 percent of total trips (1882 of 2193) enter the network from the north end of SB I-5. The majority of these added trips leave the network from offramps located closest to the employer worksites. On NB I-5, 1617 trips exit from Seneca and Olive off-ramps that are closest to employer worksites. Similarly on SB I-5, 1863 trips exit from Stewart, Union, and $6^{\text {th }}$ Avenue off-ramps.

Table 27: Origin-destination of Reduced Trips during PM Peak

\begin{tabular}{|c|c|c|c|c|c|c|c|c|c|c|c|c|c|c|}
\hline \multirow{2}{*}{$\begin{array}{c}\text { NB } \\
\text { On- } \\
\text { ramps }\end{array}$} & \multicolumn{14}{|c|}{ NB Off-ramps } \\
\hline & Spokane & $\mathrm{I}-90$ & \multicolumn{2}{|c|}{$4^{\text {th }}$ Ave } & \multicolumn{2}{|c|}{ Seneca } & Olive & \multicolumn{2}{|c|}{ Mercer } & $\begin{array}{l}\text { Lake- } \\
\text { view }\end{array}$ & $\begin{array}{l}\text { SR } \\
520\end{array}$ & $\begin{array}{l}\mathrm{NE} \\
45^{\text {th }}\end{array}$ & $\mathrm{I}-5$ & Total \\
\hline $\mathrm{I}-5$ & 0 & 0 & \multicolumn{2}{|c|}{0} & \multicolumn{2}{|c|}{0} & 0 & \multicolumn{2}{|c|}{0} & 0 & 0 & 0 & 0 & 0 \\
\hline Corson & 0 & 0 & \multicolumn{2}{|c|}{0} & \multicolumn{2}{|c|}{0} & 0 & \multicolumn{2}{|c|}{0} & 0 & 0 & 0 & 0 & 0 \\
\hline Spokane & - & \multicolumn{2}{|l|}{3} & 0 & \multicolumn{2}{|c|}{1} & 0 & \multicolumn{2}{|c|}{0} & 1 & 0 & 0 & 15 & 20 \\
\hline $\mathrm{I}-90$ & - & - & \multicolumn{2}{|c|}{-} & \multicolumn{2}{|c|}{ - } & 7 & 0 & & 7 & 2 & 0 & 57 & 73 \\
\hline University & - & - & - & & - & & 0 & 0 & & 74 & 102 & 0 & 1026 & 1202 \\
\hline Olive & - & - & - & & - & & - & 0 & & 40 & 39 & 0 & 432 & 511 \\
\hline Mercer & - & - & - & & - & & - & - & & 27 & 32 & 0 & 213 & 272 \\
\hline SR 520 & - & - & . & & - & & - & - & & - & - & 0 & 35 & 35 \\
\hline Harvard & - & - & - & & - & & - & - & & - & - & 0 & 90 & 90 \\
\hline Total & $\mathbf{0}$ & 3 & 0 & & 1 & & 7 & $\mathbf{0}$ & & 149 & 175 & $\mathbf{0}$ & 1868 & 2203 \\
\hline SB & & & & & & & & SB Off-rc & mps & & & & & \\
\hline $\begin{array}{c}\text { On- } \\
\text { ramps }\end{array}$ & Boylston & $\begin{array}{l}\text { SR } \\
520 \\
\end{array}$ & Mercer & Stev & vart & Uni & & $6^{\text {th }}$ Ave & $\begin{array}{l}\text { I- } \\
90 \\
\end{array}$ & Forest & Spokan & Corson & $\mathrm{I}-5$ & Total \\
\hline I-5 & 0 & 0 & 0 & c & 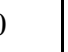 & 0 & & 0 & 0 & 0 & 0 & 0 & 0 & 0 \\
\hline $\mathrm{NE} 45^{\text {th }}$ & 0 & 0 & 0 & 0 & ) & 0 & & 0 & 0 & 0 & 0 & 0 & 0 & 0 \\
\hline SR 520 & - & - & 0 & 0 & ) & 0 & & 0 & 1 & 0 & 0 & 1 & 1 & 3 \\
\hline Boylston & - & - & 3 & 0 & 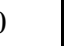 & 0 & & 0 & 2 & 0 & 2 & 2 & 11 & 20 \\
\hline Mercer & - & - & - & 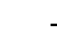 & . & 0 & & 0 & 10 & 0 & 5 & 6 & 33 & 54 \\
\hline Yale & - & - & - & 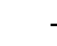 & . & 5 & & 4 & 58 & 0 & 24 & 43 & 345 & 479 \\
\hline $\mathrm{I}-90$ & - & - & - & 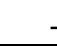 & - & - & & - & - & 0 & 0 & 0 & 0 & 0 \\
\hline $6^{\text {th }}$ Ave & - & - & - & - & 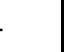 & - & & - & - & - & - & 102 & 917 & 1019 \\
\hline Spokane & - & - & - & 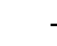 & . & - & & - & - & - & - & 0 & 34 & 34 \\
\hline Total & 0 & 0 & 3 & 0 & 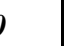 & 5 & & 4 & 71 & 0 & 31 & 154 & 1341 & 1609 \\
\hline
\end{tabular}

As seen in Table 27, the distribution of the added trips during the PM peak indicates that the majority of the trips enter the network from on-ramps located closest to the employer worksites. On NB I-5, 90 percent of total trips (1985 of 2203) enter the network from University, Olive, and Mercer on-ramps. Similarly, 93 percent of total trips (1498 of 1609) enter the network from Yale and 6th Avenue on-ramps on SB I-5.

These trips reduced by TDM programs of 189 employers during the peak periods as shown in Table 26 and Table 27, were used to determine the trips that need to be added on each link of 
the network in the scenario without TDM Programs. Table 28 shows the number of trips that were added to each link of the network for AM and PM peaks. During the AM peak, the majority of the added trips on NB I-5 affected the volume on links 10 through 110, which are located between the center of the network and the south end of NB I-5. On SB I-5, the majority of added trips affected the volume on links 255 through 155, which are located between the center of the network and the north end of SB I-5.

Table 28: Additional Volumes on Links in the Without TDM Scenario

\begin{tabular}{|c|c|c|c|c|c|c|c|c|c|c|c|}
\hline \multicolumn{6}{|c|}{ AM Peak } & \multicolumn{6}{|c|}{ PM Peak } \\
\hline \multicolumn{3}{|c|}{ NORTHBOUND } & \multicolumn{3}{|c|}{ SOUTHBOUND } & \multicolumn{3}{|c|}{ NORTHBOUND } & \multicolumn{3}{|c|}{ SOUTHBOUND } \\
\hline Links & $\begin{array}{c}\text { Added } \\
\text { Volume }\end{array}$ & $\begin{array}{c}\% \text { of } \\
\text { Original } \\
\text { Volume }\end{array}$ & Links & $\begin{array}{c}\text { Added } \\
\text { Volume }\end{array}$ & $\begin{array}{c}\% \text { of } \\
\text { Original } \\
\text { Volume }\end{array}$ & Links & $\begin{array}{c}\text { Added } \\
\text { Volume }\end{array}$ & $\begin{array}{c}\% \text { of } \\
\text { Original } \\
\text { Volume }\end{array}$ & Links & $\begin{array}{c}\text { Added } \\
\text { Volume }\end{array}$ & $\begin{array}{l}\% \text { of } \\
\text { Original } \\
\text { Volume }\end{array}$ \\
\hline 10 & 1345 & 6.4 & 255 & 1881 & 10.1 & 10 & 0 & 0.0 & 255 & 0 & 0.0 \\
\hline 20 & 1498 & 6.4 & 245 & 1881 & 10.1 & 20 & 0 & 0.0 & 245 & 0 & 0.0 \\
\hline 30 & 1498 & 6.4 & 235 & 1881 & 9.2 & 30 & 0 & 0.0 & 235 & 0 & 0.0 \\
\hline 40 & 1498 & 6.4 & 225 & 1881 & 10.2 & 40 & 0 & 0.0 & 225 & 0 & 0.0 \\
\hline 50 & 1465 & 8.2 & 215 & 1778 & 12.6 & 50 & 0 & 0.0 & 215 & 0 & 0.0 \\
\hline 60 & 1596 & 6.5 & 205 & 1928 & 8.9 & 60 & 18 & 0.1 & 205 & 1 & 0.0 \\
\hline 70 & 1596 & 6.5 & 195 & 2039 & 8.9 & 70 & 18 & 0.1 & 195 & 20 & 0.1 \\
\hline 80 & 1596 & 6.5 & 185 & 1875 & 9.4 & 80 & 18 & 0.1 & 185 & 18 & 0.1 \\
\hline 90 & 1561 & 10.2 & 175 & 1386 & 7.9 & 90 & 16 & 0.1 & 175 & 18 & 0.1 \\
\hline 100 & 1349 & 9.1 & 165 & 1423 & 7.0 & 100 & 16 & 0.1 & 165 & 70 & 0.3 \\
\hline 110 & 1349 & 9.1 & 155 & 1423 & 6.2 & 110 & 16 & 0.2 & 155 & 548 & 2.2 \\
\hline 120 & 197 & 1.8 & 145 & 352 & 1.7 & 120 & 16 & 0.2 & 145 & 545 & 2.3 \\
\hline 130 & 503 & 2.8 & 135 & 54 & 0.3 & 130 & 87 & 0.5 & 135 & 542 & 2.6 \\
\hline 140 & 507 & 2.7 & 125 & 19 & 0.3 & 140 & 1287 & 6.5 & 125 & 473 & 3.4 \\
\hline 150 & 45 & 0.3 & 115 & 19 & 0.1 & 150 & 1281 & 7.1 & 115 & 473 & 3.4 \\
\hline 160 & 45 & 0.2 & 105 & 19 & 0.1 & 160 & 1791 & 7.8 & 105 & 473 & 1.9 \\
\hline 170 & 45 & 0.3 & 95 & 19 & 0.1 & 170 & 1791 & 9.0 & 95 & 473 & 1.9 \\
\hline 180 & 51 & 0.3 & 85 & 19 & 0.1 & 180 & 2062 & 8.8 & 85 & 473 & 1.9 \\
\hline 190 & 10 & 0.1 & 75 & 19 & 0.1 & 190 & 1914 & 8.5 & 75 & 473 & 2.0 \\
\hline 200 & 10 & 0.1 & 65 & 3 & 0.0 & 200 & 1914 & 8.5 & 65 & 444 & 2.3 \\
\hline 210 & 1 & 0.0 & 55 & 6 & 0.0 & 210 & 1740 & 10.9 & 55 & 1461 & 6.2 \\
\hline 220 & 1 & 0.0 & 45 & 6 & 0.0 & 220 & 1774 & 8.6 & 45 & 1494 & 6.0 \\
\hline 230 & 1 & 0.0 & 35 & 6 & 0.0 & 230 & 1863 & 8.2 & 35 & 1494 & 6.0 \\
\hline 240 & 1 & 0.0 & 25 & 6 & 0.0 & 240 & 1863 & 10.5 & 25 & 1494 & 6.0 \\
\hline- & - & - & 15 & 3 & 0.0 & - & - & - & 15 & 1342 & 5.9 \\
\hline
\end{tabular}


During the PM peak period, the added trips on NB I-5 affect the volume on links 140 through 240 , which are located between the center of the network and the north end of NB I-5. On SB I-5, added trips affected the volume on links 125 through 15 located between the center of the network and the south end of SB I-5. Table 28 shows that the impact of added trips was not uniform throughout the network but varied from no impact on certain links to as high as 12.6 percent on other links during the AM peak and 10.9 percent during the PM peak period. 


\section{Chapter 5 - Performance Measures With TDM and Without TDM}

The summary of the results of microscopic simulation analysis are shown in Table 29. The findings were a significant reduction in recurring delay, a reduction in spatial and temporal extent of congestion, and lesser emissions due to TDM programs. In addition, TDM programs resulted in fuel savings, VMT reduction, and an increase in the average speed of the corridor. These results indicate that TDM had significant impact on the performance of the transportation corridor. The next subsections will detail the definition of each performance measure and the analysis results.

Table 29: Summary of Performance Measures

\begin{tabular}{|c|c|c|}
\hline Performance Measures & AM Period & PM Period \\
\hline Delay Savings (veh-mins) & 152,489 & 169,486 \\
\hline Spatial Congestion Reduction & 101.7 lane-miles & 142.9 lane-miles \\
\hline Temporal Congestion Reduction & 60 minutes & 45 minutes \\
\hline Average Speed Increase (mph) & Up to $19 \mathrm{mph}$ & Up to $11 \mathrm{mph}$ \\
\hline VMT Reduction (veh-miles) & $17,297.4$ & $14,510.6$ \\
\hline Fuel Savings (gals) & 3,489 & 4,314 \\
\hline HC Emissions Reduction (kgs) & 16.4 & 21.7 \\
\hline CO Emissions Reduction (kgs) & $1,109.2$ & $1,545.1$ \\
\hline NO Emissions Reduction (kgs) & 54.3 & 67.9 \\
\hline
\end{tabular}

\subsection{Average Recurring Delay}

Average recurring delay is the average delay in seconds per vehicle encountered by each vehicle on a section of roadway within a given time period. Delay is calculated as actual time taken by a vehicle to traverse a section of roadway minus the time it would have taken if it were traveling at free-flow speed. The delay was calculated for each of the 17 times on each link on the I-5 corridor. Table 30 shows the difference in the average delay between With TDM and Without TDM scenarios for the AM period. A positive value in the " $\Delta$ Average delay" column indicates more of an average delay in Without TDM than With TDM. On the other hand, a negative value (shaded cells in Table) is a less average delay in Without TDM than With TDM).

The table shows change in the average delay ranging from 124.7 seconds per vehicle on link 10 to -0.6 seconds per vehicle on link 110 on NB I-5. The change in average delay on SB I-5 ranged from 36.5 seconds per vehicle on link 205 to -16.9 seconds per vehicle on link 115 . The Table shows that in scenario B the majority of increase in delay, when compared with scenario A, during the AM period occurred on the southern portion (links 10 through 40) of NB I-5 and the northern portion of the SB I-5 (links 255 through 245 and links 215 through $195)$. 
Table 30: Difference in AM Peak Average Delay With TDM and Without TDM

\begin{tabular}{|c|c|c|c|c|c|c|c|}
\hline \multicolumn{4}{|c|}{ NORTHBOUND I-5 } & \multicolumn{4}{|c|}{ SOUTHBOUND I-5 } \\
\hline Link & $\begin{array}{l}\text { \# of vehicles } \\
\text { With TDM }\end{array}$ & $\begin{array}{c}\text { \# of Vehicles } \\
\text { Without TDM }\end{array}$ & $\begin{array}{c}\Delta \text { Average Delay } \\
\text { (secs/vehicle) }\end{array}$ & Link & $\begin{array}{l}\text { \# of vehicles } \\
\text { With TDM }\end{array}$ & $\begin{array}{c}\text { \# of Vehicles } \\
\text { Without TDM }\end{array}$ & $\begin{array}{c}\Delta \text { Average Delay } \\
\text { (secs/vehicle) }\end{array}$ \\
\hline 10 & 28491 & 29835 & 124.7 & 255 & 25081 & 25845 & 28.7 \\
\hline 20 & 31804 & 33311 & 27.6 & 245 & 25159 & 25604 & 10.6 \\
\hline 30 & 31822 & 33341 & 12.0 & 235 & 27998 & 28266 & 1.1 \\
\hline 40 & 31827 & 33243 & 13.1 & 225 & 25369 & 25782 & 0.0 \\
\hline 50 & 24751 & 26137 & 1.6 & 215 & 19612 & 20139 & 25.2 \\
\hline 60 & 33797 & 35153 & 0.0 & 205 & 29503 & 30170 & 36.5 \\
\hline 70 & 33805 & 35157 & 0.5 & 195 & 31191 & 31965 & 18.6 \\
\hline 80 & 33811 & 35150 & 0.2 & 185 & 26794 & 27460 & 2.6 \\
\hline 90 & 20749 & 22331 & 0.1 & 175 & 23244 & 23724 & 0.0 \\
\hline 100 & 20066 & 21405 & -0.2 & 165 & 27068 & 27593 & 0.1 \\
\hline 110 & 20082 & 21408 & -0.6 & 155 & 30944 & 31465 & 0.0 \\
\hline 120 & 15439 & 15492 & 0.5 & 145 & 27399 & 27129 & -0.1 \\
\hline 130 & 25303 & 25644 & 0.7 & 135 & 20852 & 20569 & -0.1 \\
\hline 140 & 26505 & 26821 & 0.0 & 125 & 10290 & 10320 & -3.5 \\
\hline 150 & 24111 & 24223 & 0.0 & 115 & 17385 & 17402 & -16.9 \\
\hline 160 & 28203 & 28310 & 0.0 & 105 & 29415 & 29435 & 0.2 \\
\hline 170 & 23758 & 23891 & 0.1 & 95 & 29421 & 29451 & 0.1 \\
\hline 180 & 28067 & 28184 & 0.1 & 85 & 29423 & 29451 & 0.1 \\
\hline 190 & 26569 & 26650 & 0.1 & 75 & 28204 & 28205 & 0.0 \\
\hline 200 & 26575 & 26629 & 0.3 & 65 & 22015 & 22067 & 0.1 \\
\hline 210 & 20453 & 20503 & 0.1 & 55 & 25967 & 26039 & 0.0 \\
\hline 220 & 23658 & 23707 & 0.0 & 45 & 27082 & 27151 & 0.0 \\
\hline 230 & 25544 & 25583 & 0.2 & 35 & 27082 & 27151 & 0.0 \\
\hline \multirow[t]{2}{*}{240} & 20133 & 20067 & 0.2 & 25 & 27079 & 27157 & 0.0 \\
\hline & & & & 15 & 23408 & 23414 & -0.2 \\
\hline
\end{tabular}

Table 31 shows the difference in the average delay between With TDM and Without TDM scenarios for the PM period. A positive value in the " $\Delta$ Average delay" column indicates more average delay in Without TDM than With TDM. On the other hand, a negative value (shaded cells in Table) is a less average delay in Without TDM than With TDM). 
The Table shows change in the average delay ranging from 91.1 seconds per vehicle on link 150 to -0.5 seconds per vehicle on link 110 on NB I-5. The change in average delay on SB I5 ranged from 38.7 seconds per vehicle on link 185 to -3.7 seconds per vehicle on link 255 . The table shows that in scenario B the majority of increase in delay, when compared with scenario A, during the PM period occurred on the central portion of the network, i.e., links 130 through 190 of the NB I-5 and on links 185 through 55 of the SB I-5.

Table 31: Difference in PM Peak Average Delay With TDM and Without TDM

\begin{tabular}{|c|c|c|c|c|c|c|c|}
\hline \multicolumn{4}{|c|}{ NORTHBOUND I-5 } & \multicolumn{4}{|c|}{ SOUTHBOUND I-5 } \\
\hline Link & $\begin{array}{c}\text { \# of vehicles } \\
\text { With TDM }\end{array}$ & $\begin{array}{c}\text { \# of Vehicles } \\
\text { Without TDM }\end{array}$ & $\begin{array}{c}\Delta \text { Average Delay } \\
\text { (secs/vehicle) }\end{array}$ & Link & $\begin{array}{c}\text { \# of vehicles } \\
\text { With TDM }\end{array}$ & $\begin{array}{c}\text { \# of Vehicles } \\
\text { Without TDM }\end{array}$ & $\begin{array}{c}\Delta \text { Average Delay } \\
\text { (secs/vehicle) }\end{array}$ \\
\hline 10 & 25248 & 25248 & 0.0 & 255 & 26668 & 26668 & -3.7 \\
\hline 20 & 29611 & 29616 & 0.0 & 245 & 26724 & 26728 & -1.5 \\
\hline 30 & 29643 & 29636 & 0.0 & 235 & 30343 & 30338 & -0.2 \\
\hline 40 & 29645 & 29650 & 0.1 & 225 & 27668 & 27656 & 0.0 \\
\hline 50 & 24182 & 24301 & 0.1 & 215 & 23799 & 23865 & 0.0 \\
\hline 60 & 32432 & 32563 & 0.0 & 205 & 30319 & 30375 & 0.0 \\
\hline 70 & 32451 & 32587 & 0.0 & 195 & 31880 & 31944 & 1.6 \\
\hline 80 & 32493 & 32638 & 0.1 & 185 & 26271 & 26331 & 38.7 \\
\hline 90 & 21113 & 21198 & 0.0 & 175 & 22625 & 22714 & 16.5 \\
\hline 100 & 20440 & 20554 & -0.1 & 165 & 28407 & 28549 & 33.0 \\
\hline 110 & 12685 & 12737 & -0.5 & 155 & 33850 & 34456 & 8.5 \\
\hline 120 & 9711 & 9810 & 0.7 & 145 & 31653 & 32126 & 2.0 \\
\hline 130 & 23419 & 23583 & 11.0 & 135 & 27293 & 27766 & 1.5 \\
\hline 140 & 26326 & 27698 & 5.8 & 125 & 17749 & 18190 & 0.3 \\
\hline 150 & 24095 & 25315 & 91.1 & 115 & 17761 & 18202 & 21.3 \\
\hline 160 & 30771 & 31455 & 8.3 & 105 & 32185 & 32623 & 3.6 \\
\hline 170 & 26484 & 27115 & 35.0 & 95 & 32208 & 32641 & 6.5 \\
\hline 180 & 31448 & 32355 & 8.7 & 85 & 32218 & 32648 & 11.9 \\
\hline 190 & 29711 & 30652 & 6.8 & 75 & 31467 & 31919 & 10.2 \\
\hline 200 & 29731 & 30680 & 1.6 & 65 & 24862 & 25392 & 34.9 \\
\hline 210 & 20965 & 21931 & 1.3 & 55 & 30071 & 31616 & 7.9 \\
\hline 220 & 27140 & 28128 & 0.4 & 45 & 32021 & 33586 & 2.3 \\
\hline 230 & 30028 & 31111 & 1.3 & 35 & 32043 & 33599 & 2.2 \\
\hline 240 & 22823 & 24196 & 0.3 & 25 & 32058 & 33625 & 0.2 \\
\hline & & & & 15 & 28762 & 30171 & 0.5 \\
\hline
\end{tabular}


In the Without TDM scenario, the increase in delay occurred on the southern portion of NB I-5 and northern portion of SB I-5 during the AM period and on the central portion of the network during the PM period. This was found consistent with location of impact of the TDM programs on the number of trips on each link, as seen in Table 31.

\subsection{Recurring Delay}

Recurring delay is the cumulative delay encountered by all the vehicles on a section of roadway during a predefined time period. Delay is calculated as the actual time taken by a vehicle to traverse a section of roadway minus the time it would have taken if it were traveling at free-flow speed. Figure 13 and Figure 14 compare the AM recurring delay of the With TDM and Without TDM scenarios for NB I-5 and SB I-5, respectively.

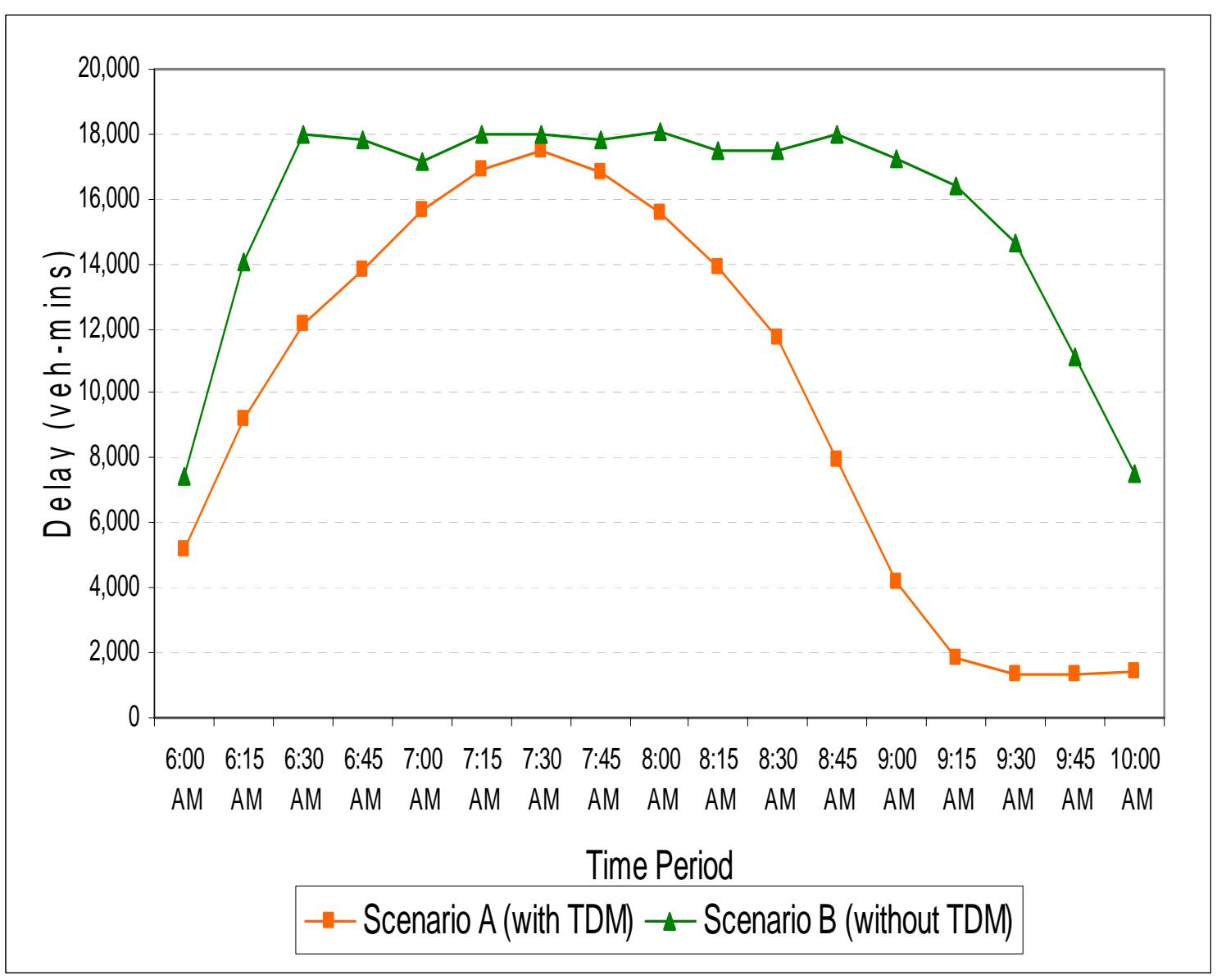

Figure 13: AM Recurring Delay on NB I-5 


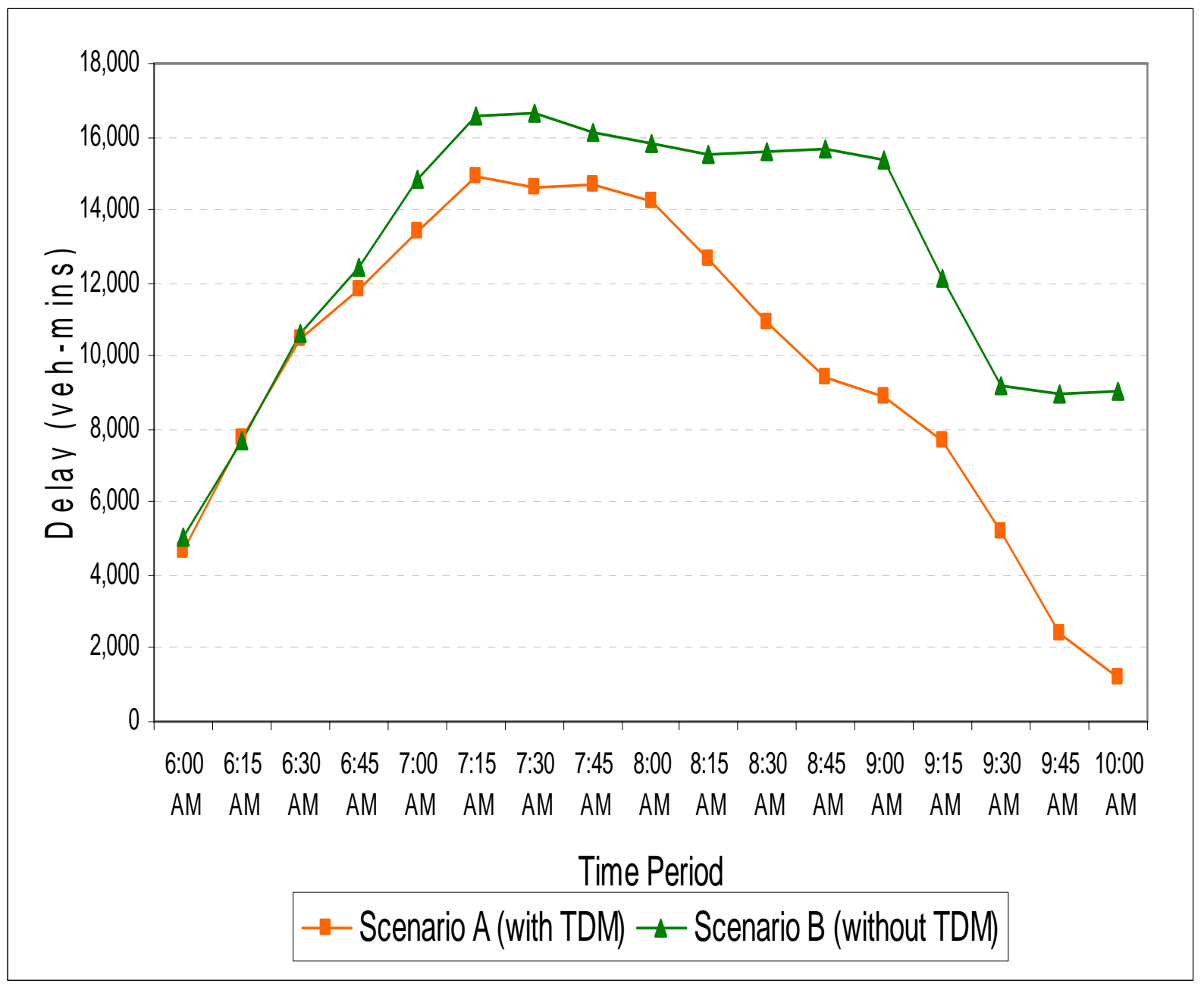

Figure 14: AM Recurring Delay on SB I-5

The horizontal axis represents the 17 time periods of 15 minutes each, while the vertical axis shows total recurring delay accumulated in vehicle-minutes. As seen in the figures, Without TDM has significantly more delay than With TDM, particularly for the time periods after 8:00 AM because of capacity constraint on the freeway mainline. The vehicle trips that entered the network before 8:00 AM in Without TDM encountered more delay as compared to With TDM, resulting in increased delay even after 8:00 AM.

Figures 15 and 16 compare the PM recurring delay of the With TDM and Without TDM scenarios for NB I-5 and SB I-5, respectively. The increase in delay in Without TDM was significant for the entire PM periods, except for the last 15-minute interval on NB and the last 45 minutes on the SB. Without TDM had more recurring delay of 169,486 vehicle minutes during the PM period and 152,489 vehicle minutes during the AM period, compared to With TDM. 


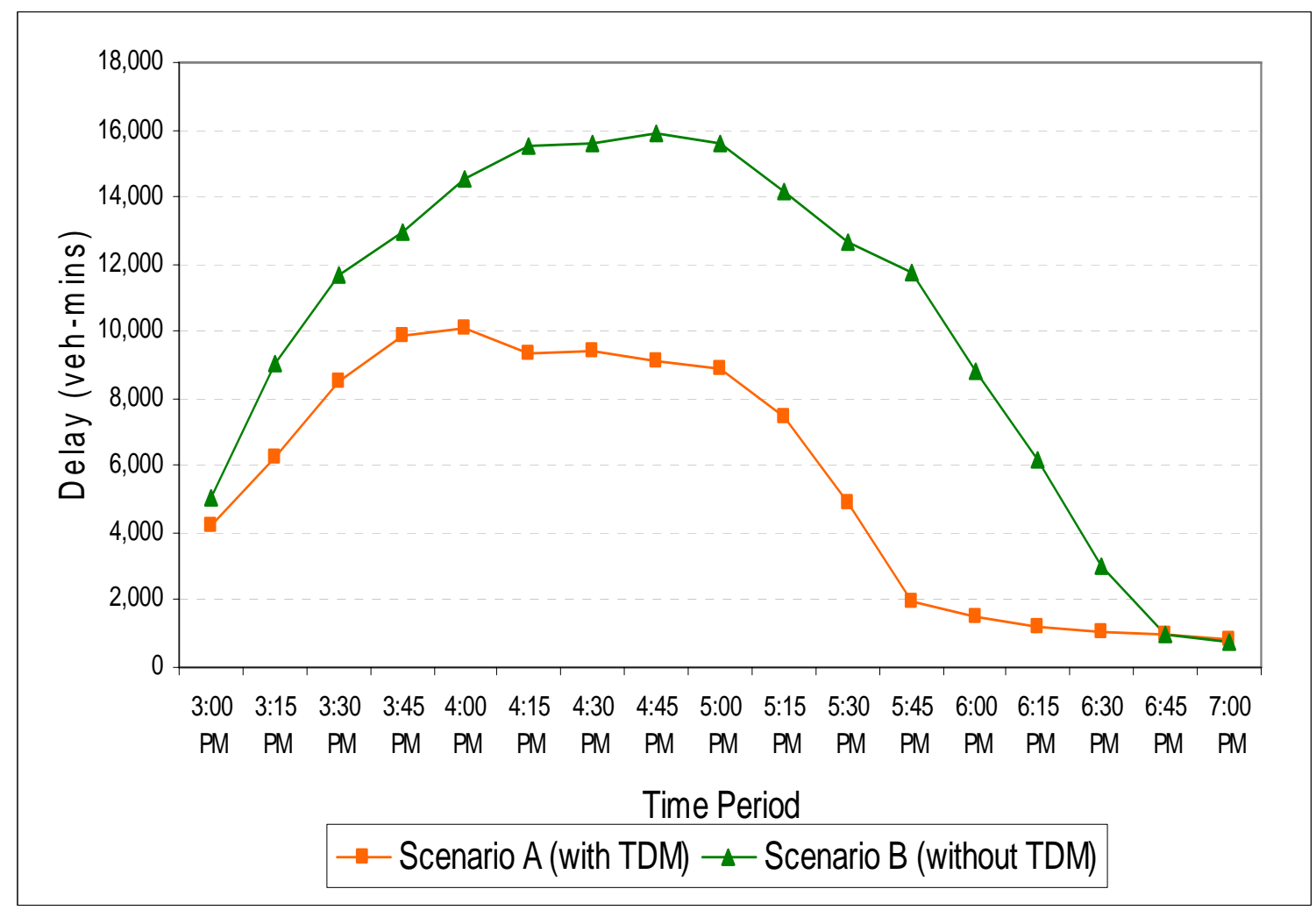

Figure 15: PM Recurring Delay on NB I-5 


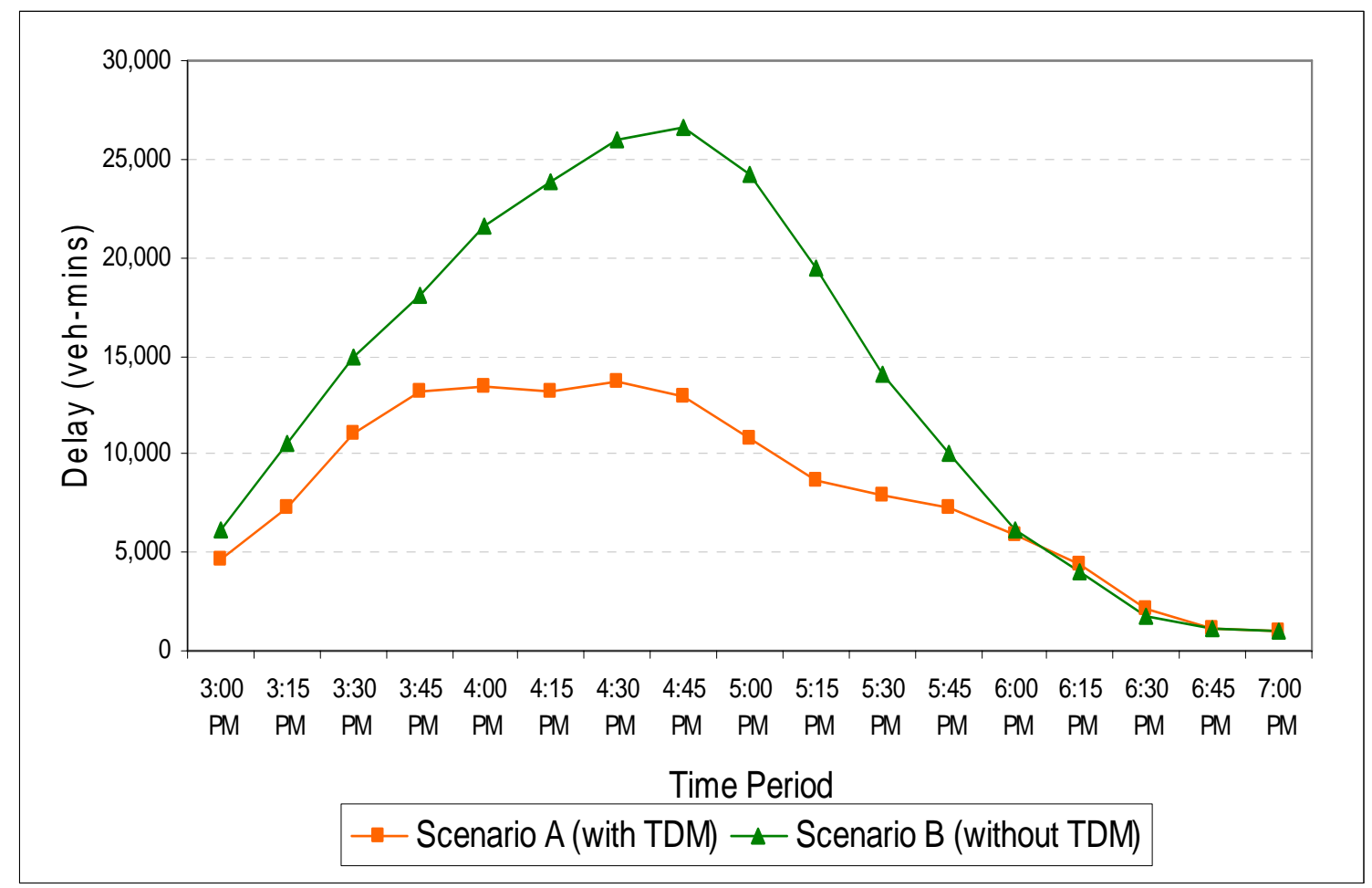

Figure 16: PM Recurring Delay on SB I-5

\subsection{Spatial Extent of Congestion}

The spatial extent of congestion, as defined in the final report of the NTOC performance measure initiative, is the length of roadway within a predefined area and time period for which the average travel times are 30 percent longer than the unconstrained travel time. Unconstrained travel time is the time it takes for a motorist to traverse a roadway section when traveling at the free-flow speed of $65 \mathrm{mph}$. If the travel speed were $50 \mathrm{mph}$ or lower, it would take 30 percent longer to travel the same distance when compared with a speed of 65 $\mathrm{mph}$. For the purposes of this study, spatial congestion was measured for 30 percent longer and also for 60 percent, 100 percent and 200 percent longer than the unconstrained travel time as seen in Table 32.

Table 32: Levels of Spatial Congestion

\begin{tabular}{|c|c|c|}
\hline Unconstrained Speed & Level of Spatial Congestion & Congested Speed \\
\hline \multirow{3}{*}{$\begin{array}{c}\text { Free-flow Speed: } \\
65 \mathrm{mph}\end{array}$} & $30 \%$ longer than unconstrained travel time & $<50.0 \mathrm{mph}$ \\
\cline { 2 - 3 } & $60 \%$ longer than unconstrained travel time & $<40.6 \mathrm{mph}$ \\
\cline { 2 - 3 } & $100 \%$ longer than unconstrained travel time & $<32.5 \mathrm{mph}$ \\
\cline { 2 - 3 } & $200 \%$ longer than unconstrained travel time & $<21.7 \mathrm{mph}$ \\
\hline
\end{tabular}


Spatial congestion was measured in lane-miles of the network with speeds lower than the corresponding congested speed. The travel time on a link during a particular time period was calculated to determine the level of congestion on the network. The lane-miles of congested links were added to determine the total lane-miles of congestion on the network during a particular time period. Table 33 shows the increase in the spatial extent of congestion for different levels of congestion for each time period during the AM period.

As seen in Table 33, cumulative spatial congestion for AM peak periods increased from 442.7 lane-miles for With TDM to 544.4 lane-miles Without TDM, where it took 30 percent longer or more than unconstrained travel time. There was a 34 percent increase in lane-miles in Without TDM where it took 60 percent longer or more than the unconstrained travel time. Similarly, there were 40 percent and 75 percent increases in lane miles in Without TDM where it took 100 percent and 200 percent longer or more than the unconstrained travel time, respectively, during the AM period. 
Table 33: AM Spatial Extent of Congestion

\begin{tabular}{|c|c|c|c|c|c|c|c|c|c|c|}
\hline \multirow{3}{*}{$\begin{array}{l}\text { Time } \\
\text { Period }\end{array}$} & \multirow{3}{*}{$\begin{array}{l}\text { From } \\
\text { (AM) }\end{array}$} & \multirow{3}{*}{$\begin{array}{c}\text { To } \\
\text { (AM) }\end{array}$} & \multicolumn{8}{|c|}{ Spatial Congestion - Lane Miles (AM period) } \\
\hline & & & \multicolumn{2}{|c|}{$30 \%$ Longer } & \multicolumn{2}{|c|}{$60 \%$ Longer } & \multicolumn{2}{|c|}{$100 \%$ Longer } & \multicolumn{2}{|c|}{$200 \%$ Longer } \\
\hline & & & $\begin{array}{l}\text { With } \\
\text { TDM }\end{array}$ & $\begin{array}{l}\text { Without } \\
\text { TDM }\end{array}$ & $\begin{array}{l}\text { With } \\
\text { TDM }\end{array}$ & $\begin{array}{c}\text { Without } \\
\text { TDM }\end{array}$ & $\begin{array}{l}\text { With } \\
\text { TDM }\end{array}$ & $\begin{array}{l}\text { Without } \\
\text { TDM }\end{array}$ & $\begin{array}{l}\text { With } \\
\text { TDM }\end{array}$ & $\begin{array}{l}\text { Without } \\
\text { TDM }\end{array}$ \\
\hline 1 & $6: 00$ & $6: 15$ & 21.0 & 21.0 & 10.1 & 9.7 & 4.3 & 6.6 & 4.3 & 6.6 \\
\hline 2 & $6: 15$ & $6: 30$ & 32.5 & 29.4 & 16.7 & 22.3 & 6.6 & 19.3 & 6.6 & 12.6 \\
\hline 3 & $6: 30$ & $6: 45$ & 34.9 & 35.5 & 29.3 & 29.3 & 19.7 & 20.6 & 6.6 & 12.6 \\
\hline 4 & $6: 45$ & 7:00 & 35.5 & 36.2 & 30.7 & 31.4 & 25.0 & 20.6 & 12.6 & 13.9 \\
\hline 5 & 7:00 & $7: 15$ & 36.4 & 37.5 & 28.5 & 30.7 & 25.6 & 21.7 & 13.9 & 15.1 \\
\hline 6 & $7: 15$ & $7: 30$ & 35.4 & 34.8 & 29.7 & 26.6 & 26.7 & 23.6 & 15.1 & 17.0 \\
\hline 7 & $7: 30$ & $7: 45$ & 36.4 & 34.2 & 28.1 & 29.6 & 21.7 & 23.6 & 15.1 & 17.0 \\
\hline 8 & $7: 45$ & 8:00 & 34.2 & 34.2 & 30.0 & 27.0 & 22.5 & 23.6 & 15.1 & 17.0 \\
\hline 9 & $8: 00$ & $8: 15$ & 32.7 & 32.7 & 27.0 & 30.0 & 22.5 & 24.0 & 15.1 & 17.0 \\
\hline 10 & $8: 15$ & $8: 30$ & 30.8 & 34.2 & 27.7 & 28.9 & 21.7 & 23.6 & 15.1 & 17.0 \\
\hline 11 & $8: 30$ & $8: 45$ & 31.9 & 34.2 & 22.9 & 28.6 & 20.6 & 23.6 & 8.0 & 17.0 \\
\hline 12 & $8: 45$ & 9:00 & 29.7 & 34.2 & 18.7 & 30.0 & 13.3 & 24.4 & 6.6 & 15.1 \\
\hline 13 & 9:00 & $9: 15$ & 19.2 & 34.2 & 15.0 & 30.0 & 10.9 & 23.6 & 3.0 & 15.1 \\
\hline 14 & $9: 15$ & $9: 30$ & 14.1 & 32.3 & 12.4 & 28.1 & 8.3 & 22.1 & 1.7 & 13.9 \\
\hline 15 & $9: 30$ & $9: 45$ & 12.0 & 29.7 & 4.7 & 23.7 & 1.7 & 19.6 & 1.7 & 12.6 \\
\hline 16 & $9: 45$ & $10: 00$ & 5.4 & 27.9 & 1.7 & 23.7 & 1.7 & 19.6 & 0.0 & 13.3 \\
\hline 17 & $10: 00$ & $10: 15$ & 0.7 & 22.0 & 0.0 & 17.7 & 0.0 & 14.0 & 0.0 & 13.3 \\
\hline \multicolumn{3}{|c|}{ Total } & 442.7 & 544.4 & 333.0 & 447.2 & 252.7 & 354.2 & 140.4 & 245.9 \\
\hline \multicolumn{3}{|c|}{$\%$ increase } & \multicolumn{2}{|c|}{$23 \%$} & \multicolumn{2}{|c|}{$34 \%$} & \multicolumn{2}{|c|}{$40 \%$} & \multicolumn{2}{|c|}{$75 \%$} \\
\hline
\end{tabular}

Table 34 shows the increase in the spatial extent of congestion for different levels of congestion during the PM period. The table shows spatial congestion cumulative for all the time periods increased from 324.2 lane-miles for scenario A to 467.1 lane-miles for scenario $\mathrm{B}$ during the PM periods, where it took 30 percent longer or more than unconstrained travel time. There was a 49 percent increase in lane-miles in scenario B where it took 60 percent longer or more than the unconstrained travel time. Similarly, there were 75 percent and 125 percent increases in lane miles in scenario B, where it took 100 percent and 200 percent longer or more than the unconstrained travel time, respectively. 
Table 34: PM Spatial Extent of Congestion

\begin{tabular}{|c|c|c|c|c|c|c|c|c|c|c|}
\hline \multirow{3}{*}{$\begin{array}{l}\text { Time } \\
\text { Period }\end{array}$} & \multirow{3}{*}{$\begin{array}{l}\text { From } \\
\text { (PM) }\end{array}$} & \multirow{3}{*}{$\begin{array}{c}\text { To } \\
\text { (PM) }\end{array}$} & \multicolumn{8}{|c|}{ Spatial Congestion - Lane Miles (PM period) } \\
\hline & & & \multicolumn{2}{|c|}{$30 \%$ Longer } & \multicolumn{2}{|c|}{$60 \%$ Longer } & \multicolumn{2}{|c|}{$100 \%$ Longer } & \multicolumn{2}{|c|}{$200 \%$ Longer } \\
\hline & & & $\begin{array}{l}\text { With } \\
\text { TDM }\end{array}$ & $\begin{array}{c}\text { Without } \\
\text { TDM }\end{array}$ & $\begin{array}{l}\text { With } \\
\text { TDM }\end{array}$ & $\begin{array}{c}\text { Without } \\
\text { TDM }\end{array}$ & $\begin{array}{l}\text { With } \\
\text { TDM }\end{array}$ & $\begin{array}{c}\text { Without } \\
\text { TDM }\end{array}$ & $\begin{array}{l}\text { With } \\
\text { TDM }\end{array}$ & $\begin{array}{c}\text { Without } \\
\text { TDM }\end{array}$ \\
\hline 1 & $3: 00$ & $3: 15$ & 12.4 & 22.3 & 9.5 & 12.6 & 4.8 & 4.7 & 1.4 & 2.7 \\
\hline 2 & $3: 15$ & $3: 30$ & 22.8 & 27.4 & 15.7 & 19.3 & 8.3 & 14.2 & 3.7 & 8.3 \\
\hline 3 & $3: 30$ & $3: 45$ & 29.8 & 32.9 & 14.1 & 20.5 & 12.8 & 17.4 & 9.6 & 14.7 \\
\hline 4 & $3: 45$ & 4:00 & 27.4 & 33.9 & 16.9 & 24.8 & 12.8 & 20.3 & 10.0 & 18.3 \\
\hline 5 & 4:00 & $4: 15$ & 35.2 & 44.5 & 20.5 & 23.5 & 14.4 & 23.1 & 9.5 & 19.2 \\
\hline 6 & $4: 15$ & $4: 30$ & 29.8 & 43.5 & 24.0 & 33.9 & 11.8 & 22.4 & 9.5 & 20.1 \\
\hline 7 & $4: 30$ & $4: 45$ & 32.1 & 45.0 & 23.6 & 36.5 & 17.9 & 32.8 & 9.1 & 20.1 \\
\hline 8 & $4: 45$ & $5: 00$ & 31.6 & 45.0 & 22.3 & 36.5 & 17.2 & 32.8 & 9.1 & 19.2 \\
\hline 9 & $5: 00$ & $5: 15$ & 23.8 & 41.3 & 20.9 & 38.0 & 16.8 & 32.2 & 8.0 & 17.9 \\
\hline 10 & $5: 15$ & $5: 30$ & 20.7 & 33.3 & 20.1 & 30.5 & 15.0 & 27.5 & 6.0 & 15.6 \\
\hline 11 & $5: 30$ & $5: 45$ & 19.0 & 31.1 & 16.3 & 24.4 & 12.6 & 19.0 & 3.7 & 11.6 \\
\hline 12 & $5: 45$ & $6: 00$ & 13.6 & 24.5 & 12.9 & 22.6 & 8.3 & 11.6 & 1.7 & 10.0 \\
\hline 13 & 6:00 & $6: 15$ & 13.0 & 22.1 & 11.4 & 13.1 & 1.7 & 8.3 & 1.7 & 6.3 \\
\hline 14 & $6: 15$ & $6: 30$ & 6.3 & 10.9 & 4.7 & 10.3 & 1.7 & 6.6 & 1.7 & 6.0 \\
\hline 15 & $6: 30$ & $6: 45$ & 5.4 & 8.0 & 1.7 & 3.3 & 0.0 & 0.9 & 0.0 & 0.9 \\
\hline 16 & $6: 45$ & $7: 00$ & 0.7 & 0.7 & 0.0 & 0.0 & 0.0 & 0.0 & 0.0 & 0.0 \\
\hline 17 & $7: 00$ & $7: 15$ & 0.7 & 0.7 & 0.0 & 0.0 & 0.0 & 0.0 & 0.0 & 0.0 \\
\hline \multicolumn{3}{|c|}{ Total } & 324.2 & 467.1 & 234.5 & 349.8 & 156.1 & 273.7 & 84.7 & 191.0 \\
\hline \multicolumn{3}{|c|}{$\%$ increase } & \multicolumn{2}{|c|}{$44 \%$} & \multicolumn{2}{|c|}{$49 \%$} & \multicolumn{2}{|c|}{$75 \%$} & \multicolumn{2}{|c|}{$125 \%$} \\
\hline
\end{tabular}

\subsection{Temporal Extent of Congestion}

The temporal extent of congestion, as defined in the final report of the NTOC performance measure initiative, is the "time duration" during which more than 20 percent of the roadway sections in a predefined area are congested as defined by "spatial extent of congestion." One time period is considered as the "time duration"; therefore, if 20 percent of the network is congested for a particular time period, that particular time period is considered congested. For the purpose of this study, the congestion level is measured at all four levels of congestion as mentioned in previous sections regarding spatial extent of congestion. Table 35 shows the increase in the temporal extent of congestion for different level of congestion during the AM period. 
Table 35: AM Temporal Extent of Congestion

\begin{tabular}{|c|c|c|c|c|c|c|c|c|c|c|}
\hline \multirow{3}{*}{$\begin{array}{l}\text { Time } \\
\text { Period }\end{array}$} & \multirow{3}{*}{$\begin{array}{l}\text { From } \\
\text { (AM) }\end{array}$} & \multirow{3}{*}{$\begin{array}{c}\text { To } \\
\text { (AM) }\end{array}$} & \multicolumn{8}{|c|}{ Spatial Congestion - minutes (AM period) } \\
\hline & & & \multicolumn{2}{|c|}{$30 \%$ Longer } & \multicolumn{2}{|c|}{$60 \%$ Longer } & \multicolumn{2}{|c|}{$100 \%$ Longer } & \multicolumn{2}{|c|}{$200 \%$ Longer } \\
\hline & & & $\begin{array}{l}\text { With } \\
\text { TDM }\end{array}$ & $\begin{array}{c}\text { Without } \\
\text { TDM }\end{array}$ & $\begin{array}{l}\text { With } \\
\text { TDM }\end{array}$ & $\begin{array}{c}\text { Without } \\
\text { TDM }\end{array}$ & $\begin{array}{l}\text { With } \\
\text { TDM }\end{array}$ & $\begin{array}{c}\text { Without } \\
\text { TDM }\end{array}$ & $\begin{array}{l}\text { With } \\
\text { TDM }\end{array}$ & $\begin{array}{c}\text { Without } \\
\text { TDM }\end{array}$ \\
\hline 1 & $6: 00$ & $6: 15$ & 15.0 & 15.0 & 0.0 & 0.0 & 0.0 & 0.0 & 0.0 & 0.0 \\
\hline 2 & $6: 15$ & $6: 30$ & 15.0 & 15.0 & 0.0 & 15.0 & 0.0 & 15.0 & 0.0 & 0.0 \\
\hline 3 & $6: 30$ & $6: 45$ & 15.0 & 15.0 & 15.0 & 15.0 & 15.0 & 15.0 & 0.0 & 0.0 \\
\hline 4 & $6: 45$ & $7: 00$ & 15.0 & 15.0 & 15.0 & 15.0 & 15.0 & 15.0 & 0.0 & 0.0 \\
\hline 5 & $7: 00$ & $7: 15$ & 15.0 & 15.0 & 15.0 & 15.0 & 15.0 & 15.0 & 0.0 & 0.0 \\
\hline 6 & $7: 15$ & $7: 30$ & 15.0 & 15.0 & 15.0 & 15.0 & 15.0 & 15.0 & 0.0 & 0.0 \\
\hline 7 & $7: 30$ & $7: 45$ & 15.0 & 15.0 & 15.0 & 15.0 & 15.0 & 15.0 & 0.0 & 0.0 \\
\hline 8 & $7: 45$ & 8:00 & 15.0 & 15.0 & 15.0 & 15.0 & 15.0 & 15.0 & 0.0 & 0.0 \\
\hline 9 & 8:00 & $8: 15$ & 15.0 & 15.0 & 15.0 & 15.0 & 15.0 & 15.0 & 0.0 & 0.0 \\
\hline 10 & $8: 15$ & $8: 30$ & 15.0 & 15.0 & 15.0 & 15.0 & 15.0 & 15.0 & 0.0 & 0.0 \\
\hline 11 & $8: 30$ & $8: 45$ & 15.0 & 15.0 & 15.0 & 15.0 & 15.0 & 15.0 & 0.0 & 0.0 \\
\hline 12 & $8: 45$ & 9:00 & 15.0 & 15.0 & 15.0 & 15.0 & 0.0 & 15.0 & 0.0 & 0.0 \\
\hline 13 & 9:00 & $9: 15$ & 15.0 & 15.0 & 0.0 & 15.0 & 0.0 & 15.0 & 0.0 & 0.0 \\
\hline 14 & $9: 15$ & 9:30 & 0.0 & 15.0 & 0.0 & 15.0 & 0.0 & 15.0 & 0.0 & 0.0 \\
\hline 15 & $9: 30$ & $9: 45$ & 0.0 & 15.0 & 0.0 & 15.0 & 0.0 & 15.0 & 0.0 & 0.0 \\
\hline 16 & $9: 45$ & $10: 00$ & 0.0 & 15.0 & 0.0 & 15.0 & 0.0 & 15.0 & 0.0 & 0.0 \\
\hline 17 & $10: 00$ & $10: 15$ & 0.0 & 15.0 & 0.0 & 15.0 & 0.0 & 0.0 & 0.0 & 0.0 \\
\hline \multicolumn{3}{|c|}{ Total } & 195.0 & 225.0 & 150.0 & 240.0 & 135.0 & 225.0 & 0.0 & 0.0 \\
\hline \multicolumn{3}{|c|}{$\%$ increase } & \multicolumn{2}{|c|}{$31 \%$} & \multicolumn{2}{|c|}{$60 \%$} & \multicolumn{2}{|c|}{$67 \%$} & \multicolumn{2}{|c|}{$0 \%$} \\
\hline
\end{tabular}

During the AM peak, the temporal extent of congestion increased by 31 percent in the Without TDM scenario, as compared to With TDM at the level of congestion of 30 percent longer or more than the unconstrained travel time.

Table 36 shows that the temporal extent of congestion for different level of congestion during the PM period increased from 150 minutes to 195 minutes in the Without TDM scenario, as compared to With TDM for the level of congestion of 30 percent longer or more than the unconstrained travel time. 
Table 36: PM Temporal Extent of Congestion

\begin{tabular}{|c|c|c|c|c|c|c|c|c|c|c|}
\hline \multirow{3}{*}{$\begin{array}{l}\text { Time } \\
\text { Period }\end{array}$} & \multirow{3}{*}{$\begin{array}{l}\text { From } \\
\text { (PM) }\end{array}$} & \multirow{3}{*}{$\begin{array}{c}\text { To } \\
\text { (PM) }\end{array}$} & \multicolumn{8}{|c|}{ Spatial Congestion - minutes (PM period) } \\
\hline & & & \multicolumn{2}{|c|}{$30 \%$ Longer } & \multicolumn{2}{|c|}{$60 \%$ Longer } & \multicolumn{2}{|c|}{$100 \%$ Longer } & \multicolumn{2}{|c|}{$200 \%$ Longer } \\
\hline & & & $\begin{array}{l}\text { With } \\
\text { TDM }\end{array}$ & $\begin{array}{c}\text { Without } \\
\text { TDM }\end{array}$ & $\begin{array}{l}\text { With } \\
\text { TDM }\end{array}$ & $\begin{array}{c}\text { Without } \\
\text { TDM }\end{array}$ & $\begin{array}{l}\text { With } \\
\text { TDM }\end{array}$ & $\begin{array}{c}\text { Without } \\
\text { TDM }\end{array}$ & $\begin{array}{l}\text { With } \\
\text { TDM }\end{array}$ & $\begin{array}{c}\text { Without } \\
\text { TDM }\end{array}$ \\
\hline 1 & $3: 00$ & $3: 15$ & 0.0 & 15.0 & 0.0 & 0.0 & 0.0 & 0.0 & 0.0 & 0.0 \\
\hline 2 & $3: 15$ & $3: 30$ & 15.0 & 15.0 & 0.0 & 15.0 & 0.0 & 0.0 & 0.0 & 0.0 \\
\hline 3 & $3: 30$ & $3: 45$ & 15.0 & 15.0 & 0.0 & 15.0 & 0.0 & 0.0 & 0.0 & 0.0 \\
\hline 4 & $3: 45$ & 4:00 & 15.0 & 15.0 & 0.0 & 15.0 & 0.0 & 15.0 & 0.0 & 15.0 \\
\hline 5 & $4: 00$ & $4: 15$ & 15.0 & 15.0 & 15.0 & 15.0 & 0.0 & 15.0 & 0.0 & 15.0 \\
\hline 6 & $4: 15$ & $4: 30$ & 15.0 & 15.0 & 15.0 & 15.0 & 0.0 & 15.0 & 0.0 & 15.0 \\
\hline 7 & $4: 30$ & $4: 45$ & 15.0 & 15.0 & 15.0 & 15.0 & 15.0 & 15.0 & 0.0 & 15.0 \\
\hline 8 & $4: 45$ & $5: 00$ & 15.0 & 15.0 & 15.0 & 15.0 & 0.0 & 15.0 & 0.0 & 15.0 \\
\hline 9 & $5: 00$ & $5: 15$ & 15.0 & 15.0 & 15.0 & 15.0 & 0.0 & 15.0 & 0.0 & 15.0 \\
\hline 10 & $5: 15$ & $5: 30$ & 15.0 & 15.0 & 15.0 & 15.0 & 0.0 & 15.0 & 0.0 & 0.0 \\
\hline 11 & $5: 30$ & $5: 45$ & 15.0 & 15.0 & 0.0 & 15.0 & 0.0 & 15.0 & 0.0 & 0.0 \\
\hline 12 & $5: 45$ & $6: 00$ & 0.0 & 15.0 & 0.0 & 15.0 & 0.0 & 0.0 & 0.0 & 0.0 \\
\hline 13 & $6: 00$ & $6: 15$ & 0.0 & 15.0 & 0.0 & 0.0 & 0.0 & 0.0 & 0.0 & 0.0 \\
\hline 14 & $6: 15$ & $6: 30$ & 0.0 & 0.0 & 0.0 & 0.0 & 0.0 & 0.0 & 0.0 & 0.0 \\
\hline 15 & $6: 30$ & $6: 45$ & 0.0 & 0.0 & 0.0 & 0.0 & 0.0 & 0.0 & 0.0 & 0.0 \\
\hline 16 & $6: 45$ & $7: 00$ & 0.0 & 0.0 & 0.0 & 0.0 & 0.0 & 0.0 & 0.0 & 0.0 \\
\hline 17 & $7: 00$ & $7: 15$ & 0.0 & 0.0 & 0.0 & 0.0 & 0.0 & 0.0 & 0.0 & 0.0 \\
\hline \multicolumn{3}{|c|}{ Total } & 324.2 & 467.1 & 150.0 & 195.0 & 90.0 & 165.0 & 15.0 & 120.0 \\
\hline \multicolumn{3}{|c|}{$\%$ increase } & \multicolumn{2}{|c|}{$30 \%$} & \multicolumn{2}{|c|}{$83 \%$} & \multicolumn{2}{|c|}{$700 \%$} & \multicolumn{2}{|c|}{ All } \\
\hline
\end{tabular}

Figures 17 through 20 show the temporal and spatial extents of congestion on the network for the AM and PM periods. The network is shown on the vertical axis, and the 17 periods are on the horizontal axis. The figures show side-by-side comparisons of spatial and temporal extent of congestion of both With TDM and Without TDM scenarios. 

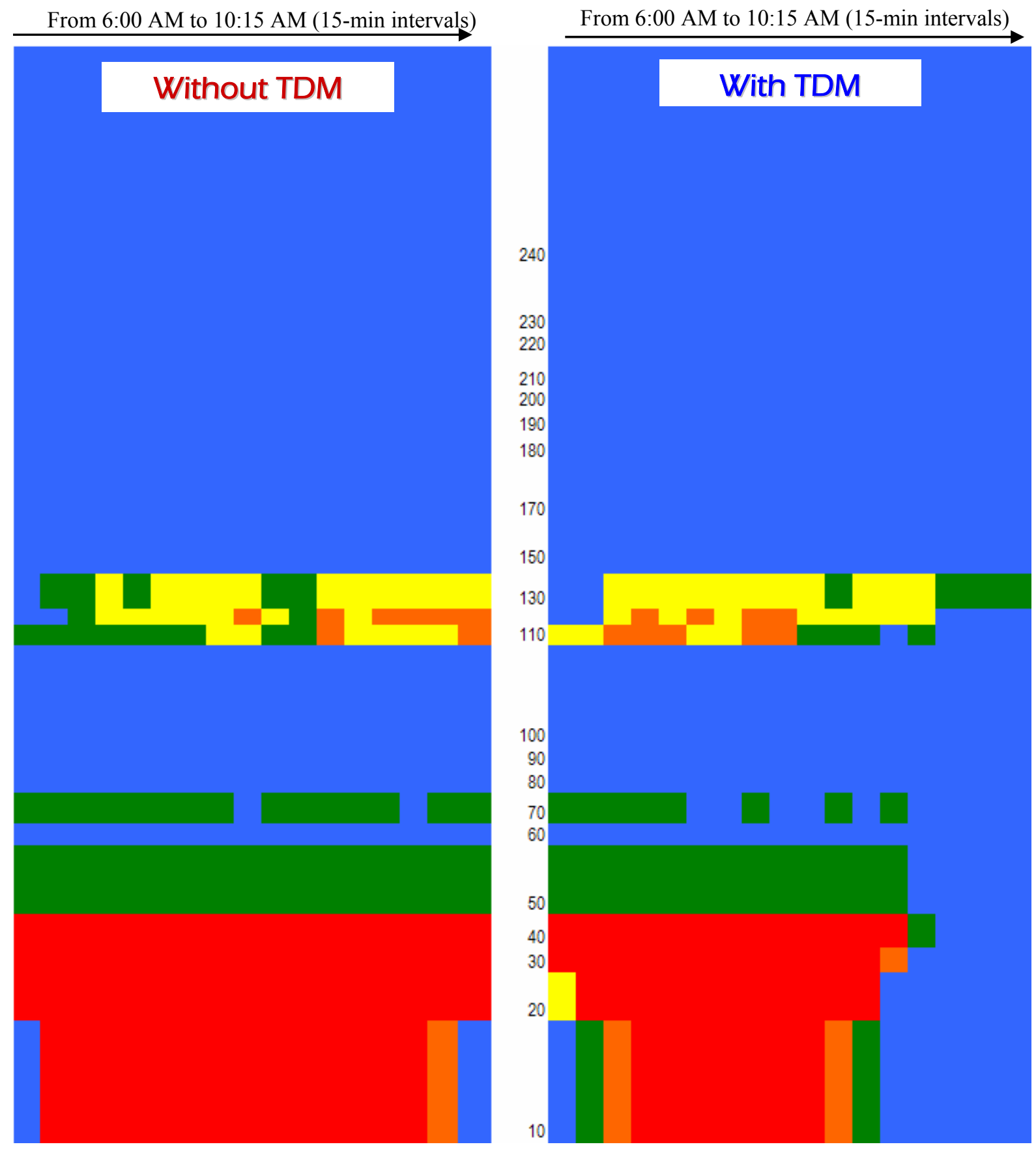

\section{$30 \%$ longer or more} $60 \%$ longer or more $100 \%$ longer or more $200 \%$ longer or more

Figure 17: AM Spatial and Temporal Extents of Congestion on NB I-5 

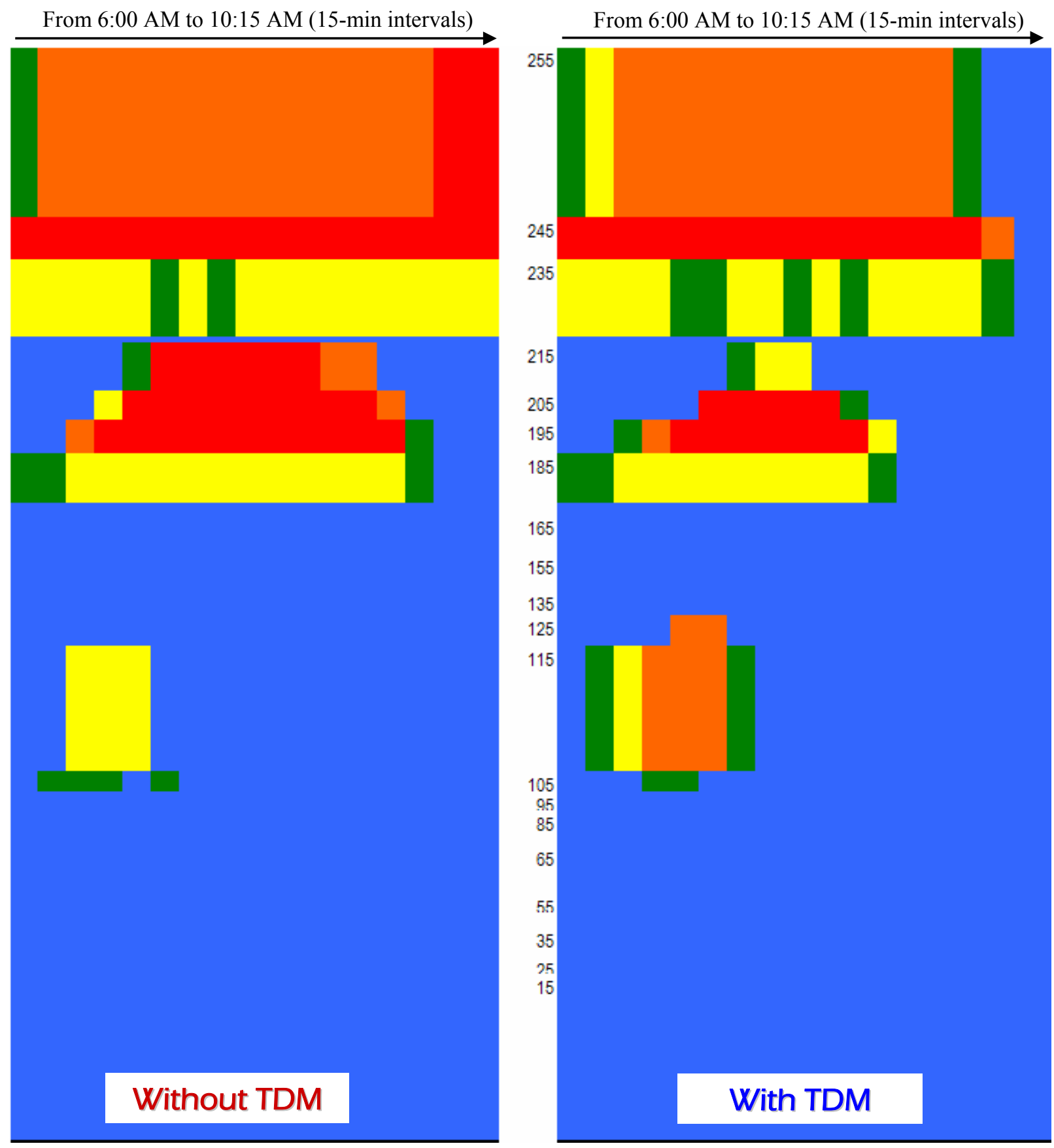

$30 \%$ longer or more Un-congested Condition $60 \%$ longer or more $100 \%$ longer or more $200 \%$ longer or more
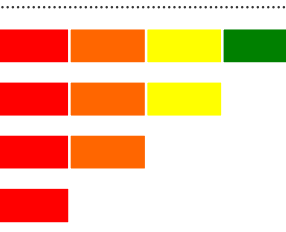

Figure 18: AM Spatial and Temporal Extents of Congestion on SB I-5 


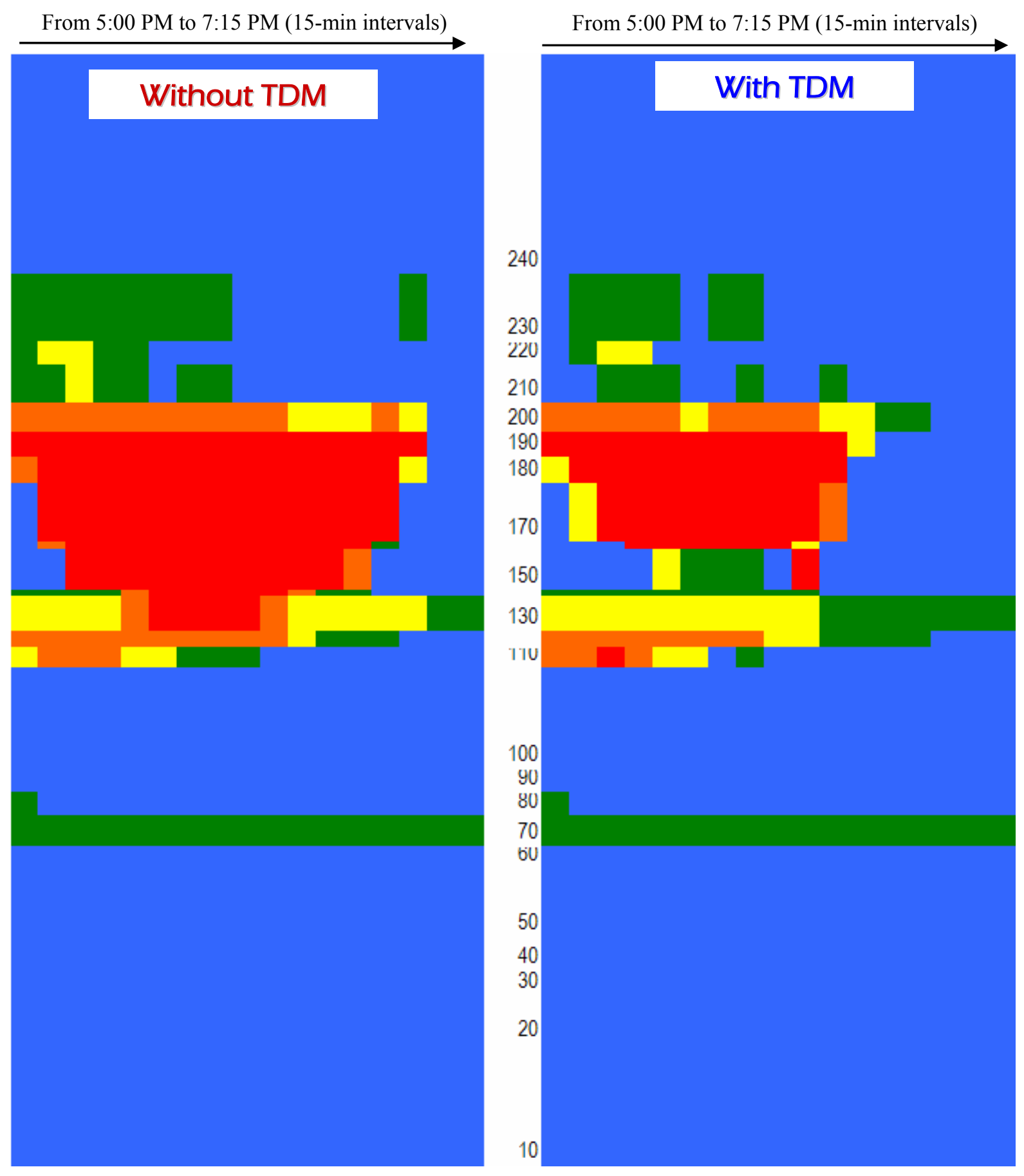

$30 \%$ longer or more

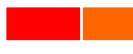

Un-congested Condition

$60 \%$ longer or more $100 \%$ longer or more $200 \%$ longer or more

Figure 19: PM Spatial and Temporal Extents of Congestion on NB I-5 


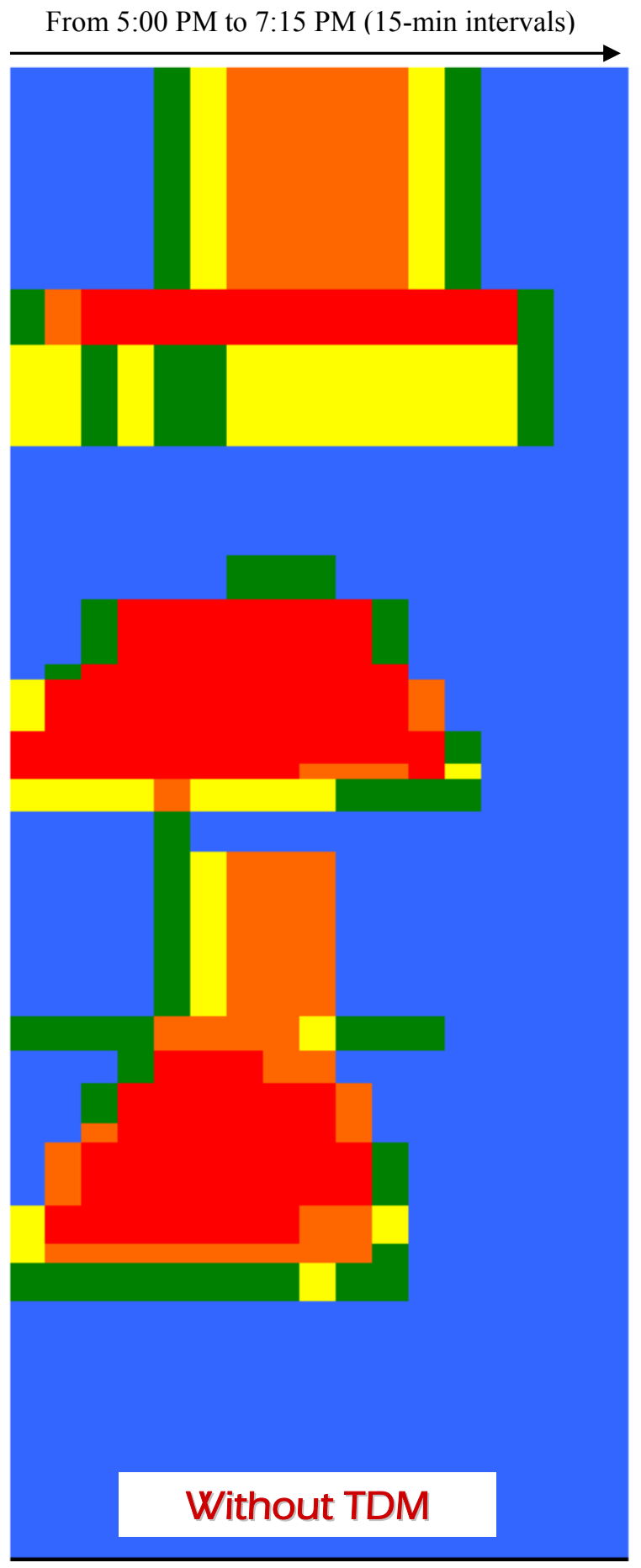

$30 \%$ longer or more $60 \%$ longer or more $100 \%$ longer or more $200 \%$ longer or more

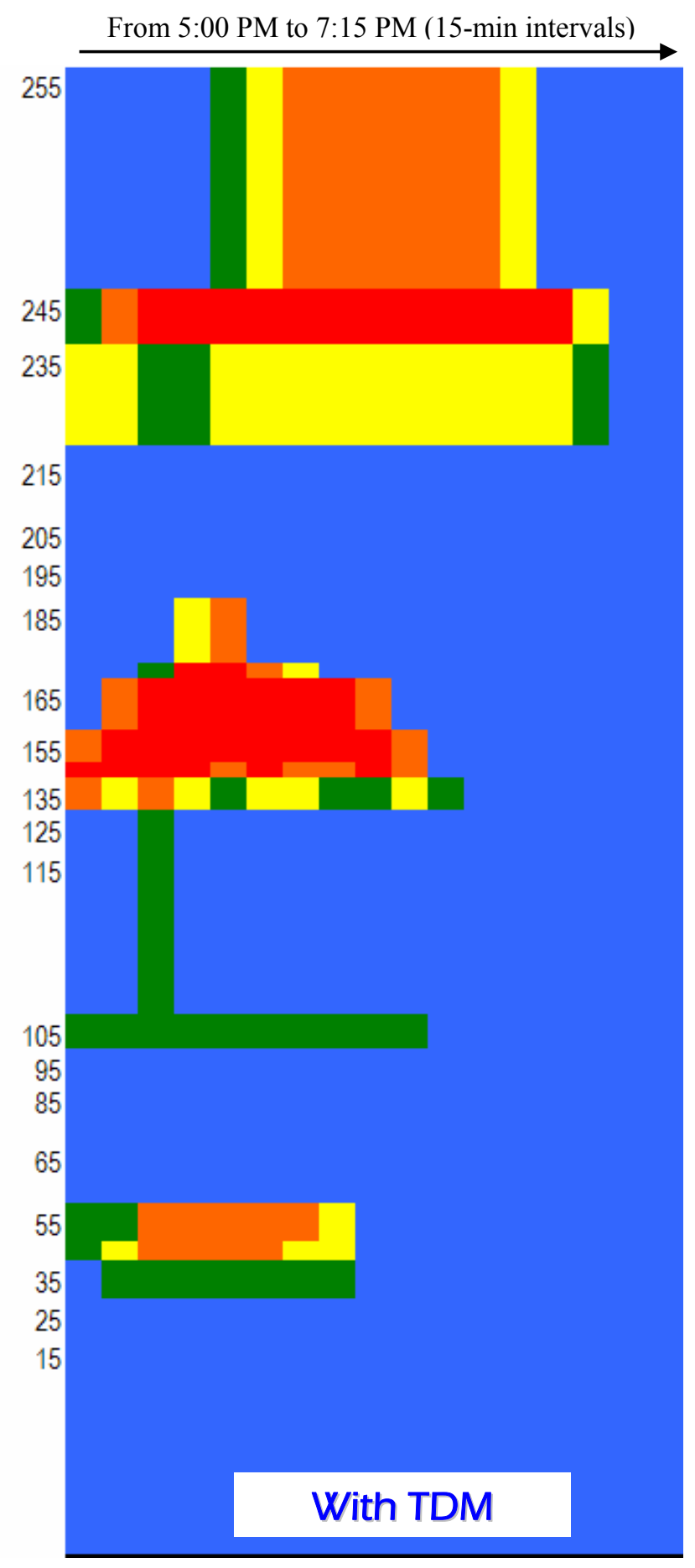

Un-congested Condition

Figure 20: PM Spatial and Temporal Extents of Congestion on SB I-5 


\subsection{Average Speed}

The average speed for the corridor was calculated for each of the 17 time periods. Figure 21 shows the average speed of the network for the AM period for With TDM and Without TDM. The average speed is lower for all the time periods for Without TDM, and the difference between the average speeds is more significant from 8:30 AM onwards. The difference in average speed ranges from $2 \mathrm{mph}$ to $19 \mathrm{mph}$ for different time periods.

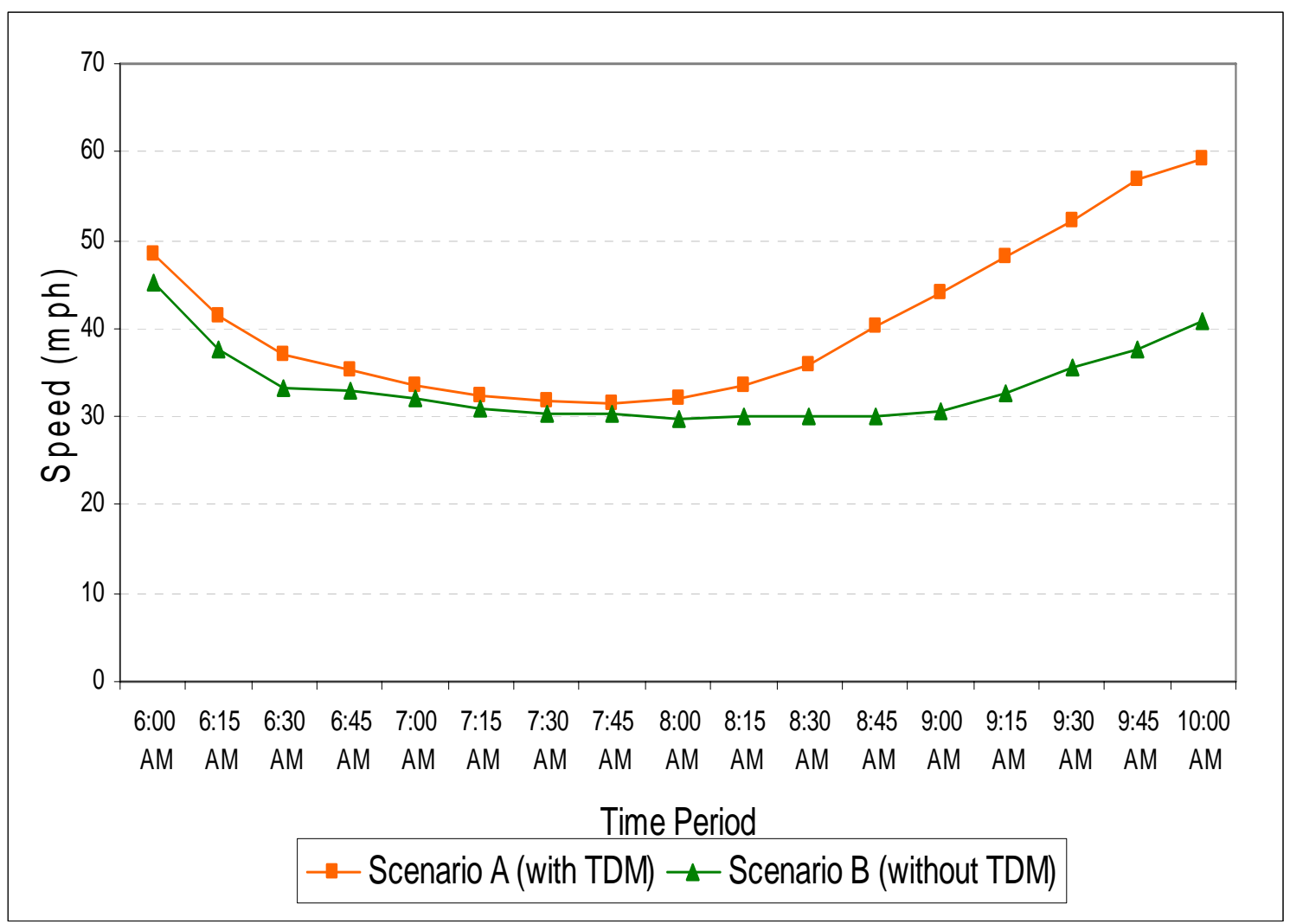

Figure 21: Average Corridor Speed During AM Peak 
Figure 22 shows the average speed of the corridor for the PM period for With TDM and Without TDM. The average speed is higher in With TDM for all time periods. The difference in the average speed varies from more than $11 \mathrm{mph}$ at 4:45 PM to almost $0 \mathrm{mph}$ at 6:45 PM.

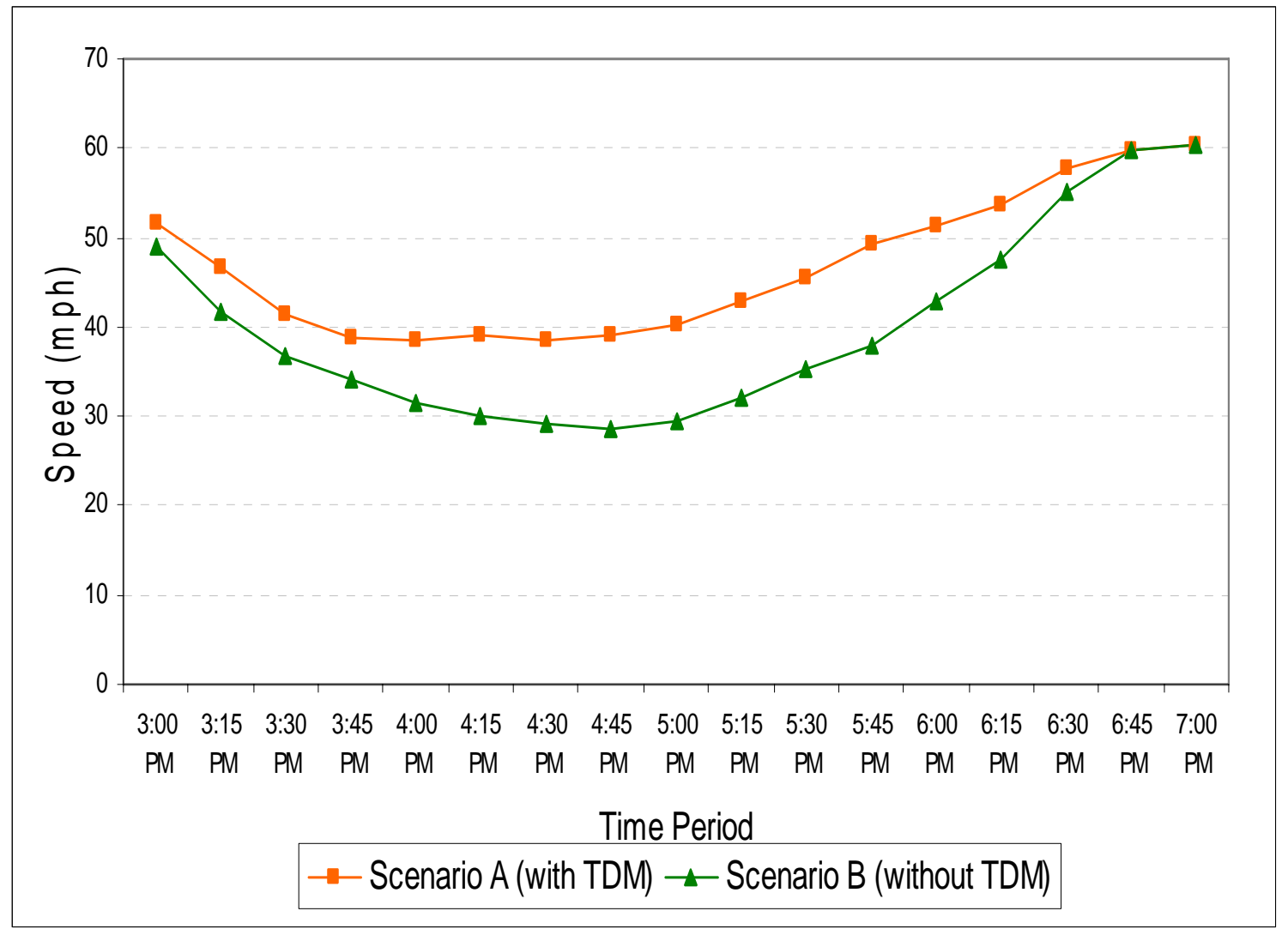

Figure 22: Average Corridor Speed During PM Peak

The figures show that TDM programs have a significant impact on the average corridor speed during both AM and PM peak periods.

\subsection{Vehicle Miles Traveled}

Trips added to the network in the Without TDM scenario resulted in more vehicle miles traveled (VMT) compared to With TDM. This increase in VMT takes into account only the increase within the network. This VMT would be less than the "total VMT" increase, which should be calculated from the origin of trips, which may be outside the 8.6-mile network, to the destination of trips.

Table 37 shows the increase in VMT for AM and PM periods. VMT increased by 7659 miles and 9638 miles for NB and SB directions, respectively, during the AM period. During the PM period, the VMT increased by 9448 miles and 5061 miles for the NB and SB directions, respectively. 
Table 37: Reductions in Vehicle Miles Traveled

\begin{tabular}{|c|c|c|c|c|c|c|c|c|c|c|c|}
\hline \multicolumn{6}{|c|}{ AM Period } & \multicolumn{6}{|c|}{ PM period } \\
\hline \multicolumn{3}{|c|}{ NORTHBOUND } & \multicolumn{3}{|c|}{ SOUTHBOUND } & \multicolumn{3}{|c|}{ NORTHBOUND } & \multicolumn{3}{|c|}{ SOUTHBOUND } \\
\hline Links & $\begin{array}{l}\text { Added } \\
\text { Volume }\end{array}$ & $\begin{array}{l}\text { Added } \\
\text { VMT }\end{array}$ & Links & $\begin{array}{l}\text { Added } \\
\text { Volume }\end{array}$ & $\begin{array}{l}\text { Added } \\
\text { VMT }\end{array}$ & Links & $\begin{array}{c}\text { Added } \\
\text { Volume }\end{array}$ & $\begin{array}{l}\text { Added } \\
\text { VMT }\end{array}$ & Links & $\begin{array}{l}\text { Added } \\
\text { Volume }\end{array}$ & Added VMT \\
\hline 10 & 1345 & 71.3 & 255 & 1881 & 997.5 & 10 & 0 & 0.0 & 255 & 0 & 0.0 \\
\hline 20 & 1498 & 715.0 & 245 & 1881 & 785.5 & 20 & 0 & 0.0 & 245 & 0 & 0.0 \\
\hline 30 & 1498 & 368.8 & 235 & 1881 & 1425.0 & 30 & 0 & 0.0 & 235 & 0 & 0.0 \\
\hline 40 & 1498 & 505.0 & 225 & 1881 & 118.3 & 40 & 0 & 0.0 & 225 & 0 & 0.0 \\
\hline 50 & 1465 & 981.7 & 215 & 1778 & 845.2 & 50 & 0 & 0.0 & 215 & 0 & 0.0 \\
\hline 60 & 1596 & 360.3 & 205 & 1928 & 547.7 & 60 & 18 & 4.1 & 205 & 1 & 0.3 \\
\hline 70 & 1596 & 492.1 & 195 & 2039 & 687.4 & 70 & 18 & 5.6 & 195 & 20 & 6.7 \\
\hline 80 & 1596 & 375.4 & 185 & 1875 & 905.5 & 80 & 18 & 4.2 & 185 & 18 & 8.7 \\
\hline 90 & 1561 & 354.8 & 175 & 1386 & 170.6 & 90 & 16 & 3.6 & 175 & 18 & 2.2 \\
\hline 100 & 1349 & 1331.1 & 165 & 1423 & 552.5 & 100 & 16 & 15.8 & 165 & 70 & 27.2 \\
\hline 110 & 1349 & 273.4 & 155 & 1423 & 354.4 & 110 & 16 & 3.2 & 155 & 548 & 136.5 \\
\hline 120 & 197 & 31.7 & 145 & 352 & 43.0 & 120 & 16 & 2.6 & 145 & 545 & 66.6 \\
\hline 130 & 503 & 171.5 & 135 & 54 & 13.3 & 130 & 87 & 29.7 & 135 & 542 & 133.4 \\
\hline 140 & 507 & 30.2 & 125 & 19 & 5.8 & 140 & 1287 & 76.8 & 125 & 473 & 143.3 \\
\hline 150 & 45 & 18.3 & 115 & 19 & 23.4 & 150 & 1281 & 521.6 & 115 & 473 & 582.3 \\
\hline 160 & 45 & 3.4 & 105 & 19 & 3.8 & 160 & 1791 & 135.7 & 105 & 473 & 95.3 \\
\hline 170 & 45 & 25.6 & 95 & 19 & 3.6 & 170 & 1791 & 1017.6 & 95 & 473 & 90.7 \\
\hline 180 & 51 & 13.5 & 85 & 19 & 3.9 & 180 & 2062 & 546.7 & 85 & 473 & 96.1 \\
\hline 190 & 10 & 2.4 & 75 & 19 & 2.9 & 190 & 1914 & 453.1 & 75 & 473 & 71.7 \\
\hline 200 & 10 & 2.1 & 65 & 3 & 1.4 & 200 & 1914 & 398.8 & 65 & 444 & 208.5 \\
\hline 210 & 1 & 0.3 & 55 & 6 & 1.1 & 210 & 1740 & 593.2 & 55 & 1461 & 276.7 \\
\hline 220 & 1 & 0.2 & 45 & 6 & 0.8 & 220 & 1774 & 386.4 & 45 & 1494 & 211.1 \\
\hline 230 & 1 & 0.7 & 35 & 6 & 1.8 & 230 & 1863 & 1234.9 & 35 & 1494 & 436.9 \\
\hline 240 & 1 & 1.0 & 25 & 6 & 1.1 & 240 & 1863 & 1898.3 & 25 & 1494 & 268.8 \\
\hline- & - & & 15 & 3 & 1.5 & - & - & & 15 & 1342 & 673.5 \\
\hline \multicolumn{2}{|c|}{ Total VMT } & 7659.4 & \multicolumn{2}{|c|}{ Total } & 9638.0 & \multicolumn{2}{|c|}{ Total } & 9448.9 & \multicolumn{2}{|c|}{ Total } & 5061.7 \\
\hline
\end{tabular}




\subsection{Fuel Consumption and Emissions}

The microscopic tool CORSIM provides fuel consumption and emissions statistics for each vehicle on the network. These statistics are accumulated for each time period of the analysis. Figures 23 and 24 show the fuel consumption for both scenarios for AM period and PM period, respectively. During the AM period, Without TDM had significantly more fuel consumption for time periods after 8:00 AM as compared to With TDM. During the PM period, this difference in fuel consumption occurred between 4:00 PM to 6:00 PM. Without TDM had 3,489 gallons of excess fuel consumption during AM period and 4,314 gallons during the PM period.

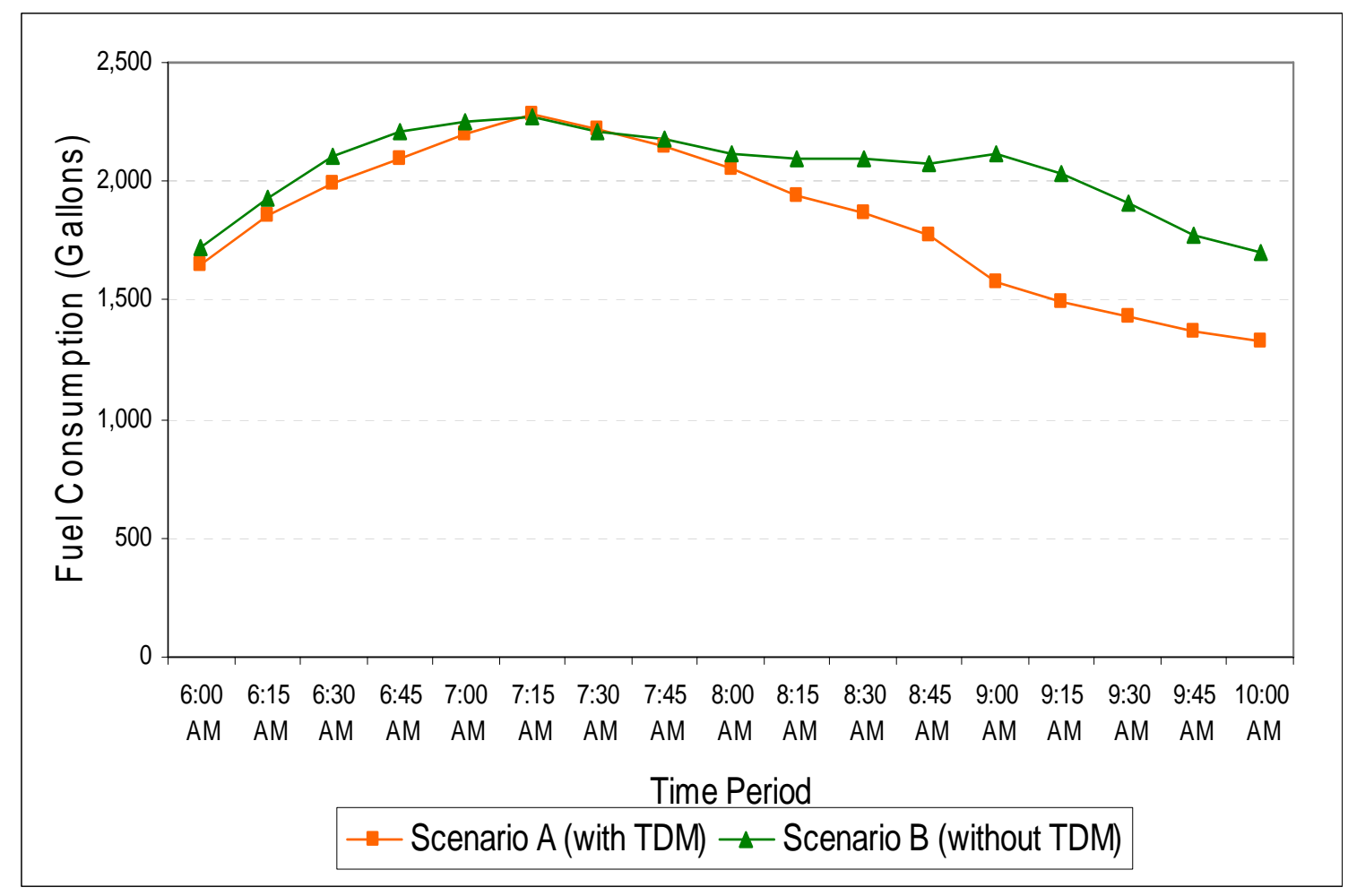

Figure 23: Fuel Consumption During AM Peak 


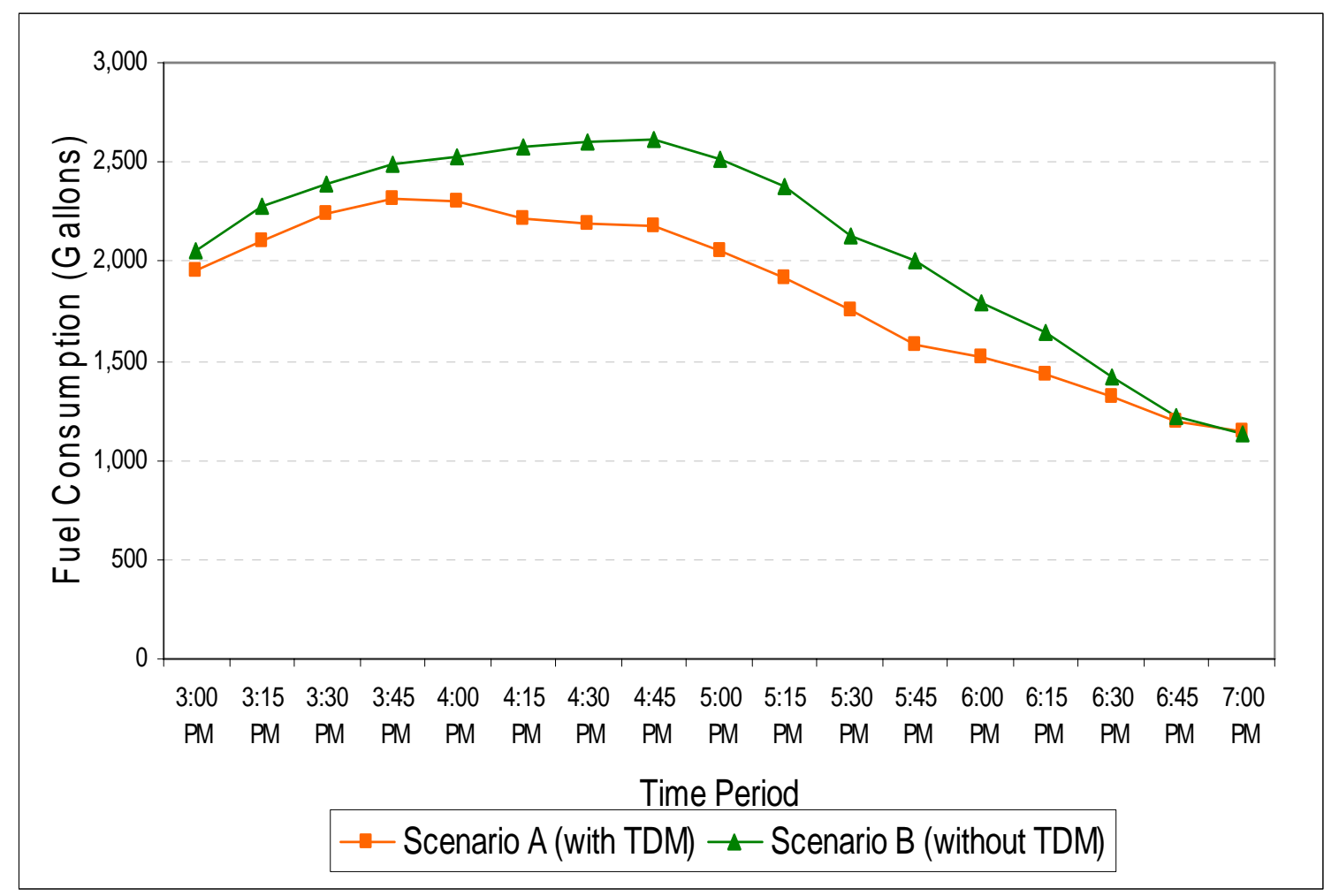

Figure 24: Fuel Consumption During PM Peak

CORSIM provides HC, $\mathrm{CO}$ and NOx emission statistics for each vehicle on the network. These values were compared for With TDM and Without TDM, as seen in Tables 38 and 39 for AM period and PM period, respectively. Table 38 shows an increase in $\mathrm{HC}$ emissions by $10.3 \%, \mathrm{CO}$ emissions by 9.6 percent and $\mathrm{NO}$ emissions by 8.3 percent for the Without TDM scenario as compared to With TDM during the AM period.

Table 38: Emissions during AM Peak

\begin{tabular}{|c|c|c|c|c|}
\hline Pollutant & With TDM & Without TDM & $\begin{array}{c}\text { Added } \\
\text { Emissions }\end{array}$ & $\begin{array}{c}\text { Percentage } \\
\text { Increase }\end{array}$ \\
\hline HC Emissions $(\mathrm{Kg})$ & 159.0 & 175.4 & 16.4 & 10.3 \\
\hline CO Emissions $(\mathrm{Kg})$ & 11563.5 & 12672.7 & 1109.2 & 9.6 \\
\hline NOx Emissions $(\mathrm{Kg})$ & 608.6 & 662.9 & 54.3 & 8.9 \\
\hline
\end{tabular}

Table 39 shows an increase in $\mathrm{HC}$ emissions by $21.7 \mathrm{~kg}$, CO emissions by 1,545 kg, and NO emissions by $67.9 \mathrm{~kg}$ for Without TDM as compared to With TDM during the PM period.

Table 39: Emissions during PM Peak

\begin{tabular}{|c|c|c|c|c|}
\hline Pollutant & With TDM & Without TDM & $\begin{array}{c}\text { Added } \\
\text { Emissions }\end{array}$ & $\begin{array}{c}\text { Percentage } \\
\text { Increase }\end{array}$ \\
\hline HC Emissions $(\mathrm{Kg})$ & 165.4 & 187.1 & 21.7 & 13.1 \\
\hline CO Emissions $(\mathrm{Kg})$ & 12170.8 & 13715.9 & 1545.1 & 12.7 \\
\hline NO Emissions $(\mathrm{Kg})$ & 625.2 & 693.1 & 67.9 & 10.9 \\
\hline
\end{tabular}




\subsection{Sensitivity Analysis}

The TDM set of programs in the Seattle region are very aggressive programs, with high levels of employee participation in employer-based programs. A sensitivity analysis was conducted to assess the impact for less aggressive TDM programs. A hypothetical Scenario $\mathrm{C}$ was assumed with only a 4 percent trip reduction at the 189 employer sites, as compared to the estimated 14 percent trip reduction With TDM. Scenario C assumes all basic CTR programs are in place, with the exception of parking costs and employer-provided subsidies (co-payments) for transit, carpool, vanpool, walk, and bicycle. This analysis was also conducted to determine whether the impact of trip reduction is proportional.
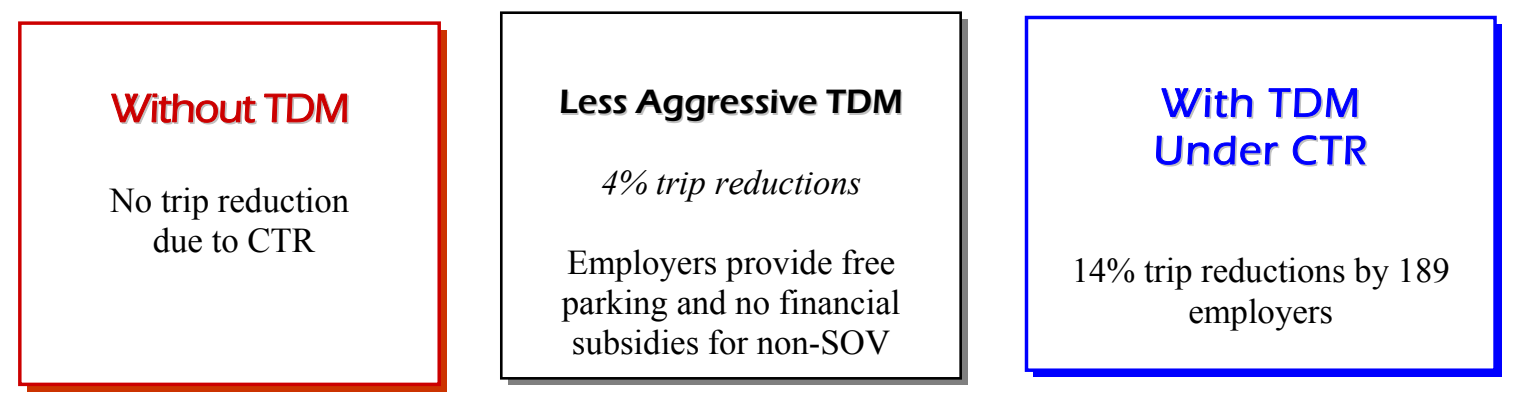

Sensitivity analysis was conducted by assuming Without TDM as the base scenario. This analysis was conducted to determine whether 3.5 times more reductions in trips With TDM (14 percent trip reduction) compared to Scenario C (4 percent trip reduction) yielded proportional benefits in terms of delay savings, fuel consumption, and other performance measures.

\subsubsection{Groundwork for CORSIM Input for Sensitivity Analysis}

Since the implementation of TDM programs varies across employers, there is no standard definition of the With TDM scenario. In other words, the calculated VTR for each employer is a reflection of levels of implementation of CTR programs. To analyze the impact of each group of TDM strategies, a sensitivity analysis was performed. To perform the sensitivity analysis, the values of one group of TDM program were artificially changed while holding others as original. The original represents the Washington CTR database.

To estimate the impact of employer TDM support strategies, VTRs are calculated assuming the program level is $0,1,2,3$, and 4 , respectively, for all of the target employers while holding other groups of strategies as the original. If the program level is 0 for all of the employers, the average percentage of reduced vehicle trips is 13.1 percent. Compared with the original 14.2 percent, it means the employer TDM support strategies contribute about 1 percent of vehicle trips reduction. It also shows that, for all the employers, the average program level is about two. The possible contribution of the employer TDM support strategies is 3.1 percent. 
Similarly, the contribution of commute travel cost change, the alternative work hours, and flexible work hours is 10.3 percent, 1.0 percent, and 1.1 percent respectively. The results of the sensitivity analysis are presented in Table 40.

Table 40: VTR Calculation Process for Sensitivity Analysis

\begin{tabular}{|c|c|c|c|c|c|c|c|c|c|}
\hline \multicolumn{4}{|c|}{ Employer TDM support strategies } & \multicolumn{2}{|c|}{$\begin{array}{c}\text { Parking and } \\
\text { Financial Subsidies }\end{array}$} & \multicolumn{2}{|c|}{ Alternative Work Hours } & \multirow{2}{*}{$\begin{array}{c}\text { Flexible } \\
\text { Work } \\
\text { Hours } \\
\end{array}$} & \multirow{2}{*}{$\begin{array}{c}\text { Vehicle } \\
\text { Trip } \\
\text { Change }\end{array}$} \\
\hline Carpool & Vanpool & Bicycle & Walk & Parking & Financial & Telecommuting & CWW & & \\
\hline Original & Original & Original & Original & Original & Original & Original & Original & Original & 0.142 \\
\hline 0 & 0 & 0 & 0 & Original & Original & Original & Original & Original & 0.131 \\
\hline 1 & 1 & 1 & 1 & Original & Original & Original & Original & Original & 0.135 \\
\hline 2 & 2 & 2 & 2 & Original & Original & Original & Original & Original & 0.141 \\
\hline 3 & 3 & 3 & 3 & Original & Original & Original & Original & Original & 0.153 \\
\hline 4 & 4 & 4 & 4 & Original & Original & Original & Original & Original & 0.162 \\
\hline Original & Original & Original & Original & Original & 0 & Original & Original & Original & 0.098 \\
\hline Original & Original & Original & Original & 0 & Original & Original & Original & Original & 0.097 \\
\hline Original & Original & Original & Original & 0 & 0 & Original & Original & Original & 0.039 \\
\hline Original & Original & Original & Original & Original & Original & Original & 0 & Original & 0.141 \\
\hline Original & Original & Original & Original & Original & Original & 0 & Original & Original & 0.133 \\
\hline Original & Original & Original & Original & Original & Original & 0 & 0 & Original & 0.132 \\
\hline Original & Original & Original & Original & Original & Original & Original & Original & 0 & 0.131 \\
\hline
\end{tabular}

\subsubsection{CORSIM Analysis}

Table 41 shows different performance measures for With TDM and Scenario C compared to Without TDM for the AM period. Scenario C had 21.9 percent reduction in delay as compared to 31.5 percent delay reduction in With TDM. Although the delay savings were more in With TDM, it did not yield proportional delay reduction. Similarly, for fuel consumption and emissions, With TDM showed more benefits but the savings were not proportional to the percentage trip reductions.

Table 41: Performance Measures during AM Peak

\begin{tabular}{|c|c|c|c|c|}
\hline Performance Measures & \multicolumn{2}{|c|}{$\begin{array}{c}\text { With TDM } \\
\text { (14\% trip Reduction) }\end{array}$} & \multicolumn{2}{c|}{$\begin{array}{c}\text { Scenario C } \\
\text { (4\% trip Reduction) }\end{array}$} \\
\hline Decrease in Delay (vehicle-min) & 152488.6 & $31.5 \%$ & 105930.5 & $21.9 \%$ \\
\hline Decrease in Fuel consumption (gal) & 3488.8 & $10.0 \%$ & 2367.0 & $6.8 \%$ \\
\hline Decrease in HC Emissions (kg) & 16.4 & $9.4 \%$ & 11.3 & $6.4 \%$ \\
\hline Decrease in CO Emissions (kg) & 1109.2 & $8.8 \%$ & 780.8 & $6.2 \%$ \\
\hline Decrease in NO Emissions (kg) & 54.3 & $8.2 \%$ & 38.1 & $5.8 \%$ \\
\hline
\end{tabular}


Table 42 shows different performance measures for scenarios $\mathrm{A}$ and $\mathrm{C}$ compared to $\mathrm{B}$ for the PM period. The results were consistent with the results of the AM period.

Table 42: Performance Measures during PM Peak

\begin{tabular}{|c|c|c|c|c|}
\hline \multirow{2}{*}{ Performance Measures } & \multicolumn{2}{|c|}{$\begin{array}{c}\text { With TDM } \\
\text { (14\% trip Reduction) }\end{array}$} & \multicolumn{2}{c|}{$\begin{array}{c}\text { Scenario C } \\
\text { (4\% trip Reduction) }\end{array}$} \\
\hline Decrease in Delay (vehicle-min) & 169486.3 & $42.0 \%$ & 130276.0 & $32.3 \%$ \\
\hline Decrease in Fuel consumption (gal) & 4314.1 & $12.1 \%$ & 3157.1 & $8.8 \%$ \\
\hline Decrease in HC Emissions (kg) & 21.7 & $11.6 \%$ & 15.2 & $8.1 \%$ \\
\hline Decrease in CO Emissions (kg) & 1545.1 & $11.3 \%$ & 1046.2 & $7.6 \%$ \\
\hline Decrease in NO Emissions (kg) & 67.9 & $9.8 \%$ & 47.4 & $6.8 \%$ \\
\hline
\end{tabular}

Tables 43 and 44 show decreases in the spatial extent of congestion for Scenario A and C for different levels of congestion during the AM period and PM period, respectively.

Table 43: Spatial Extent of Congestion during AM Peak

\begin{tabular}{|c|c|c|c|c|}
\hline Spatial Congestion & \multicolumn{2}{|c|}{$\begin{array}{c}\text { With TDM } \\
\text { (14\% trip Reduction) }\end{array}$} & \multicolumn{2}{|c|}{$\begin{array}{c}\text { Scenario C } \\
\text { (4\% trip Reduction) }\end{array}$} \\
\hline $\begin{array}{c}\text { Decrease in lane-miles } \\
\text { 30\% longer to travel }\end{array}$ & 101.7 & $18.7 \%$ & 60.5 & $11.1 \%$ \\
\hline $\begin{array}{c}\text { Decrease in lane-miles } \\
\text { 60\% longer to travel }\end{array}$ & 114.2 & $25.5 \%$ & 78.4 & $17.5 \%$ \\
\hline $\begin{array}{c}\text { Decrease in lane-miles } \\
\text { 100\% longer to travel }\end{array}$ & 101.5 & $28.6 \%$ & 67.6 & $19.1 \%$ \\
\hline $\begin{array}{c}\text { Decrease in lane-miles } \\
\text { 200\% longer to travel }\end{array}$ & 105.5 & $42.9 \%$ & 71.5 & $29.1 \%$ \\
\hline
\end{tabular}

Table 44: Spatial Extent of Congestion during PM Peak

\begin{tabular}{|c|c|c|c|c|}
\hline Spatial Congestion & \multicolumn{2}{|c|}{$\begin{array}{c}\text { With TDM } \\
\text { (14\% trip Reduction) }\end{array}$} & \multicolumn{2}{|c|}{$\begin{array}{c}\text { Scenario C } \\
\text { (4\% trip Reduction) }\end{array}$} \\
\hline $\begin{array}{c}\text { Decrease in lane-miles } \\
\text { 30\% longer to travel }\end{array}$ & 142.9 & $30.6 \%$ & 114.7 & $24.6 \%$ \\
\hline $\begin{array}{c}\text { Decrease in lane-miles } \\
60 \% \text { longer to travel }\end{array}$ & 115.3 & $33.0 \%$ & 92.0 & $26.3 \%$ \\
\hline $\begin{array}{c}\text { Decrease in lane-miles } \\
\text { 100\% longer to travel }\end{array}$ & 117.6 & $43.0 \%$ & 89.6 & $32.7 \%$ \\
\hline $\begin{array}{c}\text { Decrease in lane-miles } \\
\text { 200\% longer to travel }\end{array}$ & 106.3 & $55.7 \%$ & 79.6 & $41.7 \%$ \\
\hline
\end{tabular}

The sensitivity analysis showed that even small reductions in vehicle trips had significant impact on the performance of the transportation network. 


\subsection{Factors Affecting the Results}

It is important to note that this study was on an 8.6 mile section corridor and results may vary for a different roadway section. The major factors that affected the results are:

1. The level of congestion on the roadway section that was selected. If the roadway section selected for the analysis is operating well below capacity, then the impacts of the TDM programs will not be proportional. Similarly, if the roadway section is operating well above capacity then a small reduction in vehicle trips due to TDM programs may not have significant impact on the performance of the corridor. Therefore, a sufficiently long segment that may have roadway sections operating at different levels of capacity may be suitable for this analysis.

2. The percentage of VTR due to TDM programs depended on the types of TDM strategies implemented, the level of TDM programs, and the number of employees participating in these programs.

3. This research was limited to only 189 employers. Even a slightly larger study area with even a few more CTR employers could have affected the corridor analyzed in this study.

4. The CTR databases include data of employers with 100 or more employees. There are probably more employer-based TDM programs in and around the Seattle region not part of CTR and were not accounted for in this study.

\subsubsection{Factors Affecting Traffic Flow Change on Ramps}

While the average traffic flow change of I-5 ramp traffic is about 4 percent, the distribution of the change is not even. The factors that affect the ramp traffic flow change include:

1. Location of the ramp. While the 189 worksites around I-5 are scattered between NE 45TH Street and South Corson Avenue, most of them are clustered within the downtown area. At the AM peak period, people go to work from the north, south, and west to downtown. The reduced vehicle trips take the on-ramps at the north and south ends of I-5, I-90, and SR520, which connect I-5 to the west area of King County. Travelers take the off-ramp at the downtown area. The significant traffic flow changes only occur at southbound on-ramps close to the north end, northbound on-ramps close to the south end, the northbound on-ramps of 1-90, the southbound on-ramps of SR520, and the off-ramps close to downtown. At the PM peak period, people go home from the downtown area to the north, south, and west areas. The reduced vehicle trips take the on-ramp close to downtown and the off-ramps at the north and south end of I-5 and that of I-90 and SR520, which connect I-5 to the west area of King County. The significant traffic flow changes only occur at northbound off-ramps close to the north end, southbound off-ramps close to the south end, southbound off-ramps of 1-90, northbound off-ramps of SR520, and the on-ramp close to downtown.

2. Location of the centroid of ZIP codes. The centroid of ZIP codes are used to represent the location of the employees' homes. Obviously, it is not accurate 
enough. For example, if there is only one centroid between two contiguous ramps, all of the trips to or from that centroid will take either of the ramps while leaving another one without traffic.

3. The number of VTR at each worksite and the number of commute trips between each of the worksite-home pair. For the big employers with big reduced vehicle trips, the impacts to the surrounding areas are significant.

The fact is that traffic flow changes on the I-5 ramps vary dramatically, based on their geographic locations, their relationships with other ramps, and the characteristics of surrounding worksites. Therefore, each ramp was examined to find the source of the traffic flow change.

Tables 45, 46, 47, and 48 present the original traffic flow (With TDM) and the possible traffic flow increase if the CTR program is not implemented for each on-ramp or off-ramp at AM and PM peak periods. A brief comment is included to describe the source of the traffic flow change for each ramp.

Table 45: On-ramp Traffic Flow at AM Peak (Home to Work)

\begin{tabular}{|c|c|c|c|c|}
\hline $\begin{array}{c}\text { On-ramp } \\
\text { north to south }\end{array}$ & $\begin{array}{c}\text { Original } \\
\text { Flow }\end{array}$ & $\begin{array}{c}\text { Flow } \\
\text { Change }\end{array}$ & Percentage & Comments \\
\hline $\begin{array}{c}\text { I-5 SB North } \\
\text { End }\end{array}$ & 18594 & 1884 & $10.13 \%$ & $\begin{array}{c}\text { Commuters going from north } \\
\text { (out of study area) to downtown area }\end{array}$ \\
\hline $45^{\text {th }}$ SB & 1847 & 0 & $0 \%$ & No ZIP code centroid close to the intersection \\
\hline Harvard NB & 1414 & 0 & $0 \%$ & No ZIP code centroid close to the intersection \\
\hline SR520 NB & 2188 & 0 & $0 \%$ & No worksite located north side of the intersection \\
\hline SR520 SB & 7506 & 151 & $2.01 \%$ & Commuters going from north west to downtown \\
area
\end{tabular}


Table 46: Off-ramp Traffic Flow at AM Peak (Home to Work)

\begin{tabular}{|c|c|c|c|c|}
\hline $\begin{array}{l}\text { Off-Ramp } \\
\text { north to south }\end{array}$ & $\begin{array}{c}\text { Original } \\
\text { Flow }\end{array}$ & $\begin{array}{c}\text { Flow } \\
\text { Change }\end{array}$ & Percentage & Comments \\
\hline $\begin{array}{l}\text { I-5 NB North } \\
\text { End }\end{array}$ & 14200 & 0 & $0 \%$ & $\begin{array}{l}\text { No commuting traffic going north } \\
\text { out of the study area at AM peak }\end{array}$ \\
\hline 45th NB & 3713 & 0 & $0 \%$ & No worksite located nearby \\
\hline Boylston SB & 1992 & 0 & $0 \%$ & No worksite located nearby \\
\hline SR520 NB & 4168 & 10 & $0.24 \%$ & $\begin{array}{l}\text { Commuters going from south to } \\
\text { north west of I-5 }\end{array}$ \\
\hline SR520 SB & 4323 & 104 & $2.41 \%$ & $\begin{array}{l}\text { Commuters going from north to } \\
\text { north west of I-5 }\end{array}$ \\
\hline $\begin{array}{l}\text { Lakeview } \\
\text { NB }\end{array}$ & 942 & 42 & $4.46 \%$ & Close to Downtown area \\
\hline Mercer SB & 2995 & 164 & $5.48 \%$ & Close to Downtown area \\
\hline Mercer NB & 3408 & 0 & $0 \%$ & $\begin{array}{l}\text { No worksites close to the } \\
\text { intersection, traffic either takes } \\
\text { Lakeview or Oliver off }\end{array}$ \\
\hline Stewart SB & 2477 & 491 & $19.82 \%$ & Downtown area \\
\hline Oliver NB & 1854 & 187 & $10.09 \%$ & Downtown area \\
\hline Union SB & 2726 & 1073 & $39.36 \%$ & Downtown area \\
\hline Seneca NB & 3641 & 1431 & $39.30 \%$ & Downtown area \\
\hline $6^{\text {th }} \mathrm{SB}$ & 4820 & 300 & $6.22 \%$ & Close to downtown area \\
\hline I-90 SB & 8170 & 37 & $0.45 \%$ & $\begin{array}{l}\text { Commuters going from north to } \\
\text { south west of I-5 }\end{array}$ \\
\hline I-90 NB & 9262 & 36 & $0.39 \%$ & $\begin{array}{l}\text { Commuters going from south to } \\
\text { south west of I-5 }\end{array}$ \\
\hline $4^{\text {th }} \mathrm{NB}$ & 443 & 213 & $48.08 \%$ & $\begin{array}{l}\text { Commuters going to south east of } \\
\text { I-5 }\end{array}$ \\
\hline Forest SB & 983 & 2 & $0.20 \%$ & Few worksites nearby \\
\hline Spokane SB & 4247 & 20 & $0.47 \%$ & Few worksites nearby \\
\hline Spokane NB & 5376 & 35 & $0.65 \%$ & Few worksites nearby \\
\hline Corson SB & 2764 & 0 & $0 \%$ & No worksite nearby \\
\hline $\begin{array}{l}\text { I-5 SB South } \\
\text { End }\end{array}$ & 17147 & 0 & $0 \%$ & $\begin{array}{l}\text { No commuting traffic going south } \\
\text { out of the study area at AM peak }\end{array}$ \\
\hline
\end{tabular}


Table 47: On-ramp Traffic Flow at PM Peak (Work to Home)

\begin{tabular}{|c|c|c|c|c|}
\hline $\begin{array}{l}\text { On-ramp } \\
\text { north to } \\
\text { south }\end{array}$ & $\begin{array}{l}\text { Original } \\
\text { Flow }\end{array}$ & $\begin{array}{l}\text { Flow } \\
\text { Change }\end{array}$ & Percentage & Comments \\
\hline $\begin{array}{l}\text { I-5 SB } \\
\text { North End }\end{array}$ & 19563 & 0 & $10.13 \%$ & $\begin{array}{l}\text { No commuting traffic going from north } \\
\text { (out of the study area) to downtown area at } \\
\text { PM peak }\end{array}$ \\
\hline 45th SB & 2547 & 0 & $0 \%$ & No worksite close to the intersection \\
\hline $\begin{array}{l}\text { Harvard } \\
\text { NB }\end{array}$ & 2152 & 90 & $4.18 \%$ & Commuting traffic going to north \\
\hline SR520 NB & 4575 & 35 & $0.77 \%$ & $\begin{array}{l}\text { Commuting traffic going from north west } \\
\text { to north }\end{array}$ \\
\hline SR520 SB & 4784 & 3 & $0.06 \%$ & $\begin{array}{c}\text { Commuting traffic going from north west } \\
\text { to south }\end{array}$ \\
\hline $\begin{array}{c}\text { Boylston } \\
\text { SB }\end{array}$ & 1197 & 20 & $1.67 \%$ & Close to downtown area \\
\hline Mercer SB & 4535 & 55 & $1.21 \%$ & Close to downtown area \\
\hline $\begin{array}{l}\text { Mercer } \\
\text { NB }\end{array}$ & 3637 & 272 & $7.48 \%$ & Downtown area \\
\hline Oliver NB & 4712 & 510 & $10.82 \%$ & Downtown area \\
\hline Yale SB & 4099 & 469 & $11.44 \%$ & Downtown area \\
\hline $\begin{array}{l}\text { University } \\
\text { NB }\end{array}$ & 2192 & 1214 & $55.83 \%$ & Downtown area \\
\hline $\mathrm{I}-90 \mathrm{NB}$ & 9959 & 73 & $0.73 \%$ & Commuters going from south west to north \\
\hline $4^{\text {th }} \mathrm{SB}$ & 10594 & 0 & $0 \%$ & $\begin{array}{l}4^{\text {th }} \text { Street and } 6^{\text {th }} \text { Street on-ramps were } \\
\text { coded to connect the same link to I- } 5 \text {. The } \\
6^{\text {th }} \text { street on-ramp is prior that of } 4^{\text {th }} \text { Street, } \\
\text { based on the all-or-nothing approach of } \\
\text { traffic assignment, all traffic is assigned to } \\
6^{\text {th }} \text { Street on-ramp. }\end{array}$ \\
\hline $6^{\text {th }} \mathrm{SB}$ & 4278 & 1019 & $23.82 \%$ & $\begin{array}{l}\text { Commuters going from downtown area to } \\
\text { south }\end{array}$ \\
\hline $\begin{array}{l}\text { Spokane } \\
\text { NB }\end{array}$ & 3417 & 0 & $0 \%$ & No northbound traffic \\
\hline $\begin{array}{l}\text { Spokane } \\
\text { SB }\end{array}$ & 1527 & 35 & $2.29 \%$ & Southbound traffic \\
\hline $\begin{array}{l}\text { Corson } \\
\text { NB }\end{array}$ & 3417 & 0 & $0 \%$ & No worksite nearby \\
\hline $\begin{array}{l}\text { I-5 NB } \\
\text { South End }\end{array}$ & 19186 & 0 & $0 \%$ & $\begin{array}{l}\text { No commuting traffic going from south } \\
\text { (out of the study area) to downtown area at } \\
\text { PM peak }\end{array}$ \\
\hline
\end{tabular}


Table 48: Off-ramp Traffic Flow at PM Peak (Work to Home)

\begin{tabular}{|c|c|c|c|c|}
\hline $\begin{array}{c}\text { Off-Ramp } \\
\text { north to south }\end{array}$ & $\begin{array}{c}\text { Original } \\
\text { Flow }\end{array}$ & $\begin{array}{c}\text { Flow } \\
\text { Change }\end{array}$ & Percentage & Comments \\
\hline NB North End & 17689 & 1867 & $10.55 \%$ & Commuters going north out of study area \\
\hline 45th NB & 5039 & 0 & $0 \%$ & No centroid nearby \\
\hline Boylston SB & 2018 & 0 & $0 \%$ & No centroid nearby \\
\hline SR520 NB & 6459 & 176 & $2.72 \%$ & Commuters going from downtown area to north west of King \\
\hline County
\end{tabular}




\section{Chapter 6 - Findings, Conclusions, and Recommendations}

Clearly, the TDM program in the Seattle area had a significant impact on traffic congestion, travel delay, fuel savings, and emissions. For the portion of the corridor analyzed in this study, the cumulative savings in delay due to TDM programs were estimated to be 152,489 and 169,486 vehicle-minutes for the AM and PM periods, respectively, attributable to the extensive worksite TDM programs. There was a reduction of 101.7 lane-miles of spatial congestion in the AM peak and 142.9 lane-miles in the PM peak. A significant congestion reduction of 60 and 45 minutes for the AM and PM peaks, respectively, was observed from the CORSIM output files. The average speed increased by up to $19 \mathrm{mph}$ for the AM and up to $11 \mathrm{mph}$ for the PM peak. VMT reductions ranged from 17,297 vehicle-miles in the AM peak to 14,511 vehicle-miles in the PM peak. Fuel savings of 3,489 gallons during the AM peak period and 4,314 gallons during the PM periods were direct results of TDM programs. $\mathrm{HC}$ emissions reductions of 16.4 and 21.7 kilograms for the AM and PM peak, respectively, are a considerable improvement to air quality, as are emissions reduction of 1,109 and 1,545 kilograms of $\mathrm{CO}$ for the AM and PM peak, respectively.

The aforementioned results do not encompass all the impacts. The analysis was limited to an 8.6 mile stretch of a corridor. Also, this study takes into account the impact of only 189 CTR employers in the region. However, there might be more worksites where TDM programs might have reduced vehicle trips, which might have affected the corridor analyzed in this study. Further, the CTR database does not account for all of the TDM programs in the Seattle region. Therefore, TDM programs likely have an even greater impact on the performance of the transportation network than what is projected in this report.

This research study combined a common goal of transportation agencies: reducing traffic congestion and improving the efficiency of the existing transportation system. By monitoring, evaluating, and communicating TDM strategies and their combined impacts on the roadway system in a visual way, planners, traffic operations staff, TDM professionals, decision-makers, and elected officials can be talking the same language when comparing available cost-effective measures to reduce congestion with a focus on performance rather than a highway construction solution. The challenges, facing TDM professionals and traffic operations professionals alike, addressed by this study included:

1. Are there better ways to communicate TDM successes to elected officials?

2. Can other measures/indicators convey the effectiveness of TDM by relating employer-based TDM programs directly to traffic congestion?

3. Can TDM strategies prove their effectiveness in ways that make them eligible for consideration by traffic operations staff?

4. Can a methodology be developed where TDM benefits are calculated in terms of widely used measures of transportation system efficiency? 
5. If such a methodology exists, would different users with varied backgrounds and expertise be able to utilize it for assessing TDM impacts on their perspective areas of interest?

6. How helpful would a graphical representation of a transportation system be with employer-based TDM program(s) impacts clearly visualized in terms of speed and time?

This research report answered these questions and provided insights into future opportunities of tackling congestion by adding vehicle capacity, not necessarily road capacity. In answer to the first and last communication approach questions, this research study graphically presented the results of the CORSIM analysis showing the isolated impacts of CTR programs on the I-5 corridor study area (Figures 13 to 24). The project clearly demonstrated that small changes in the location or time could substantially alter transportation system performance. In many areas of the study corridor and/or times of day, TDM made a significant impact on congestion, but not in all areas or times of day. This recognizes that TDM, like every other transportation solution, is not a panacea for every congested segment or period. While some TDM advocates may need to manage expectations from TDM impacts, other transportation professionals and community leaders may better appreciate the benefits of TDM as an effective tool in the congestion reduction toolbox as the result of this analysis.

Like many TDM programs in the country, one of the primary CTR goals is to reduce congestion. These TDM goals are measured in terms of reductions in SOV use and VMT reduction. However, NTOC's recommended congestion measures focus on other temporal and spatial measures of performance. This gap means both the TDM and traffic operations professionals need a unified set of measures for alternatives analysis. For example, while shifting commuters from SOV to some higher occupancy mode ultimately improves travel flow, the conversion of this behavioral change into impacts on travel speed or delay was not defined in standard MOEs terms. When this conversion is fully developed and standardized, traffic operations professionals and decision-makers will comprehend and appreciate the relative impact of TDM on congestion. Furthermore, the process used by this project also accounts for demand management strategies that do not change mode but shift the time of travel (e.g., compressed work week) or eliminate the peak hour trip entirely (e.g., telework).

The findings included significant reduction in recurring delay, reduction in spatial and temporal extent of congestion, and lesser emissions due to TDM programs. In addition, TDM programs resulted in fuel savings, VMT reduction, and an increase in the average speed of the corridor. These results indicate that TDM had significant impacts on the performance of the transportation corridor.

The transferability of this analysis approach to estimate the impacts of employer-based TDM programs on a traffic network, is achieved through a web-based course. The course provides guidance to transportation and traffic professionals on the methodology developed by this research study. 
This research uses the language of traffic operations professionals to communicate the impacts of TDM strategies. In the future, data can be collected by ITS and that should help improve the methodology of assessing the impacts on TDM on the total system, not just a corridor. Since ITS is systematically used for dynamic data collection, it can be utilized in before and after TDM evaluations.

Another area for future research is the synergistic effects of TDM and ITS strategies. For example, on a given corridor, are the effects of implementing a 511 system with HOV lanes equal to the sum of the individual effects of each application or does combining these strategies have a multiplicative effect that could result in larger or smaller impacts?

Further, the impact of TDM programs was measured using the performance measures indicated by the NTOC performance measure initiative. This aids in communicating the impacts of TDM programs to the traffic operations professionals and decision makers.

Finally, the disproportionate impact of TDM is perhaps the most significant finding with respect to communities, especially to those without a commute trip reduction regulation like the Puget Sound region. The sensitivity analysis indicated that even a small reduction (4 percent) in vehicle trips could also result in significant impact on the transportation network. Though there was a reduction of about 29 percent in vehicle trips, other system performance measures such as decrease in delay in vehicle-minutes, emissions, energy consumption, and spatial extent of congestion (i.e., decrease in lane-miles that takes 30 percent longer to travel) decreased by approximately 70 percent. This reinforces the "tipping point" impact TDM can have on congestion. Clearly, every little bit helps.

With respect to future research, this study sets a foundation for future work on:

- The development of national standards for measuring the performance of TDM that integrate with other transportation systems measures

- Development of cost/benefit analysis of TDM programs to communities and businesses

- Measuring the impact of TDM programs on freeways, arterials, and surface streets

- Analyzing the additive or multiplicative effects of combining different TDM strategies with appropriate ITS applications locally and regionally 


\section{References}

1) Brown, J., Baldwin, D. and D. Shoup. 2003. Fare-Free Public Transit at Universities: An Evaluation, "Journal of Planning Education and Research" 2003; 23; 69. University of California, Los Angeles

2) The Status of Telework in the Federal Government 2005

http:/www.telework.gov/documents/tw rpt05/status-intro.asp

3) Commute Trip Reduction Task Force. 2005. "Report to the Washington State Legislature." Accessed February 13, 2007 at http://www.wsdot.wa.gov/tdm/tripreduction/download/CTR_Report_05.pdf

4) Center for Urban Transportation Research, University of South Florida. 1999. "Commuter Assistance Program Evaluation Manual," Florida Department of Transportation. http://www.nctr.usf.edu/clearinghouse/pdf/capman\%20rev\%202.pdf

5) Washington State Commute Trip Reduction Task Force. 2001. "Report to the Washington State Legislature." Accessed February 13, 2007 at http://www.wsdot.wa.gov/tdm/tripreduction/download/CTR_Report_01.pdf

6) Schrank, D., and T. Lomax. 2003. “Annual Urban Mobility Report.” Texas Transportation Institute, College Station, Texas.

7) Transportation Solutions Inc, and Cambridge Systematics, Inc. (2004). "Statewide ITS Performance Measures Final Report." FDOT. Accessed September 7, 2006 at http://www.dot.state.fl.us/TrafficOperations/ITS/Projects_Deploy/PerfMeas/Statewide_ITS PMs Report-Final-11-2004.pdf

8) FHWA Office of Operations - 21st Century Operations Using 21st Century Technologies World Wide Web address at http://ops.fhwa.dot.gov/perf_measurement/fundamentals.htm accessed August 2006.

9) National Transportation Operations Coalition. "Performance Measure Initiative Final Report." July 2005. Accessed August 2006 at http://www.ntoctalks.com/ntoc/ntoc final report.pdf

10) Transportation Research Board. 2001. "Conference Proceedings 26. Performance Measures to Improve Transportation Systems and Agency Operations: Report of a Conference." National Academy Press. http://onlinepubs.trb.org/onlinepubs/conf/reports/cp_26.pdf

11) Transportation Research Board. 2003. "NCHRP Synthesis of Highway Practice 311: Performance Measures of Operational Effectiveness for Highway Segments and Systems," National Academy Press.

12) Transportation Research Board. 2005. "Conference Proceeding 36. Performance Measures to Improve Transportation Systems: Summary of the Second National Conference." National Academy Press. Accessed February 13, 2007 at http://onlinepubs.trb.org/onlinepubs/conf/CP36.pdf 
13) McGuire, Julie. 2005. “Transportation Demand Management Evaluation Techniques REPORT ON Best Practices in Canada, the USA, the UK, and their Applicability to Ontario," IES 2002S: Applied Environmental Research and Climate-Air Connections. Accessed September 18, 2006 at http://www.climateairconnections.ca/pdf/Julie_TDM_Evaluation.pdf

14) California Air Resources Board. "Determining the Cost-Effectiveness of Employer TDM Programs.” Accessed June 2006 at http://www.arb.ca.gov/planning/tsaq/eval/eval.htm.

15) Washington State Department of Transportation. "Washington state TDM Effectiveness Estimation Methodology (TEEM) Model.” Accessed June 2006 at http://www.wsdot.wa.gov/mobility/TDM/sr520caseteem.htm

16) United States Environmental Protection Agency. "Commuter Model v2.0 User Manual." Accessed June 2006 at http://www.epa.gov/otaq/stateresources/policy/transp/commuter/commuter-v20.zip

17) Center for Urban Transportation Research at University of South Florida. "Worksite Trip Reduction Model.” Accessed June 2006 at http://www.nctr.usf.edu/worksite/.

18) Texas Transportation Institute. "2003 Annual Urban Mobility Report - Appendix B: Methodology," Texas Transportation Institute, College Station, Texas.

19) Alexiadis, V., Jeannotte, K. and Chandra, A., 2004. "Traffic Analysis Toolbox Volume I: Traffic Analysis Tools Primer," prepared by Cambridge Systematics, Inc. Federal Highway Administration, Washington D.C.

20) Jeannotte, K., Chandra, A, Alexiadis, V. and Skabardonis A., 2004. "Traffic Analysis Toolbox Volume II: Decision Support Methodology for Selecting Traffic Analysis Tools," prepared by Cambridge Systematics, Inc. Federal Highway Administration, Washington D.C.

21) The CASE STUDIES Database is at the HelpDesk of NCTR National TDM and Telework Clearinghouse. The online database containing more than 100 case studies can be found at http://www.nctr.usf.edu/helpdesk/casestudies.htm 
Appendix A 
Organization Information for 2004

US Social Security Administration

701-5th Avenue, Suite 2900, M/S 292C, Seattle, WA

Website:

Primary Business:

Non-profit organization?

Total Employees:

Affected Employees:

Is the CTR program subject to collective bargaining?

Does this worksite have multiple shifts?

Shifts description: www.ssa.gov

Government

Yes

212

201

Yes

No

$\mathrm{N} / \mathrm{A}$

\section{CTR program contact:}

David Lantry

King County Metro

400 Yesler Way, MS YES-TR-0650, Seattle, WA 98104

Phone: (206) 684-1139

Email: david.lantry@metrokc.gov

\section{Worksite Characteristics (2004)}

\begin{tabular}{|c|c|c|c|c|c|}
\hline $\begin{array}{c}\text { Bus Stop(s) } \\
\text { Availability }\end{array}$ & $\begin{array}{c}\text { Bike Lane } \\
\text { Availability }\end{array}$ & $\begin{array}{c}\text { Sidewalks } \\
\text { Availability }\end{array}$ & $\begin{array}{l}\text { Restaurants } \\
\text { Availability }\end{array}$ & $\begin{array}{c}\text { Shopping } \\
\text { Availability }\end{array}$ & Bank Availability \\
\hline Onsite & Not available & Onsite & Onsite & Onsite & Onsite \\
\hline
\end{tabular}

\section{Worksite Parking and Parking Management Information}

\section{Parking management and monitoring ( 2004 )}

Permanently assigned government owned or leased vehicles: 3spaces. Severely handicapped employees: 2spaces. Executive personnel: 8 spaces. Bargaining unit employees-AFGE Local 1122: 3 spaces. AFGE Council 224: 4 Spaces. Vehicles of visitors: 4 spaces. Vanpool/carpool: 27 spaces. SOV: 0 spaces

Parking
\begin{tabular}{|c|c|c|c|c|}
\hline $\begin{array}{c}\text { Program } \\
\text { Year }\end{array}$ & $\begin{array}{c}\text { Total \# of } \\
\text { Employees }\end{array}$ & $\begin{array}{c}\text { Onsite Parking } \\
\text { Spaces }\end{array}$ & $\begin{array}{c}\text { Offsite Parking } \\
\text { Spaces }\end{array}$ & $\begin{array}{c}\text { Leased Onsite } \\
\text { Parking Spaces }\end{array}$ \\
\hline 2002 & 208 & 48 & 0 & 48 \\
\hline 2003 & 204 & 51 & 0 & 51 \\
\hline 2004 & 212 & 48 & 0 & 48 \\
\hline
\end{tabular}

\begin{tabular}{|c|c|c|c|}
\hline Program & \multicolumn{3}{|c|}{ Leased Offsite Leased Onsite Parking Leased Offsite Parking } \\
\hline Year & Parking Spaces & Price (Space/Month) & Price (Space/Month) \\
\hline 2002 & 0 & & \\
\hline 2003 & 0 & & \\
\hline 2004 & 0 & & \\
\hline
\end{tabular}

\section{Parking management}




\begin{tabular}{|c|c|c|c|c|}
\hline $\begin{array}{c}\text { Program } \\
\text { Year }\end{array}$ & $\begin{array}{c}\text { Owned Onsite } \\
\text { Parking } \\
\text { Charge } \\
\text { (Space/Month) }\end{array}$ & $\begin{array}{c}\text { Owned Offsite } \\
\text { Parking } \\
\text { Charge } \\
\text { (Space/Month) }\end{array}$ & $\begin{array}{c}\text { Leased Onsite } \\
\text { Parking } \\
\text { Charge } \\
\text { (Space/Month) }\end{array}$ & $\begin{array}{c}\text { Leased Offsite } \\
\text { Parking } \\
\text { Charge } \\
\text { (Space/Month) }\end{array}$ \\
\hline 2002 & 0 & 0 & 0 & 0 \\
\hline 2003 & 0 & 0 & 0 & 0 \\
\hline 2004 & 0 & 0 & 0 & 0 \\
\hline
\end{tabular}

\begin{tabular}{|c|c|c|c|c|c|}
\hline $\begin{array}{c}\text { Program } \\
\text { Year }\end{array}$ & $\begin{array}{c}\text { Carpool Parking } \\
\text { Spaces }\end{array}$ & $\begin{array}{c}\text { Carpool Parking Charge } \\
\text { (Space/Month) }\end{array}$ & $\begin{array}{c}\text { Vanpool Parking } \\
\text { Spaces }\end{array}$ & $\begin{array}{c}\text { Vanpool } \\
\text { Parking } \\
\text { Charge } \\
\text { (Space/Month) }\end{array}$ & $\begin{array}{c}\text { Reduced SOV } \\
\text { Parking Space }\end{array}$ \\
\hline 2002 & 23 (Carpool \& Vanpool) & 0 & 23 (Carpool \& Vanpool) & 0 & 0 \\
\hline 2003 & 27 (Carpool \& Vanpool) & 0 & 27 (Carpool \& Vanpool) & 0 & 0 \\
\hline 2004 & 23 (Carpool \& Vanpool) & 0 & 23 (Carpool \& Vanpool) & 0 & 0 \\
\hline
\end{tabular}

\section{Program Promotion}

\section{General information ( 2004 )}

Is the ETC's name, location, and telephone number prominently displayed at this worksite? Yes

Displayed where?

Has the ETC completed a program developer/ETC training course?

On average, how many hours per week does the ETC spend on CTR activities?

Intranet site.

Does the ETC have an active worksite committee to assist with the CTR program?

Yes

5

No

\section{Program promotion}

\begin{tabular}{|c|c|c|c|c|}
\hline $\begin{array}{c}\text { Program } \\
\text { Year }\end{array}$ & $\begin{array}{c}\text { Distribute Summary } \\
\text { of CTR Program }\end{array}$ & $\begin{array}{c}\text { Provide CTR Program } \\
\text { Information to New Employees }\end{array}$ & $\begin{array}{c}\text { Post } \\
\text { Materials }\end{array}$ & $\begin{array}{c}\text { Give Managers } \\
\text { Presentation }\end{array}$ \\
\hline 2002 & Yes & Yes & Yes & No \\
\hline 2003 & Yes & Yes & Yes & No \\
\hline 2004 & Yes & Yes & Yes & No \\
\hline
\end{tabular}

\begin{tabular}{|c|c|c|c|c|c|}
\hline $\begin{array}{c}\text { Program } \\
\text { Year }\end{array}$ & $\begin{array}{c}\text { Give Employees } \\
\text { Presentation }\end{array}$ & $\begin{array}{c}\text { Conduct } \\
\text { CTR Events }\end{array}$ & $\begin{array}{c}\text { Publish CTR } \\
\text { Articles }\end{array}$ & $\begin{array}{c}\text { Distribute Information } \\
\text { with Paycheck }\end{array}$ & $\begin{array}{c}\text { Distribute Ridematch } \\
\text { Applications }\end{array}$ \\
\hline 2002 & No & Yes & No & No & No \\
\hline 2003 & No & Yes & No & No & No \\
\hline 2004 & No & Yes & No & No & Yes \\
\hline
\end{tabular}

\section{Site Amenities}




\begin{tabular}{|c|c|c|}
\hline $\begin{array}{c}\text { Program } \\
\text { Year }\end{array}$ & $\begin{array}{c}\text { Covered } \\
\text { Bicycle } \\
\text { Spaces }\end{array}$ & $\begin{array}{c}\text { Uncovered } \\
\text { Bicycle } \\
\text { Spaces }\end{array}$ \\
\hline 2002 & Yes & Yes \\
\hline 2003 & Yes & Yes \\
\hline 2004 & Yes & Yes \\
\hline
\end{tabular}

\begin{tabular}{|c|c|c|}
$\begin{array}{c}\text { Clothes } \\
\text { Lockers }\end{array}$ & $\begin{array}{c}\text { Showers } \\
\text { Loading/Unloading } \\
\text { Shelters }\end{array}$ & Non-SOV On-site \\
\hline No & No & Yes \\
\hline No & No & Yes \\
\hline No & No & Yes \\
\hline
\end{tabular}

\section{Financial Subsidies, Incentives, or Allowances}

\begin{tabular}{|c|c|c|c|c|}
\hline $\begin{array}{c}\text { Program } \\
\text { Year }\end{array}$ & $\begin{array}{c}\text { Transit Subsidy } \\
\text { (Employee/Month) }\end{array}$ & $\begin{array}{c}\text { Vanpool Subsidy } \\
\text { (Employee/Month) }\end{array}$ & $\begin{array}{c}\text { Carpool Subsidy } \\
\text { (Employee/Month) }\end{array}$ & $\begin{array}{c}\text { Walking Subsidy } \\
\text { (Employee/Month) }\end{array}$ \\
\hline 2002 & $\$ 45$ & $\$ 45$ & 0 & 0 \\
\hline 2003 & $\$ 45$ & $\$ 45$ & 0 & 0 \\
\hline 2004 & $\$ 45$ & $\$ 45$ & 0 & 0 \\
\hline
\end{tabular}

\begin{tabular}{|c|c|c|c|}
\hline $\begin{array}{c}\text { Program } \\
\text { Year }\end{array}$ & $\begin{array}{c}\text { Ferry Subsidy } \\
\text { (Employee/Month) }\end{array}$ & $\begin{array}{c}\text { Bicycling Subsidy } \\
\text { (Employee/Month) }\end{array}$ & $\begin{array}{c}\text { Other Stipend } \\
\text { (Employee/Month) }\end{array}$ \\
\hline 2002 & $\$ 45$ & 0 & 0 \\
\hline 2003 & $\$ 45$ & 0 & 0 \\
\hline 2004 & $\$ 45$ & 0 & 0 \\
\hline
\end{tabular}

\section{Fleet Vehicles and Special Programs}

Employer provided vehicles availability
\begin{tabular}{|c|c|c|c|c|c|}
\hline $\begin{array}{c}\text { Program } \\
\text { Year }\end{array}$ & $\begin{array}{c}\text { FV Guaranteed } \\
\text { Ride Home }\end{array}$ & $\begin{array}{c}\text { FV Vanpool } \\
\text { Trips }\end{array}$ & $\begin{array}{c}\text { FV Carpool } \\
\text { Related Errands }\end{array}$ & FV Work-Related & FV Non-Work \\
\hline 2002 & No & No & No & No & No \\
\hline 2003 & No & No & No & Yes & No \\
\hline 2004 & No & No & No & Yes & No \\
\hline
\end{tabular}

\section{Other services availability}

\begin{tabular}{|c|c|c|c|}
\hline $\begin{array}{c}\text { Program } \\
\text { Year }\end{array}$ & $\begin{array}{c}\text { Employer-Provided } \\
\text { Shuttle }\end{array}$ & $\begin{array}{c}\text { Guaranteed Ride Home } \\
\text { Program }\end{array}$ & $\begin{array}{c}\text { Internal Match } \\
\text { Program }\end{array}$ \\
\hline 2002 & No & No & No \\
\hline 2003 & No & No & No \\
\hline 2004 & No & No & No \\
\hline
\end{tabular}




\section{Mode Split and Vehicle Miles Traveled}

\begin{tabular}{|c|c|c|c|c|c|c|c|}
\hline $\begin{array}{l}\text { Program } \\
\text { Year }\end{array}$ & \multicolumn{2}{|c|}{$\begin{array}{l}\text { Num of Surveys Distributed } \\
\text { (Num of Affected Employees) }\end{array}$} & \multicolumn{2}{|c|}{$\begin{array}{c}\text { Total Reported } \\
\text { Commuting Days }\end{array}$} & $\begin{array}{l}\text { Driving } \\
\text { Alone }\end{array}$ & Carpooling & Vanpooling \\
\hline 2001 & \multicolumn{2}{|c|}{200} & & 757 & $20.3435 \%$ & $22.3250 \%$ & $0.6605 \%$ \\
\hline 2003 & \multicolumn{2}{|l|}{211} & & 741 & $16.3293 \%$ & $20.6478 \%$ & $1.3495 \%$ \\
\hline $\begin{array}{l}\text { Program } \\
\text { Year }\end{array}$ & Public Transit & \multicolumn{2}{|c|}{ Bicycling } & Walking & Other & \multicolumn{2}{|c|}{ Vehicle Miles Traveled } \\
\hline 2001 & $52.4439 \%$ & \multicolumn{2}{|c|}{$0.0000 \%$} & $0.6605 \%$ & $3.5667 \%$ & \multicolumn{2}{|c|}{6.21} \\
\hline 2003 & $56.5452 \%$ & \multicolumn{2}{|c|}{$0.0000 \%$} & $1.3495 \%$ & $3.7787 \%$ & \multicolumn{2}{|c|}{5.48} \\
\hline
\end{tabular}

\section{Compressed Work Week, Flex Time, and Teleworking}

\section{Percentage of employees on Compressed Work Week}

\begin{tabular}{|c|c|c|c|c|}
\hline $\begin{array}{c}\text { Program } \\
\text { Year }\end{array}$ & $\begin{array}{c}\text { Num of Surveys Distributed } \\
\text { (Affected Employees) }\end{array}$ & $\begin{array}{c}\text { Total Surveys } \\
\text { Reported }\end{array}$ & $\begin{array}{c}\text { Percentage of Employees } \\
\text { On 5 Days/Week }\end{array}$ & $\begin{array}{c}\text { Percentage of Employees } \\
\text { On 3 Days/Week }\end{array}$ \\
\hline 2001 & 200 & 162 & $88.2716 \%$ & $0.0000 \%$ \\
\hline 2003 & 211 & 153 & $91.5033 \%$ & $0.0000 \%$ \\
\hline
\end{tabular}

\begin{tabular}{|c|c|c|c|}
\hline $\begin{array}{c}\text { Program } \\
\text { Year }\end{array}$ & $\begin{array}{c}\text { Percentage of Employees } \\
\text { On 4 Days/Week }\end{array}$ & $\begin{array}{c}\text { Percentage of Employees On } \\
\text { 7 Days/Two Weeks }\end{array}$ & $\begin{array}{c}\text { Percentage of Employees } \\
\text { On 9 Days/Two Weeks }\end{array}$ \\
\hline 2001 & $2.4691 \%$ & $0.0000 \%$ & $8.0247 \%$ \\
\hline 2003 & $5.2288 \%$ & $0.0000 \%$ & $3.2680 \%$ \\
\hline
\end{tabular}

\section{Percentage of employees on Telecommuting}

\begin{tabular}{|c|c|c|c|c|}
\hline $\begin{array}{c}\text { Program } \\
\text { Year }\end{array}$ & $\begin{array}{c}\text { Num of Surveys Distributed (Num } \\
\text { of Affected Employees) }\end{array}$ & $\begin{array}{c}\text { Total Surveys } \\
\text { Reported }\end{array}$ & $\begin{array}{c}\text { Total Percentage of } \\
\text { Telecommuters }\end{array}$ & $\begin{array}{c}\text { 1 Days every } \\
\text { Two Weeks }\end{array}$ \\
\hline 2001 & 200 & 161 & $11.8012 \%$ & $4.9689 \%$ \\
\hline 2003 & 211 & 152 & $11.1842 \%$ & $3.9474 \%$ \\
\hline
\end{tabular}

\begin{tabular}{|c|c|c|c|c|c|}
\hline $\begin{array}{c}\text { Program } \\
\text { Year }\end{array}$ & $\begin{array}{c}\text { 2 Days every } \\
\text { Two Weeks }\end{array}$ & $\begin{array}{c}\text { 3 Days every } \\
\text { Two Weeks }\end{array}$ & $\begin{array}{c}\text { 4 Days every } \\
\text { Two Weeks }\end{array}$ & $\begin{array}{c}\text { 5 Days every } \\
\text { Two Weeks }\end{array}$ & $\begin{array}{c}\text { More than 5 Days } \\
\text { every Two Weeks }\end{array}$ \\
\hline 2001 & $6.8323 \%$ & $0.0000 \%$ & $0.0000 \%$ & $0.0000 \%$ & $0.0000 \%$ \\
\hline 2003 & $7.2368 \%$ & $0.0000 \%$ & $0.0000 \%$ & $0.0000 \%$ & $0.0000 \%$ \\
\hline
\end{tabular}

